\title{
Microphone Windscreen Performance
}

Robert N. Hosier

and

Paul R. Donavan

Acoustical Engineering Division

Center for Mechanical Engineering and Process Technology

National Bureau of Standards

Washington, DC 20234

January 1979

Final Report

Prepared for

Office of Noise Abatement and Control

U.S. Environmental Protection Agency

Washington, DC 20460

\section{0}

.456

$79-1599$

C.2 



\section{MICROPHONE WINDSCREEN} PERFORMANCE

Robert N. Hosier and

Paul R. Donavan

Acoustical Engineering Division Center for Mechanical Engineering and Process Technology National Bureau of Standards Washington, DC 20234

January 1979

Final Report

\section{Prepared for}

Office of Noise Abatement and Control U.S. Environmental Protection Agency Washington, DC 20460

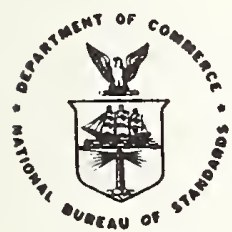

U.S. DEPARTMENT OF COMMERCE, Juanita M. Kreps, Secretary Jordan J. Baruch. Assistant Secretary for Science and Technology NATIONAL BUREAU OF STANDARDS. Ernest Ambler. Director 


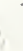




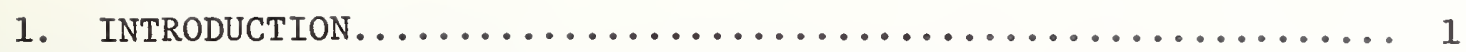

2. WINDSCREENS AND WINDSCREEN PERFORMANCE................ 1

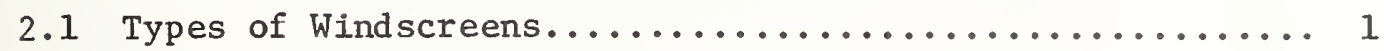

2.2 Commercially Avaliable Windscreens................ 2

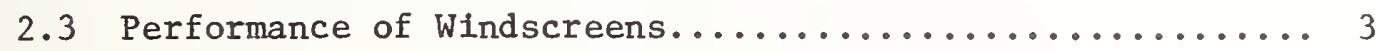

3. TEST APPARATUS.............................. 4

4. TEST PROCEDURE............................... 6

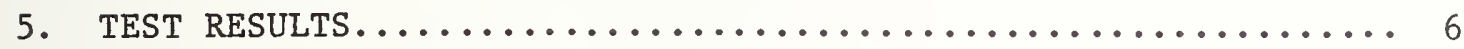

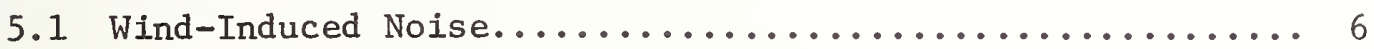

5.2 Acoustic Insertion Loss...................... 9

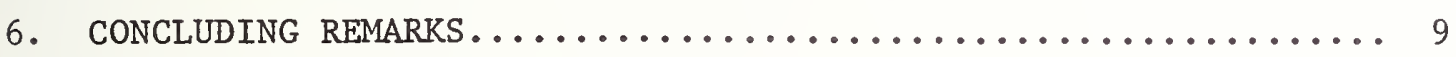

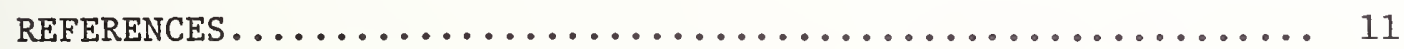

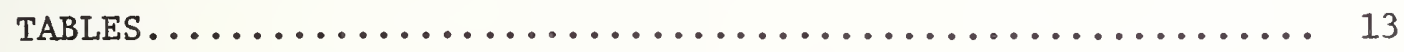

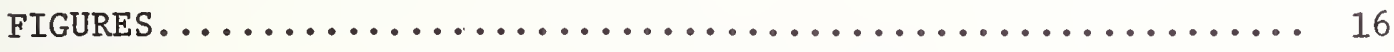

APPENDIX A: TABULATION OF WIND-INDUCED NOISE LEVELS FOR

GRAZING FLOW INCIDENCE............... 52

APPENDIX B: TABULATION OF WIND-INDUCED NOISE LEVELS FOR NORMAL FLOW INCIDENCE.................. 64

APPENDIX C: TABULATION OF ACOUSTIC INSERTION LOSS MEASUREMENTS FOR GRAZING FLOW AND NORMAL ACOUSTIC INCIDENCE.. 76 



\section{INTRODUCTION}

Microphone windscreens are used in conjunction with almost every outdoor noise measurement. As the name implies, windscreens screen or shield microphones from wind in order to improve the signal-to-nolse ratio of an acoustic measurement. Windscreens also serve to protect the microphone dlaphragm from forelgn materials carried in the wind (e.g. dust, Insects, or moisture).

In order to empirically characterize a number of microphone windscreens of the type currently in use and to provide some indication of the mechanisms of wind-induced nolse, measurements of wind induced nolse and windscreen insertion loss were made under laboratory conditions. Ten microphone windscreens were included in the study. Elght of these were reticulated polyester or polyether spheres of varying porosity. The remalning two windscreens were of the cloth-over-metal-cage type often used in long term outdoor nolse monitoring. The measurements were made at two flow orfentations and at seven wind speeds.

Section 2 of this report presents a discussion of previous work dealing with assessments of windscreen performance along with a description of the type of windscreens currently in use. Detalls of the apparatus and measurement techniques used in the current study are discussed in Sections 3 and 4. The results of the measurements are contalned in section 5 and concluding remarks are presented in section 6 .

\section{WINDSCREENS AND WINDSCREEN PERFORMANCE}

\subsection{Types of Windscreens}

With a few exceptions, microphone windscreeen deslgn has evolved very little since the prototype of Thorne [1] $]^{1}$ and Spotts [2] which consisted of elther spherical or spheroldal wire cages covered with a silk or nylon gauze. In an early work Phelps [3] developed an expression for the wind pressure around a sphere [microphone] placed in incompressible, non-turbulent flow. He then designed a perforated windscreen to take advantage of the pressure and phase differences over the surface of the sphere in order to reduce the wind pressure at the microphone diaphragm. More than twenty years later Bleazy [4] extended the work of Phelps to relate the attenuation of wind nolse to the enclosed volume of the windscreen. His experiments were conducted in an anecholc chamber with a paddle-wheel as the wind source. The wind generated by this device was turbulent, but controlled in frequency and velocity so as to simulate outdoor wind conditions. Bleazy found the following relationship to hold over the wind speed range from $2 \mathrm{~m} / \mathrm{sec}$ to $13 \mathrm{~m} / \mathrm{sec}$ :

$$
A=6.77 \log V+10.4
$$

1 Numbers in brackets indlcate the literature references at the end of this report. 
Where $A$ is the unweighted attenuation in $d B$ and $V$ is the windscreen volume in units of in $^{3}$. I The windscreens tested ranged in volume from 2 $\mathrm{in}^{3}$ to $800 \mathrm{in}^{3}$. Most recently, the U. S. Army $[5,6]$ has used concentric hemispherical and cylindrical cage windscreens of very large volume (e.g. $0.3 \mathrm{~m}^{3}$ ) to reduce the wind-induced nolse for low-frequency microphone systems. Ballard and Izquierdo [5] found that this approach enhanced the viscous dissipation of turbulent energy in the air stream by creating large velocity gradients (small eddies). Gradually, the cage windscreens have been replaced with reticulated foam spheres for many outdoor measurements.

The only major change in windscreen design came in response to the need to measure sound levels in air ducts containing turbulent flow. Nakamura, et. al. [7] and Nelse [8] performed extensive theoretical and experimental studies of long $(24 \mathrm{~cm})$ slit-tube windscreen probes. Their results indicate that turbulence-induced noise levels due to air flow parallel to the axis can be significantly reduced by using these special purpose windscreens. Shorter $(3 \mathrm{~cm})$, less sophisticated, nose cones are also frequently used in very directional flow environments. Because omni-directional response is needed for most outdoor measurements, use of the slit tube and nose cone windscreens is generally restricted to acoustic measurements in wind tunnels or air ducts.

\subsection{Commercially Available Windscreens}

For most outdoor applications today, elther spherically or cylindrically shaped windscreens are used. These windscreens are commercially available in a number of models (see Figure 1). The simplest spherical model is made of reticulated polyester foam. It is avallable in sizes from $6 \mathrm{~cm}$ to $9 \mathrm{~cm}$ in diameter and has a hole reaching nearly to the center for insertion of the microphone (e.g. windscreens A and $C$ in Figure 1).

A second commercially avallable spherical model is the wire cage type similar to the one used by Thorne and Identified as windscreen $B$ in Figure 1. It is about $11 \mathrm{~cm}$ in diameter with a nylon gauze cover and contains a conically shaped adaptor inside the cage to recelve the microphone. A multi-spiked assembly is often fitted to the sphere in order to prevent birds from roosting on the windscreen.

A third, hybrid windscreen is made by one manufacturer (see windscreen $J$ in Figure 1). This windscreen consists of a number of components, beginning with a $6 \mathrm{~cm}$ dlameter polyester sphere which is placed over the microphone. Both are then inserted about two-thirds of the way into a cylindrical, stainless steel, perforated cage and held in place by a base plate attached to the microphone preamplifier. The cage has a hemispherical cap at one end and a microphone adaptor plate at the

1 NBS recommends the use of metric units; however, to maintain the integrity of the cited references, non-metric units were used here. 
other. A reticulated polyester cover is fitted over the cage. The entire assembly is about $22 \mathrm{~cm}$ long and $7 \mathrm{~cm}$ in diameter. It also comes equipped with a $13 \mathrm{~cm}$ "bird splke" which is mounted on the hemispherical cap. The stainless steel cage serves to prevent rain from impinging on the internal windscreen by causing it to run off between the cover and the cage.

\subsection{Performance of Windscreens}

When assessing the performance of windscreens, it is common practice to measure two fundamental descriptors: wind-induced noise and acoustic insertion 1oss. Wind-induced noise is the noise produced by air flow over the microphone and windscreen assembly. As is shown in Figure 2, wind-induced noise is a function of five parameters: 1) mean flow; 2) Inflow (free-stream) turbulence due to thermal and wind speed gradients in the atmosphere; 3) self-generated turbulence caused by boundary layer separation and vortex shedding; 4) flow through the windscreen; and 5) flow incidence angle. The flow through the windscreen is dependent upon windscreen characteristics such as porosity and diameter. In a 1976 paper, Oswald [9] showed that inflow turbulence and self-generated turbulence are major factors in determining the low and high-frequency levels, respectively, of the wind-induced noise spectrum. This effect was also substantlated by the work of K1otzsch [10] which contained an excellent investigation of the wind-induced noise levels measured by microphones in flows of varying turbulence levels and with different grid cap designs. In a subsequent paper [11], K1otzsch measured the wind-induced nolse for cage windscreens of different diameters and with various covering materials. He found that the wind-induced noise depends on the mean flow velocity, the degree of turbulence, the direction of the approach flow, the windscreen diameter and covering materlal, and on the arrangement of the microphone within the windscreen. His data show that the wind-induced noise increases with increasing flow velocity and increasing turbulence levels in the inflow. Klobtzsch also found cylindrical and spherical windscreens to perform equally well in reducing wind-induced noise.

Acoustic insertion loss (IL) is the difference between the sound pressure levels measured without ( $\mathrm{L}_{\mathrm{w} / 0}$ ) and with $\left(\mathrm{L}_{\mathrm{w}}\right.$ ) the windscreen in place. In this test, it was assumed that the flow field around the windscreen may interact with the incident acoustic field and thereby affect the insertion loss. For this reason the IL is assumed to depend on the approach velocity according to the following definition:

$$
I L=I_{w / 0}(0)-L_{W}(v), d B,
$$

where $v=$ the mean flow velocity and where $L$ is a sound pressure level descriptor such as one-third octave band level or A-weighted level. Note that the level without the windscreen in place is measured at $v=0$. 
Most windscreen manufacturers provide only a modest amount of data on wind-induced noise and insertion loss for their type of windscreen. Experience has shown these data to be difficult to convert to one-third octave, A-weighted, and overall levels over the wind speed range generally considered acceptable for outdoor testing $(0 \mathrm{~m} / \mathrm{sec}$ to $6 \mathrm{~m} / \mathrm{sec})$. Furthermore, 11ttle information is avallable on the effects of porosity and manufacturing variablilty on the wind-induced noise and insertion loss. Thus, correcting acoustic data for these effects is often not possible.

With the exception of the studies by Nakamura [7] and Neise [8], little attention has been given to relating the fluid dynamics of the air flow field to the sound levels measured when a microphone windscreen is used. This is particularly true for the porous polyester windscreens frequently used in outdoor nolse measurements today. (Blomquist [12] has published some data on the effects of porosity and diameter on insertion loss and A-weighted sound level for a wind speed of $40 \mathrm{~km} / \mathrm{hr}$.) The experiment described in the remainder of this report was designed to provide a preliminary indication of the physical mechanisms contributing to the wind-induced noise and insertion loss of windscreens.

\section{TEST APPARATUS}

The ten windscreens tested are shown in Figure 1. The windscreens are shown in greater detail in Figures 3 through 6 . Windscreens $A, C, D$, $E$, and $F$ are commerclally available polyester windscreens (see Figures 3 and 4). They differ in that $A$ and $C$ were selected at random from the manufacturers' stock, while $D, E$, and $F$ were selected to cover the range of porosity judged acceptable by one manufacturer. Windscreens $G$, I, and H, shown in Figure 5, were specially made to cover the porosity range from $400 \mathrm{ppm}$ to $2200 \mathrm{ppm}{ }^{1} \mathrm{~B}$ and J (see Figure 6) are commercially avallable cage windscreens with bird spikes. B is covered with a nylon gauze and $J$ with a polyester foam. When $J$ is assembled, windscreen $C$ is placed over the microphone and the two are placed inside the perforated cage. An adaptor (shown next to windscreen $J$ in Figure 1 ) is used to hold the microphone in place. Table I summarizes the physical characteristics of these windscreens.

1 Foam porosity is commonly measured in units of pores per unit length, in this case pores per meter (ppm). Thus, a high porosity foam would have many pores per unit length, but the open area of each pore would be small. Conversely, a low porosity foam would have fewer pores per unit length, but their open area would be larger. In terms of flow resistance, low porosity would imply low flow resistance and high porosity large flow resistance. 
The measurements of wind-induced noise and insertion loss were made in the 450- $\mathrm{m}^{3}$ NBS anechoic chamber. For the wind-induced noise measurements, each windscreen was placed on a "half-inch"l diameter microphone which was mounted at the end of a $1.57 \mathrm{~m}$ rotating arm. The rotating arm was constructed out of symmetric airfoil tubing and oriented for zero lift. Thus, air recirculation in the test facility was minimized. The microphone could be swiveled in the mounting bracket to allow normal and grazing flow incidence to be simulated. This assembly was then placed on a precision rate table (see Figure 7) capable of providing a specified angular velocity to within one-half percent. To measure insertion loss, a loudspeaker of known directional characteristics was mounted at the center of the rotating assembly. The directivity pattern of the speaker was calculated to be distorted by less than two degrees in the horizontal direction, at the microphone position, for the maximum rotational speed used in these tests.

Figure 8 shows a block diagram of the data acquisition system. Two microphones were used in these tests. The primary microphone was mounted on the rotating arm and the stationary microphone was supported in the anechoic chamber $2.4 \mathrm{~m}$ from the closest approach of the arm. This second microphone was used to monitor the test and proved useful in verifying , that no spurious signal, such as that due to vortex shedding from the rotating arm, was present. The signal from the rotating microphone was recorded on two channels of the FM recorder. The first channel consisted of the pressure signal as obtained directly from the rotating microphone after amplification, while the second channel consisted of a $150 \mathrm{~Hz}$ high-pass-filtered version of the Channel 1 signal. The Channel 2 signal was amplified relative to the Channel 1 signal in order to increase the high-frequency dynamic range of the wind-induced noise measurements since most of the acoustic energy fell below $150 \mathrm{~Hz}$. All data were recorded for a minimum of 60 seconds in order to determine the sound level within $\pm 1 \mathrm{~dB}$ with 95 percent confidence for the lowest one-third octave band of interest $(6.3 \mathrm{~Hz})$. Both signals were monitored by peak level detectors to assure the maximum use of the tape recorder dynamic range. The microphone signals were also monitored during recording with a one-third octave band real time analyzer and an oscilloscope. A digital data coder was used to log test parameters such as run number, windscreen number, microphone orientation, and speaker activation.

For the insertion loss data, the loudspeaker mounted at the center of the rate table was driven by a pink nolse signal which had been passed through a $150 \mathrm{~Hz}$ high pass filter. The high pass filter was necessary to make the input signal comparable with the loud speaker frequency characteristics and thereby avold speaker signal distortion. The speaker excltation voltage was set as high as possible to assure that the wind-induced noise would be negligible over as large a frequency range as possible. Using this technique, insertion loss measurements could be made up to $4000 \mathrm{~Hz}$. Above this frequency the difference between the loud speaker signal level and the wind-induced noise level was less than $10 \mathrm{~dB}$ and the data were not used. To assure a constant electronic signal level to the loudspeaker, the voltage of the input signal was constantly monitored.

1 Commercial designation of microphone type. 


\section{TEST PROCEDURE}

The apparatus described in Section 2 were used to measure the wind-induced noise and insertion loss for each of the windscreens shown in Figure 1. The wind induced-noise was measured at normal and grazing flow incidence. After mounting each windscreen on the rotating microphone, the levels were recorded at zero air flow speed. The microphone and windscreen were then rotated at tangential speeds up to 14 $\mathrm{m} / \mathrm{sec}$ in $2 \mathrm{~m} / \mathrm{sec}$ increments and recordings were made of the wind-induced noise. The recorded data were then reduced to obtain overall (flat frequency response $20 \mathrm{~Hz}$ to $20 \mathrm{kHz}$ ), A-weighted, and one-third octave band levels.

As shown in Figure 9, insertion loss measurements were made for three combinations of acoustic and flow incidence angles. To make these measurements, the noise from the loudspeaker,as excited with the high-pass-filtered, pink noise signal, was recorded. Insertion loss was calculated for each windscreen by computing the difference between the levels measured with and without the windscreen in place. In each case, the level without the windscreen in place was a static $(v=0)$ measurement while the levels with the windscreen in place were measured over the speed range from 0 to $14 \mathrm{~m} / \mathrm{sec}$ in $2 \mathrm{~m} / \mathrm{sec}$ increments.

\section{TEST RESULTS}

\subsection{Wind-Induced Noise}

Plots of the overall and A-weighted wind-induced noise levels as a function of wind speed and windscreen type for grazing (parallel to microphone diaphragm) and normal (perpendicular to microphone diaphragm) flow incidence are presented in Figures 10 through 13 . The curves shown in these figures were determined by using a third order regression analysis, the equations for which are presented in Table II. The one-third octave band wind-induced noise data are presented in Figures 14 and 15 for each windscreen and wind speed. It will be noted in these plots that some data points for the lower speeds have been omitted. This was done because narrow band frequency analysis revealed that structural resonances in the arm assembly were sufficiently excited by the rate table governing system to contaminate some of the small amplitude acoustic signals through excessive vibration of the microphone. This phenomenon was examined thoroughly, and only those data where such contamination did not occur are presented.

In considering the results of the wind-induced noise measurements, it must be remembered that the windscreen was mounted one meter above the rotating arm so that the incident free-stream turbulence was only due to the windscreen intersecting its own wake on each revolution (a distance of more than 100 windscreen diameters). Therefore, the laboratory environment, compared to outdoor conditions, was relatively turbulence-free. For this reason, the results cannot be directly applied 
to the outdoor wind environment as characterized solely by a mean wind speed. To apply the results of the laboratory wind-induced noise measurements to estimating outdoor wind-induced noise, the turbulence intensity and length scale present in the outdoor environment must be considered in addition to mean wind speed. Realizing this limitation, the data of Figures 10 through 13 can still be useful when considering outdoor noise measurements. These data indicate that commercially available windscreens can provide on the order of 15 to $25 \mathrm{~dB}$ reduction of wind-induced notse, depending on the wind speed and flow incidence angle. The graphs can also be used by an experimenter as an aid in the selection of the most appropriate windscreen for a given measurement if there is some knowledge of the wind environment to be encountered and the frequency content of the noise to be measured. Furthermore, the data of these figures can be used to .roughly estimate the wind-induced-noise content in existing data if wind speed information is avallable.

For both grazing and normal incidence, the curves for each windscreen are more tightly grouped for the overall levels than for the A-weighted levels. This suggests that the wind-induced noise is

dominated by low-frequency components. These components can be related to vortex shedding in the subcritical Reynolds number range encountered in these tests $(8,000 \leq \operatorname{Re} \leq 90,000)$ through the Strouhal number $S=f d / V$ for spheres of varying surface roughness as measured by Achenbach [13]. His data show that, $S>0.18$ with $S$ becoming smaller as surface roughness is increased. Using $S=0.18$ for a sphere of diameter $d=0.095 \mathrm{~m}$ gives a Strouhal shedding frequency $f=27 \mathrm{~Hz}$ at a wind speed $V=14 \mathrm{~m} / \mathrm{sec}$. An examination of the spectral data obtained during these tests (Figures $14(\mathrm{a})$ through $15(1)$ ) reveals that the maximum wind-induced noise levels occur in the $16 \mathrm{~Hz}$ band at $\mathrm{v}=14 \mathrm{~m} / \mathrm{sec}$ for most of the windscreens tested. This lower peak frequency seems to suggest that a Strouhal number lower than $S=0.18$ is characteristic of porous spheres. Also, the smooth distribution of levels about the spectrum peak indicates that complex interactions are occurring between the flow over and through the porous windscreens and that the wind-induced noise cannot be totally attributed to vortex shedding from the windscreen.

The spectra from a number of the windscreens tested (e.g. D, E, F, $G, H$, and I) show a secondary velocity-dependent peak in the frequency range between $1 \mathrm{kHz}$ and $10 \mathrm{kHz}$. This peak is believed to be related to the flow through the windscreen pores, with the magnitude and frequency of the spectrum peak being inversely proportional to pore size. Because a one-third octave bandwidth analysis was used in Figures 14 and 15, it was not possible to determine the exact dependence of peak frequency on porosity; however, the magnitude of the spectrum peak seems to decrease about $8 \mathrm{~dB}$ to $10 \mathrm{~dB}$ per doubling of porosity.

Although it did not prove possible to relate the secondary peak frequency to porosity, the overall and A-weighted levels do show a porosity dependence. For example, the data from Figures 10 through 13 at $v=12 \mathrm{~m} / \mathrm{sec}$ for the spherical foam windscreens have been replotted in Figure 16. It can be seen that the overall levels increase as the 
porostty increases. A possible explanation for this dependence is that as the windscreen porosity increases the windscreen flow characteristics approach those of a smooth, solid sphere and the acoustic signal is dominated by low-frequency, discrete, vortex-shedding noise. In this case turbulence fluctuations are restricted to the boundary layer because they are of insufficient energy to propagate through the windscreen to the microphone. As the windscreen porosity is decreased the boundary layer becomes more intense and the wake becomes increasingly turbulent. Flow through the windscreen is also Increased. The spectra in Figures $14(\mathrm{~g})$ and ( 1 ) for grazing flow and $15(\mathrm{~g})$ and ( 1 ) for normal flow show predominating low-frequency energy for the high-porosity windscreens and increased high-frequency energy for the low porosity windscreens. It is not possible from these tests to absolutely determine whether the high-frequency noise is attributable to increased flow through the windscreen, increased turbulence intensity in the boundary layer and wake, or a combination of these effects; however, it seems that the high-frequency peaks may scale to a reduced frequency based on an effective velocity through the pores and an effective pore size.

In contrast to the overall levels, the A-welghted levels (Figure 16) decrease with increasing porosity. This dependence is not related to a new flow phenomenon but rather to the A-weighting filter characteristics.

The spectra in Figures $14(k)$ and $15(k)$ are from the microphone with no windscreen at grazing and normal flow incidence. Both spectra show intense low frequency content; however, the spectrum shapes are dissimilar. With the windscreen removed, the flow impinges directly on the microphone diaphragm-grid cap assembly. When the microphone is oriented for grazing flow incidence, boundary layer fluctuations are sensed directly by the microphone. This effect is mitigated when the microphone is oriented for normal flow incidence because the flow stagnates at the microphone diaphragm. For grazing flow incidence, however, the vortex shedding frequency for a $1.27 \mathrm{~cm}$ diameter cylinder is about $160 \mathrm{~Hz}$ at a flow speed of $10 \mathrm{~m} / \mathrm{sec}$ and the spectra of Figure $14(\mathrm{k})$ show a veloclty-dependent peaking In that region. Oswald's data [9] seem to Indicate that the low frequency portion, below the $100 \mathrm{~Hz}$ region, may be attributed to inflow turbulence. However, no measurements of turbulence were made in these tests to verffy that hypothesis. It does seem reasonable that such an effect would be much more noticeable in the measurements without the windscreen since the windscreen would shield the microphone from low intensity turbulence.

In general, the performance of the cage windscreens was not as good as most of the foam windscreens. This was particularly true for the spherical cage windscreen (see Figure 6). For grazing flow incidence, the cylindrical windscreen also did not provide as much wind induced nolse reduction as most of the foam windscreens; however, for normal flow, the cylindrical windscreen performed better than any of the foam windscreens over most of the wind speed range.

The data in Figures 10 through $15(\mathrm{k})$ have been tabulated in Appendices A and B. Tables Al through All contain the data for grazing flow incidence and Tables BI through B11 for normal flow incidence. 


\subsection{Acoustic Insertion Loss}

As part of this study, measurements were made of the acoustic insertion loss for each windscreen as a function of wind speed. The test was designed to acquire insertion loss data at each of the combinations of flow and acoustic incidence angles shown in Figure 9 in order to Identify not only the magnitude of the insertion loss, but also its dependence, if any, on air flow. Pink noise emitted by the loudspeaker at the center of the rate table was measured by the rotating microphone over the speed range $0<v<12 \mathrm{~m} / \mathrm{sec}$ with the windscreen in place and at $v=0$ without the windscreen. The insertion loss was computed for one-third octave bands between $250 \mathrm{~Hz}$ and $4 \mathrm{kHz}$ (the range of useful signal-to-noise ratio) as well as for the overall and A-weighted levels by subtracting the levels measured without the windscreen in place at $v=0$ from the levels with the windscreen in place over the speed range of 0 $\mathrm{m} / \mathrm{sec}<\mathrm{v}<12 \mathrm{~m} / \mathrm{sec}$.

The results of the insertion loss measurements for Orientation $B$ in Figure 9 (grazing flow and normal acoustic incidence) are tabulated in Appendix C. It can be seen from these data that the insertion loss is small ( $0.1 \mathrm{~dB}$ to $0.6 \mathrm{~dB}$, generally). Also, in most cases the insertion loss for each one-third octave band, overall, and A-weighted level varies only by one or two tenths of a decibel over the entire wind speed range. These data may be used to correct a measured broadband noise signal by subtracting the tabulated value from the measured level.

This measurement was found to be very difficult to make for a number of reasons. First of all, the frequency range was limited at the low end by speaker response and at the high end by wind-induced noise. Secondly, wind-induced noise also precluded any insertion loss measurements at v=14 $\mathrm{m} / \mathrm{sec}$. And, finally, uncertainties in the source level monitoring were found to be too great during a large portion of the testing to allow accurate computation of the small insertion loss level differences. As a consequence of these difficulties, successful insertion loss measurements could only be made for grazing flow and normal acoustic incidence. The results are tabulated in Appendix C.

\section{CONCLUDING REMARKS}

Measurements of the wind-induced nolse and acoustic insertion loss have been made on ten microphone windscreens at wind speeds from $0 \mathrm{~m} / \mathrm{sec}$ to $14 \mathrm{~m} / \mathrm{sec}$ for both grazing and normal flow incidence. The data show that the windscreens are very different in the amount of wind-induced-noise reduction they provide, with some achieving more than $25 \mathrm{~dB}$ reduction. In general the foam windscreens provided more wind-induced-noise reduction than the cage windscreens; however, the cylindrical cage windscreen performed better than any of the foam windscreens for normal flow incidence. For both grazing and normal flow incidence, the A-weighted wind-induced noise levels for all the windscreens covered a larger range (about $20 \mathrm{~dB}$ at $14 \mathrm{~m} / \mathrm{sec}$ ) than did the overall levels (about $15 \mathrm{~dB}$ at $14 \mathrm{~m} / \mathrm{sec}$ ). 
The Insertion loss measurements prc ved difficult to make because of the small values $(0.1 \mathrm{~dB}$ to $0.6 \mathrm{~dB})$ encountered and, at least for the case of grazing flow and normal acoustic incidence, the data show no strong velocity dependence for any of the windscreens tested.

The wind-induced noise and insertion loss sound pressure levels have been tabulated in the appendices of this report. These data and those in the graphs and tables of this report provide a basis for studying the nolse generating mechanisms associated with flow incident upon a porous sphere. For example, it was observed that the wind-induced-noise levels for foam windscreens showed a clear dependence on porosity, and therefore manufacturing variability. It was also observed, however, that this dependence was reversed for the A-weighted and overall levels (increasing porosity yielded increasing overall sound pressure levels but decreasing A-weighted levels.) This reversal is believed to be associated with an increase in low-frequency $(16 \mathrm{~Hz})$, vortex-shedding noise as the foam porosity increased.

Examination of the wind-induced noise spectra revealed a high-frequency ( $1 \mathrm{kHz}$ to $5 \mathrm{kHz}$ ), velocity-dependent peak. Flow through the windscreen pores seems to be the noise source for this peak. This hypothesis is confirmed by the fact that the spectra for the microphone with no windscreen show no high-frequency peaks; however, they do show a low frequency, velocity-dependent peak due to vortex shedding around the microphone preamplifier $(160 \mathrm{~Hz}$ at $10 \mathrm{~m} / \mathrm{sec}$ ). It was also for the no-windscreen case that inflow turbulence effects seemed observable in the frequency range below $20 \mathrm{~Hz}$. 
1. Thome: U. S. Patent No. 588,034, August 1897.

2. Spotts: U. S. Patent No. 1,901,065, March 1933.

3. Phelps, William D。: Microphone Wind Screening. RCA Review, vol. 3, 1938, pp. 203-212.

4. Bleazey, John C.: Experimental Determination of the Effectiveness of Microphone Wind Screens. Journ. Audio Eng. Soc., vol. 9, no. 1, Jan 1969, pp. 48-53.

5. Ballard, Harold N., and Izquierdo, Mike: Reduction of Microphone Wind Noise by the Generation of a Proper Turbulent Flow. U. S. Army Electronics Research and Development Activity Report 262, DDC no. AD 455966, Feb. 1965.

6. Breeland, A. H., and Bonner, R. S.: Results of Tests Involving Hemispherical Wind Screens in the Reduction of Wind Noise. ECOM Report no. 5119, DDC no. AD 653005, Apr11 1967.

7. Nakamura, Akira; Matsumato, Rimpey; Sugiyama, Akira; and Tanaka, Tadami: Some Investigations on Output Level of Microphones in Air Streams. Journ. Acous. Soc. Am., vol. 46, no. 6, part 1, March 1969, pp. 1391-1396.

8. Neise, W.: Theoretical and Experimental Investigations of Microphone Probes for Sound Measurements in Turbulent Flow. Journ. Acous. Soc. Am., vol 39, no. 3, 1975, pp. 371-400.

9. Oswald, Lawrence J.: The Wind Noise of Nose-Cone-Protected Microphones. Proc. of Inter-Noise 76, Washington, D. C., April 5-7, 1976. pp. 141-144. 1976. pp. 141-144.

10. Klotzsch, Von P.; and Bauer, H. J.: Das Wingerausch von Kondensatormikrophonen. Mitteilung aus der Leitsteile fur Larmschutz in dex Industrie im VEB RFT Meszelektronik und der Technischen Universitat Dresden Sektion Informationstechnik, Bereich Kommunikation und Meszwerterfassung.

11. Klotzsch, Von P.: Zur Windgerauschdampfung von Windschirmen. Hochfrequenztechnik u. Elektroakustik, Leipzig 80 (1971), 1, s. 1-9. 
12. Blomquist, Donald S.: An Experimental Investigation of Foam Windscreens. Proceedings of Inter-No1se 73, Technical University of Denmark, Copenhagen, August 22-24, 1973, pp 589-593.

13. Achenbach, Elmar: The Effects of Surface Roughness and Tunnel Blockage on the Flow Past Spheres. J. Fluld Mechanics (1974), vol. 65, part 1, pp 113-125. 


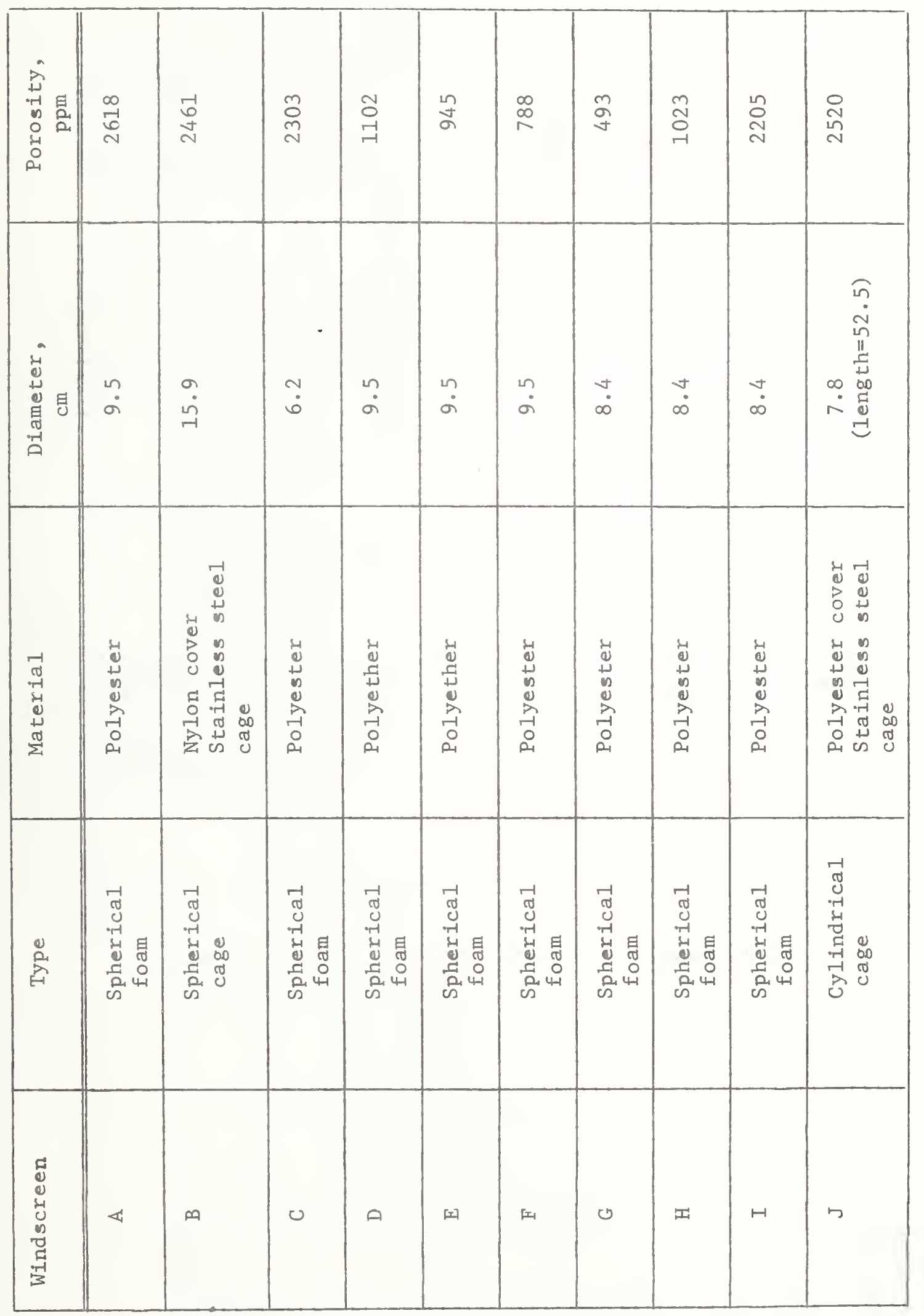




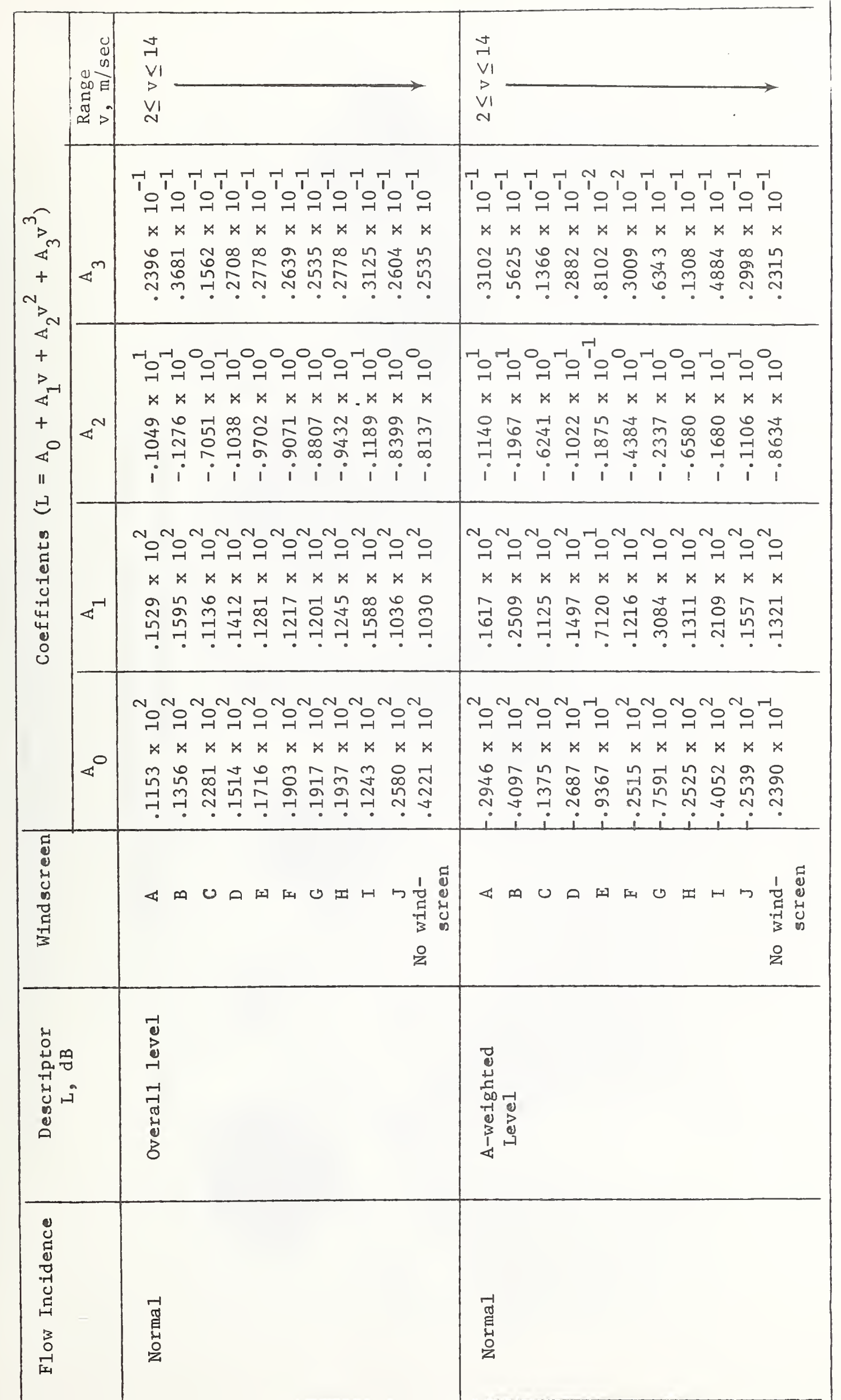




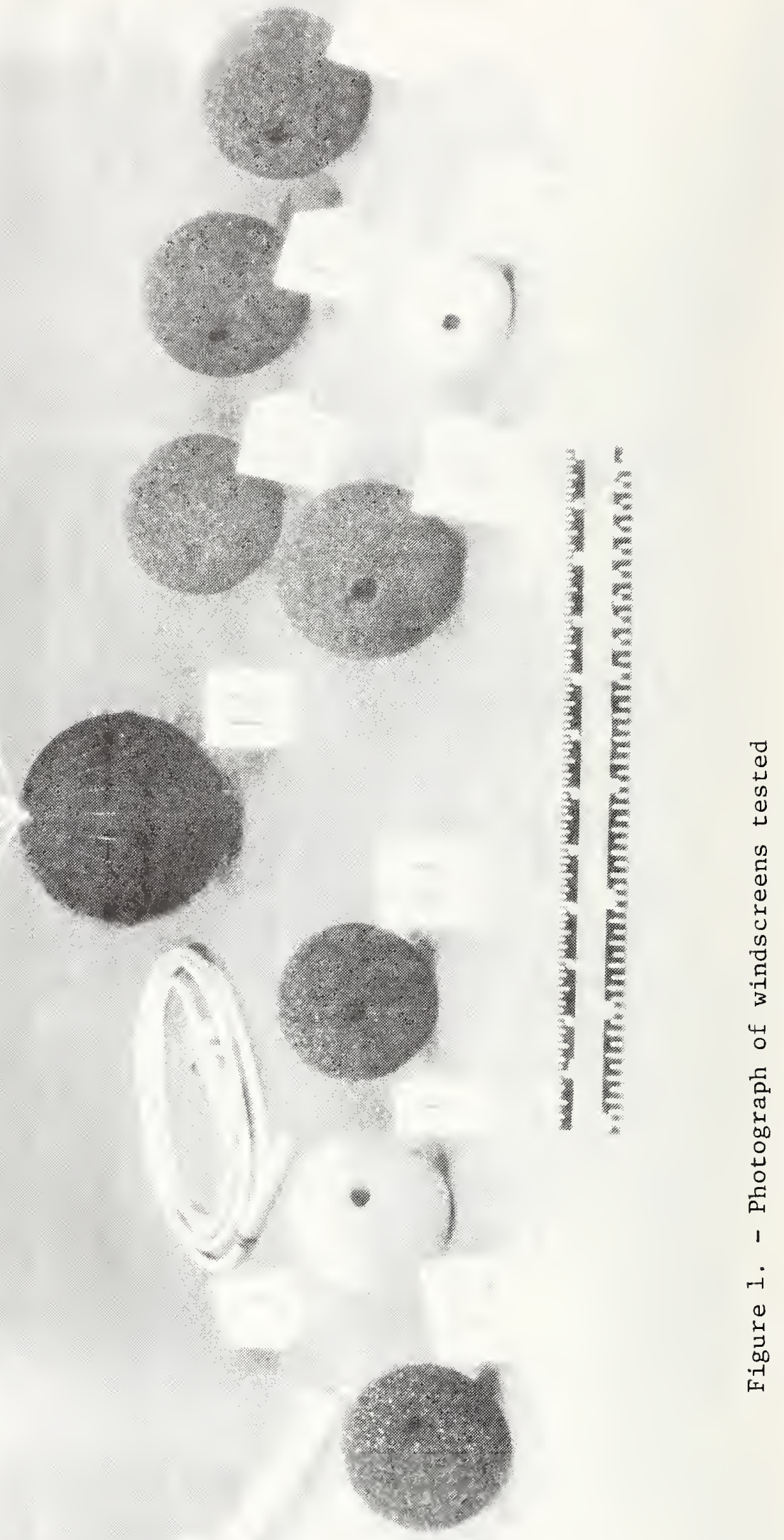




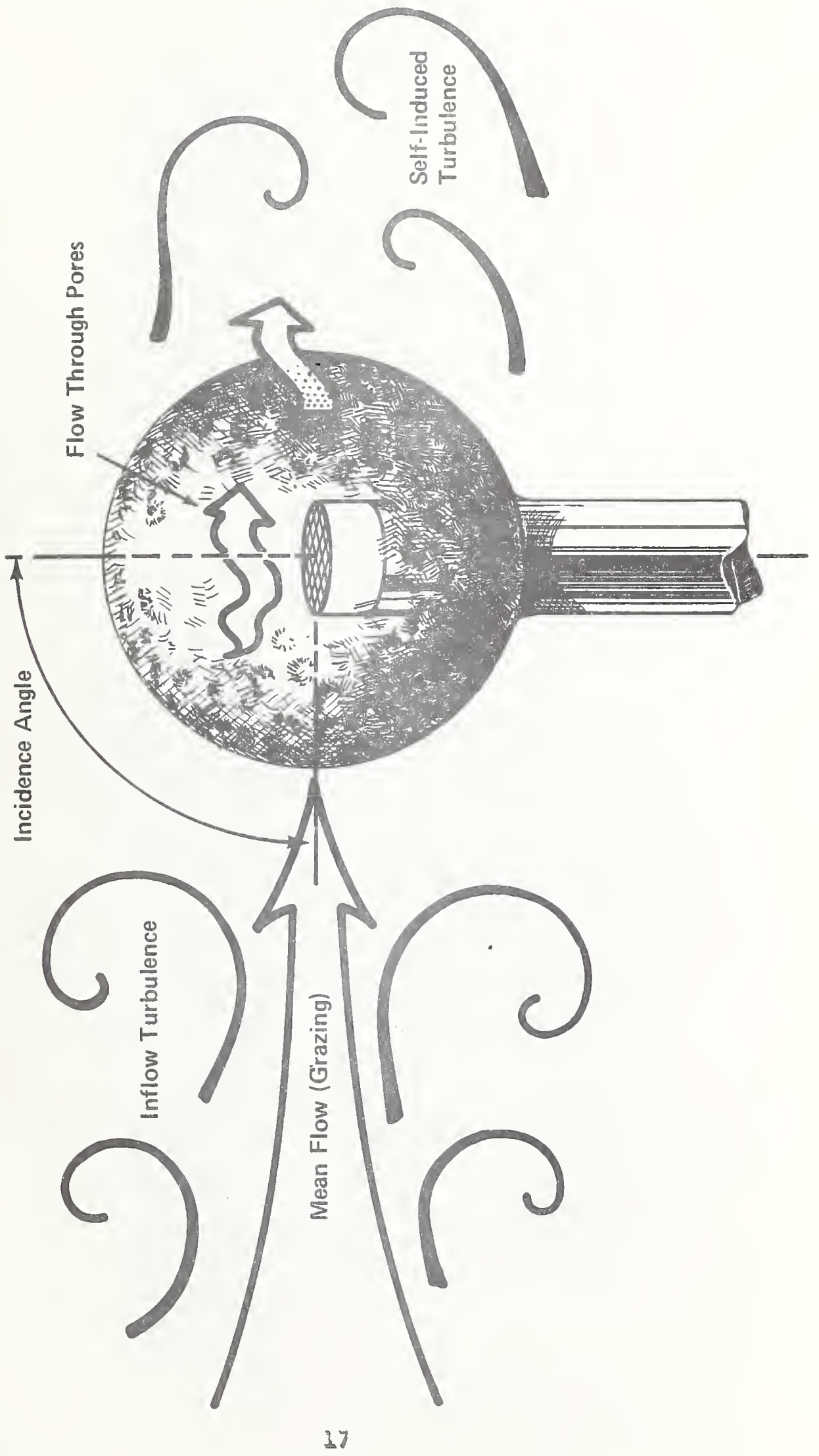

 


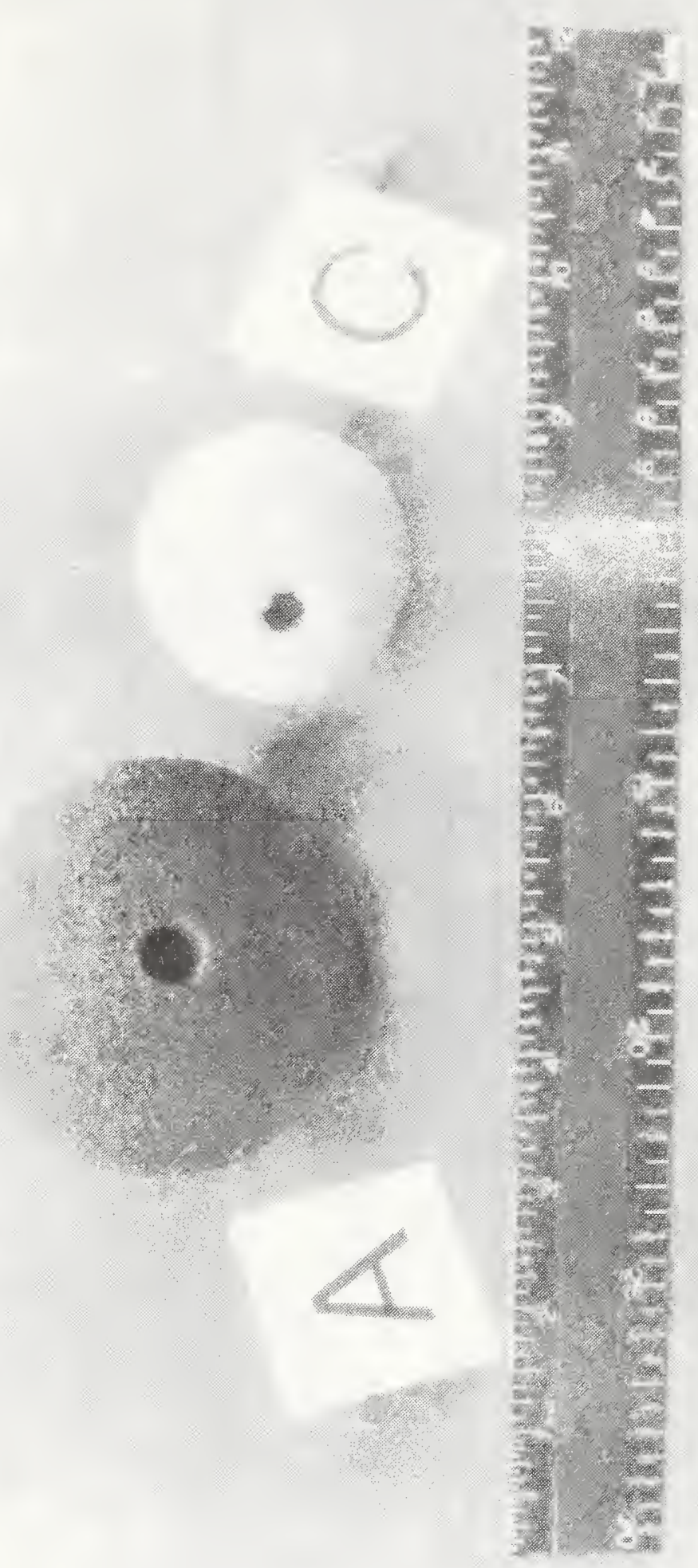

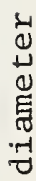

.

ป

?

ช

崩

.

白

a

2

क

a

$\stackrel{+}{0}$

年

告

걱

$\pi$

u

井

ठ

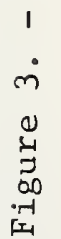



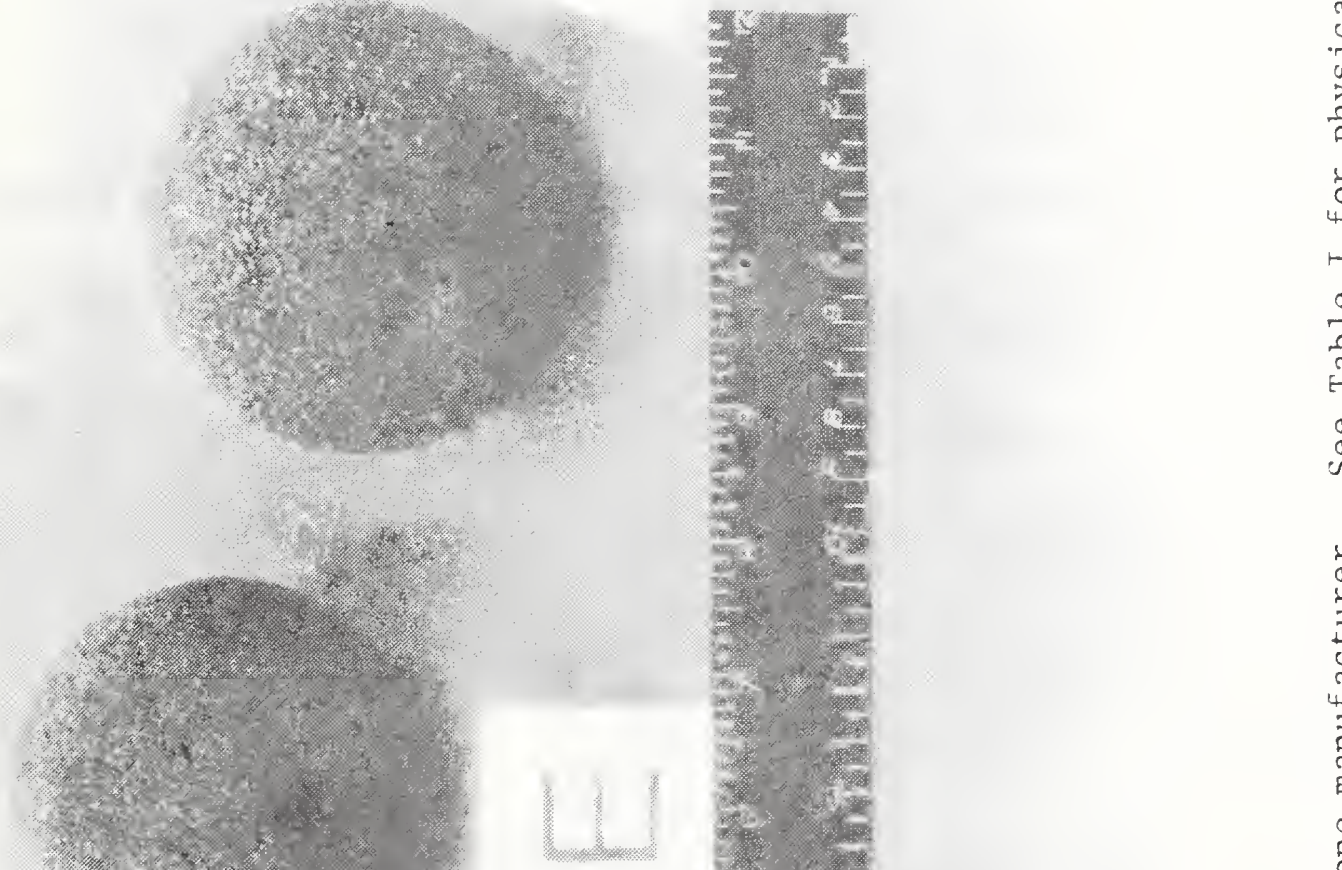

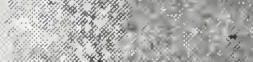

s.t.

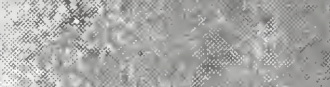

(2)

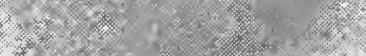

thes : $=0$

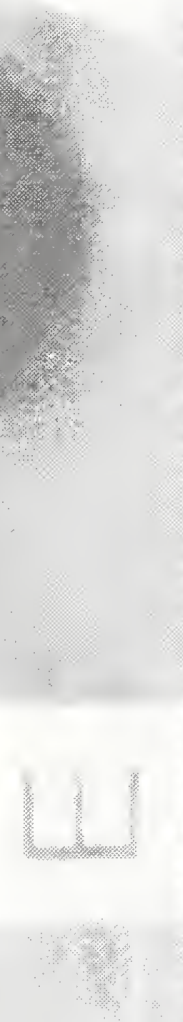

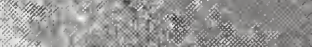

,

(2)

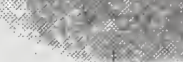
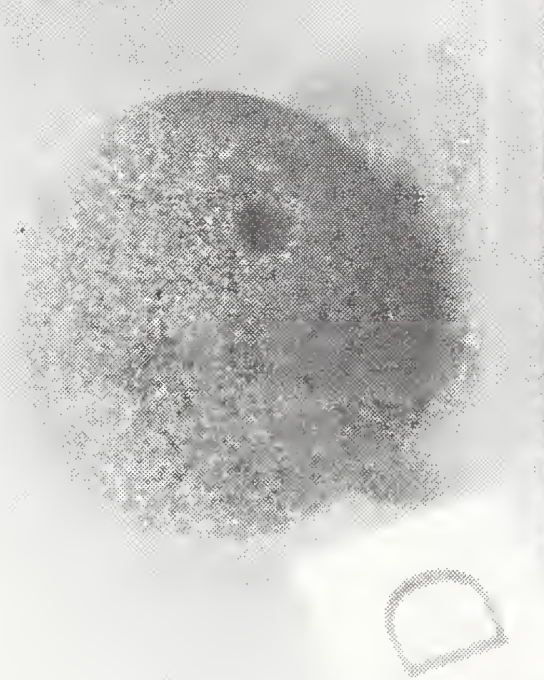

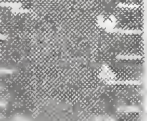

(4)

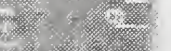

0.2

5. 3

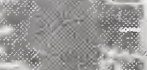

7x: $\times 2$

$-x^{2}+2 \times$

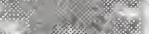

(3.) 1.2

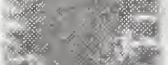

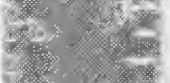

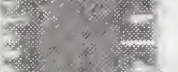

1. 3

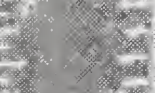

2. $\quad 2 x$

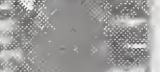

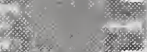

- $* 2$

5. 2,3

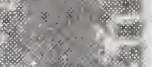

- $t .2, ., 4$

3. $(5)$

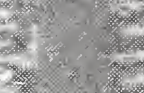

2. 25

).

t2 $x=2$

동

¿ั0 

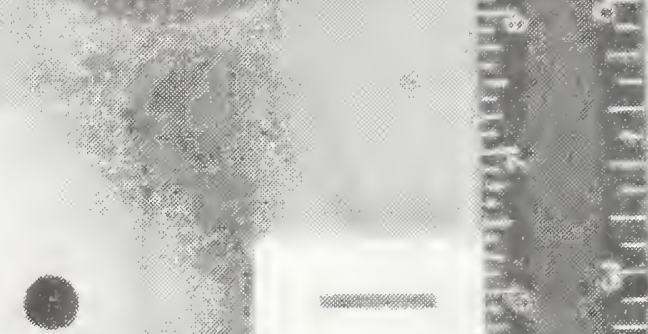

焉

i

o

임.

告

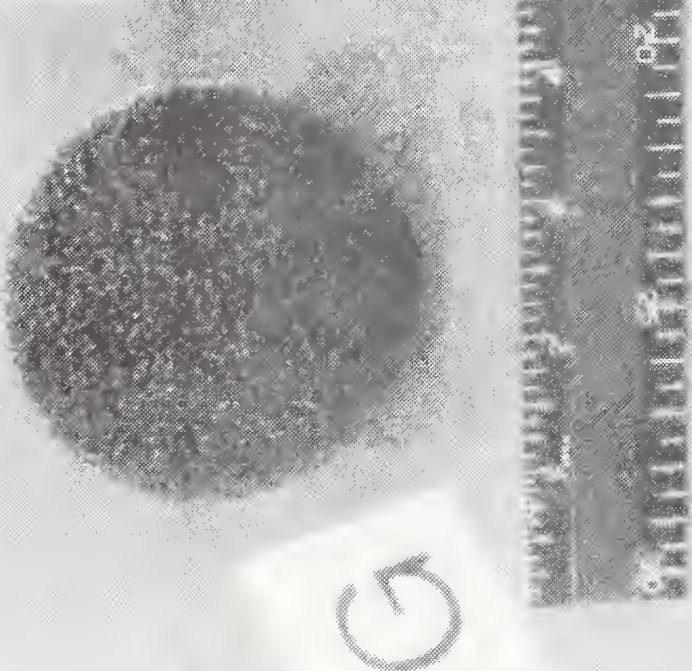

우

वृ

罚

तो

तै क्ष

-1

U

记

क

先

0

井

थै

o

岱全

I

เ่

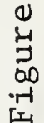




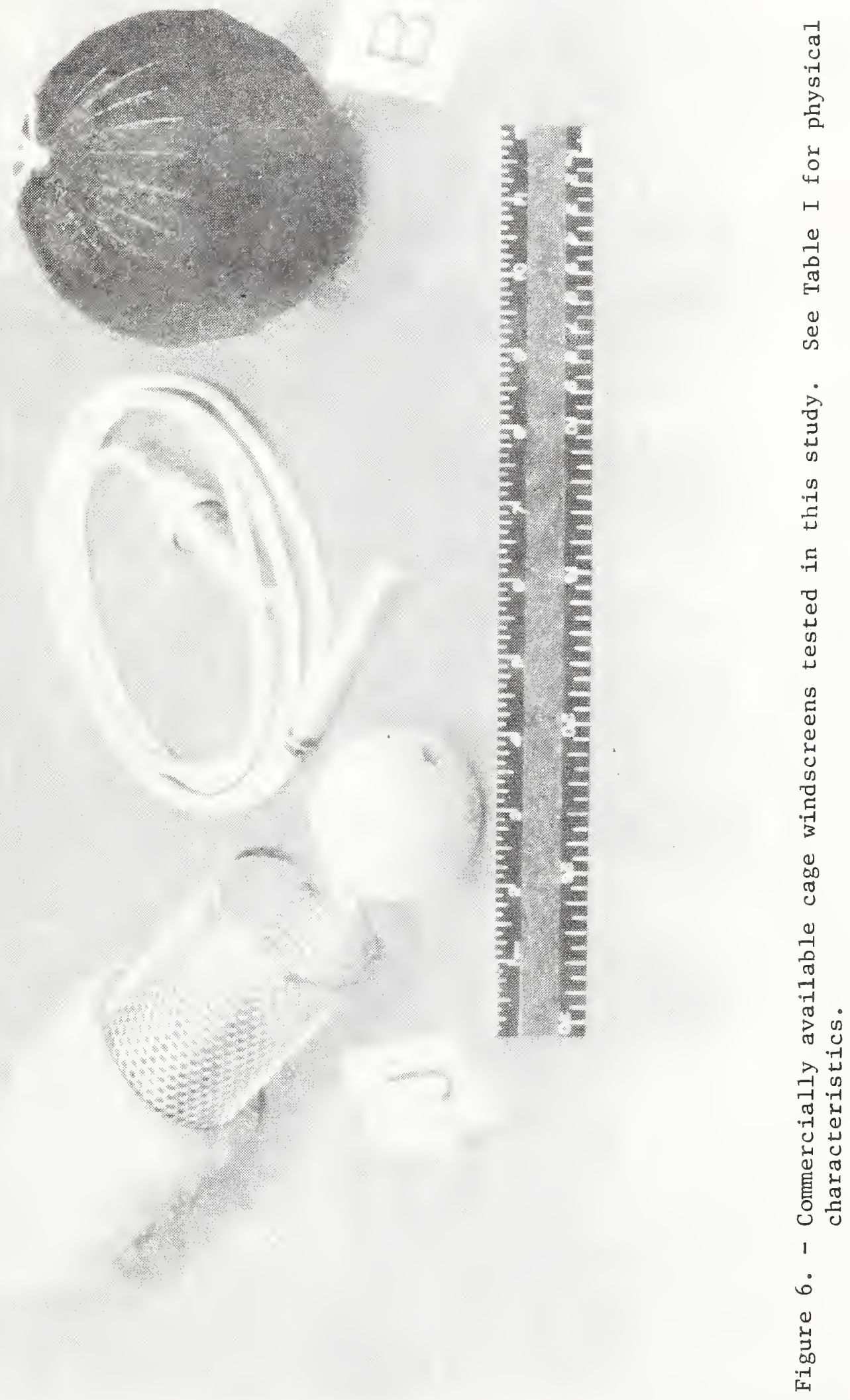




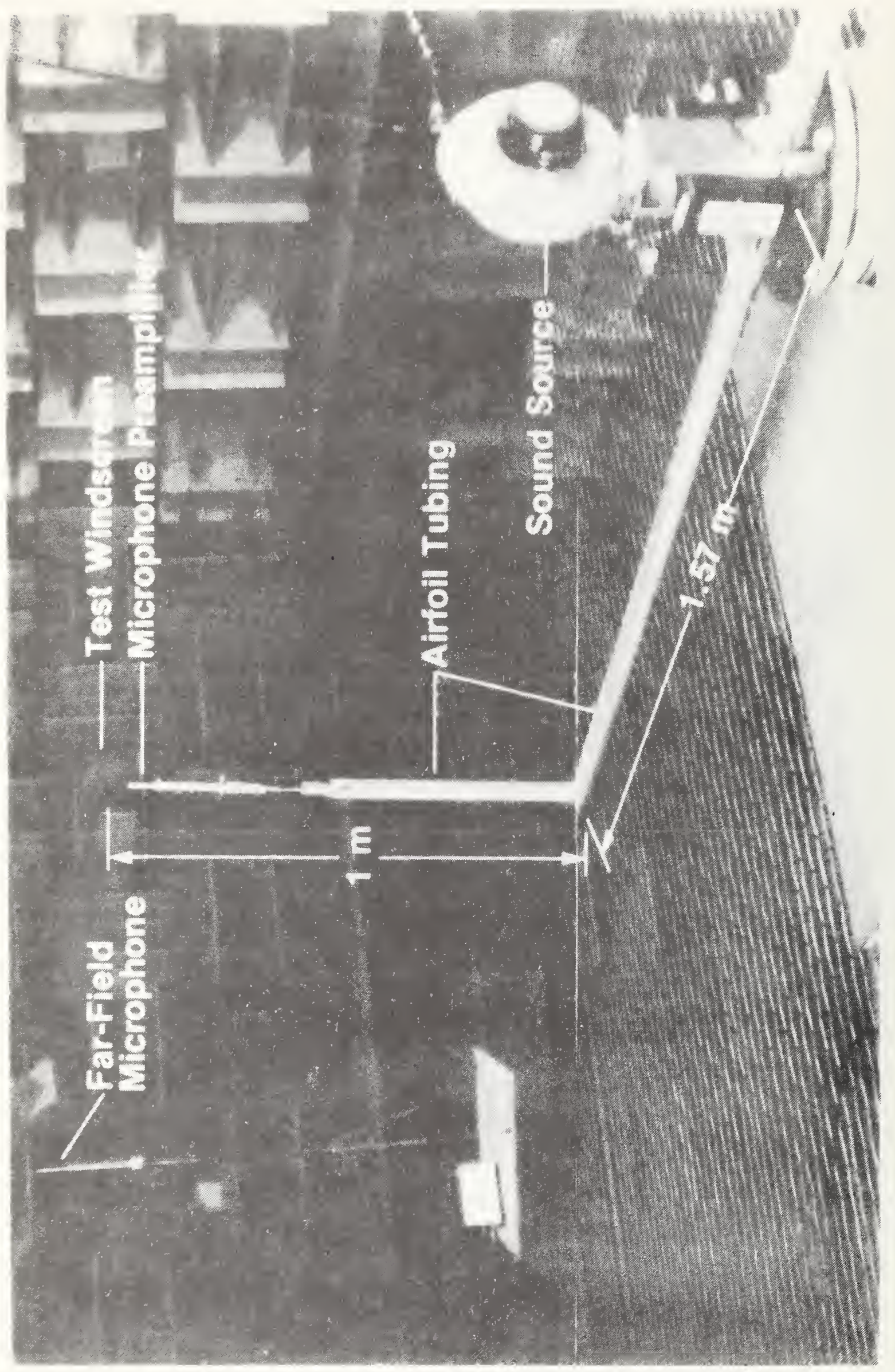

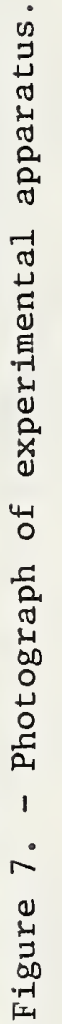




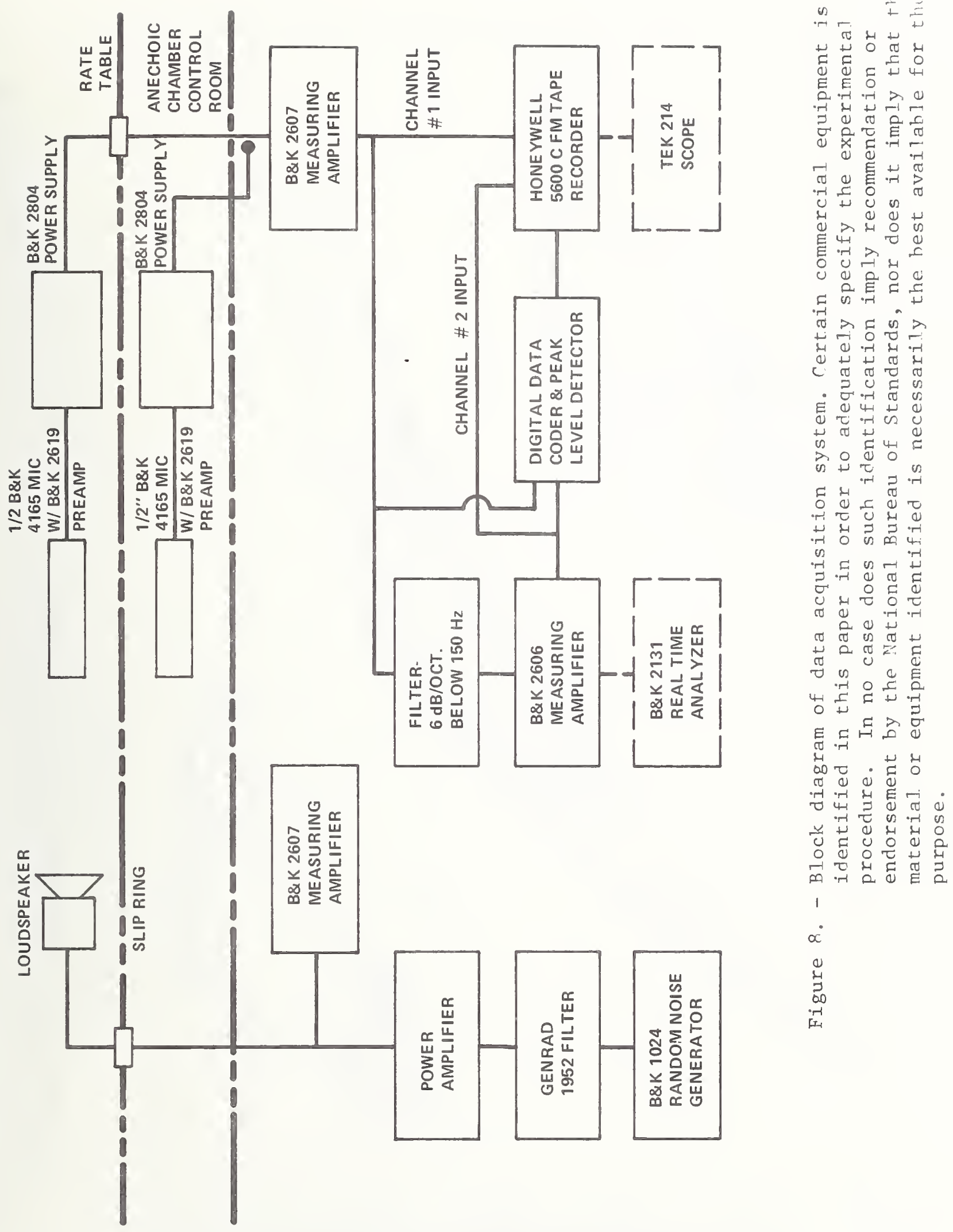



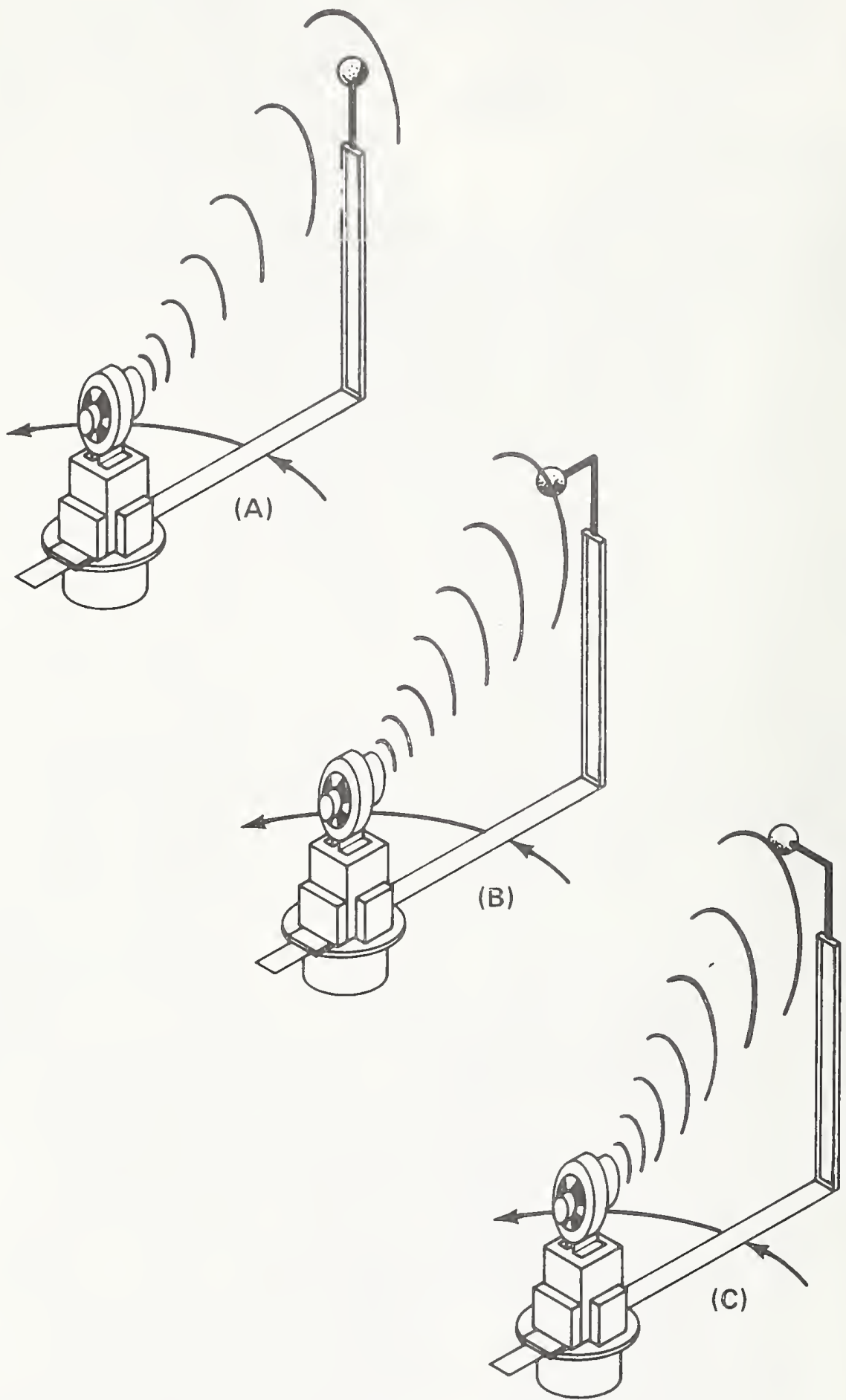

Figure 9. - Windscreen Test Configurations, (A) Grazing flow and grazing acoustic incidence angle, (B) Grazing flow and normal acoustic incidence angle, (C) Normal flow and grazing acoustic incidence angle. 


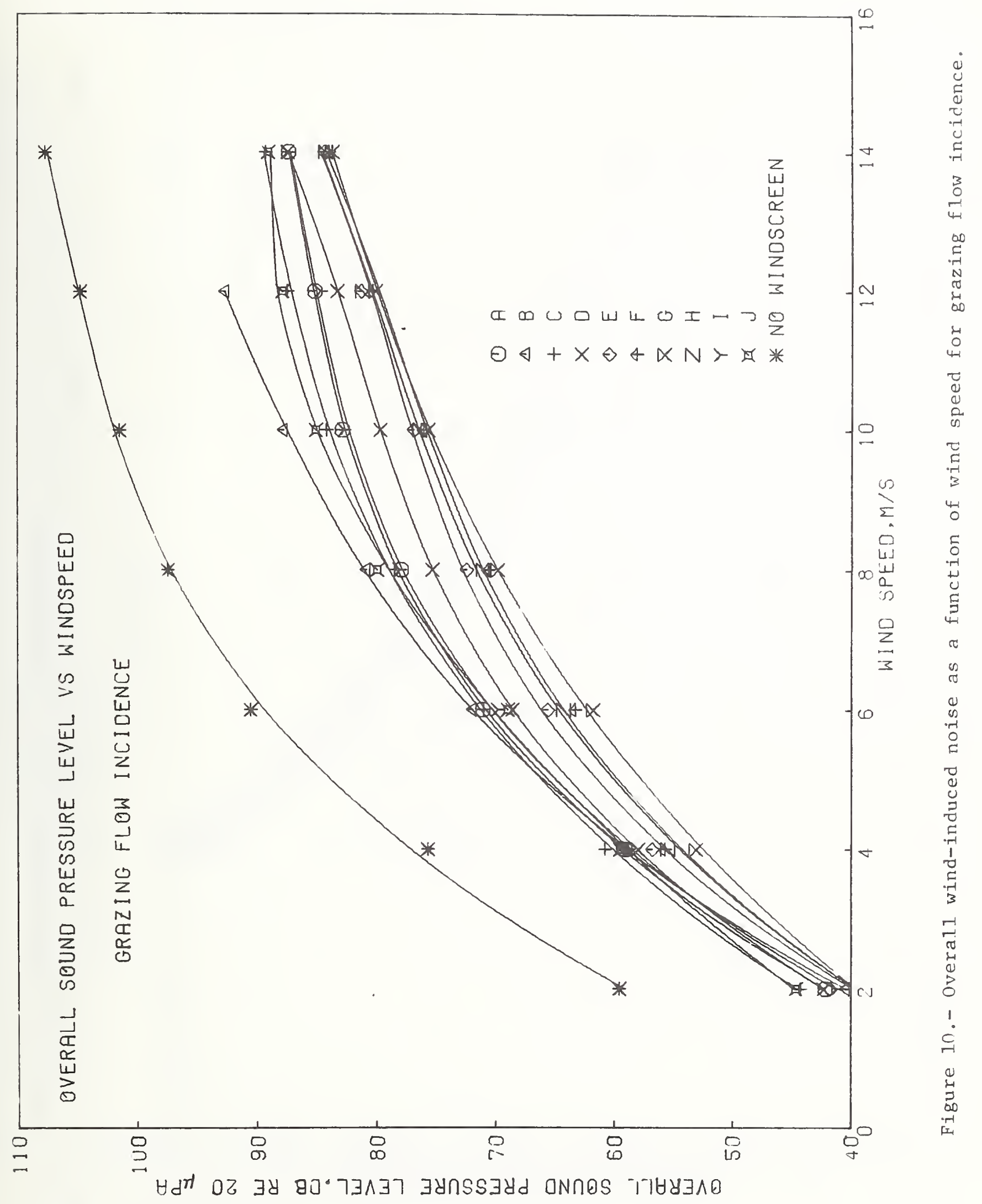




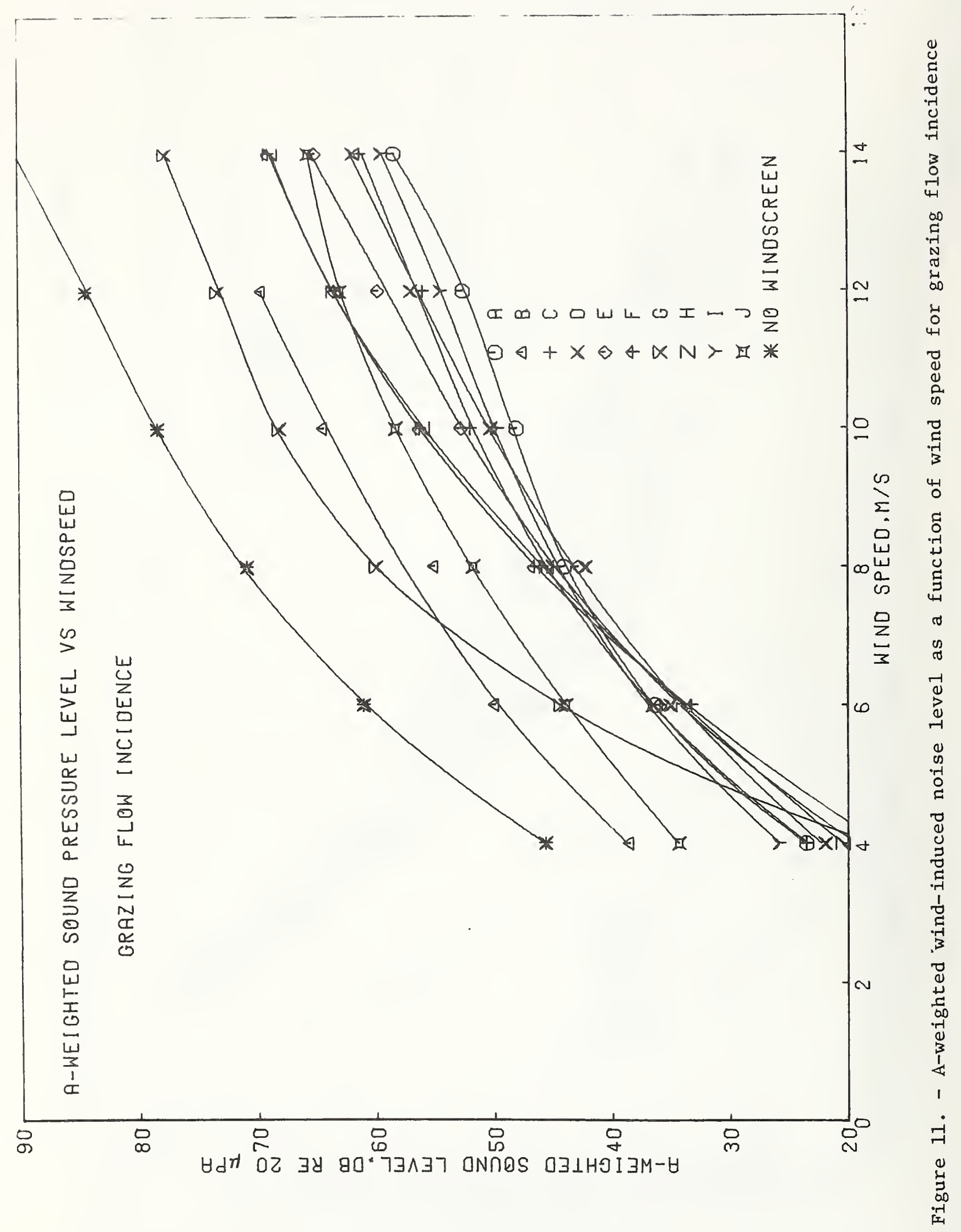




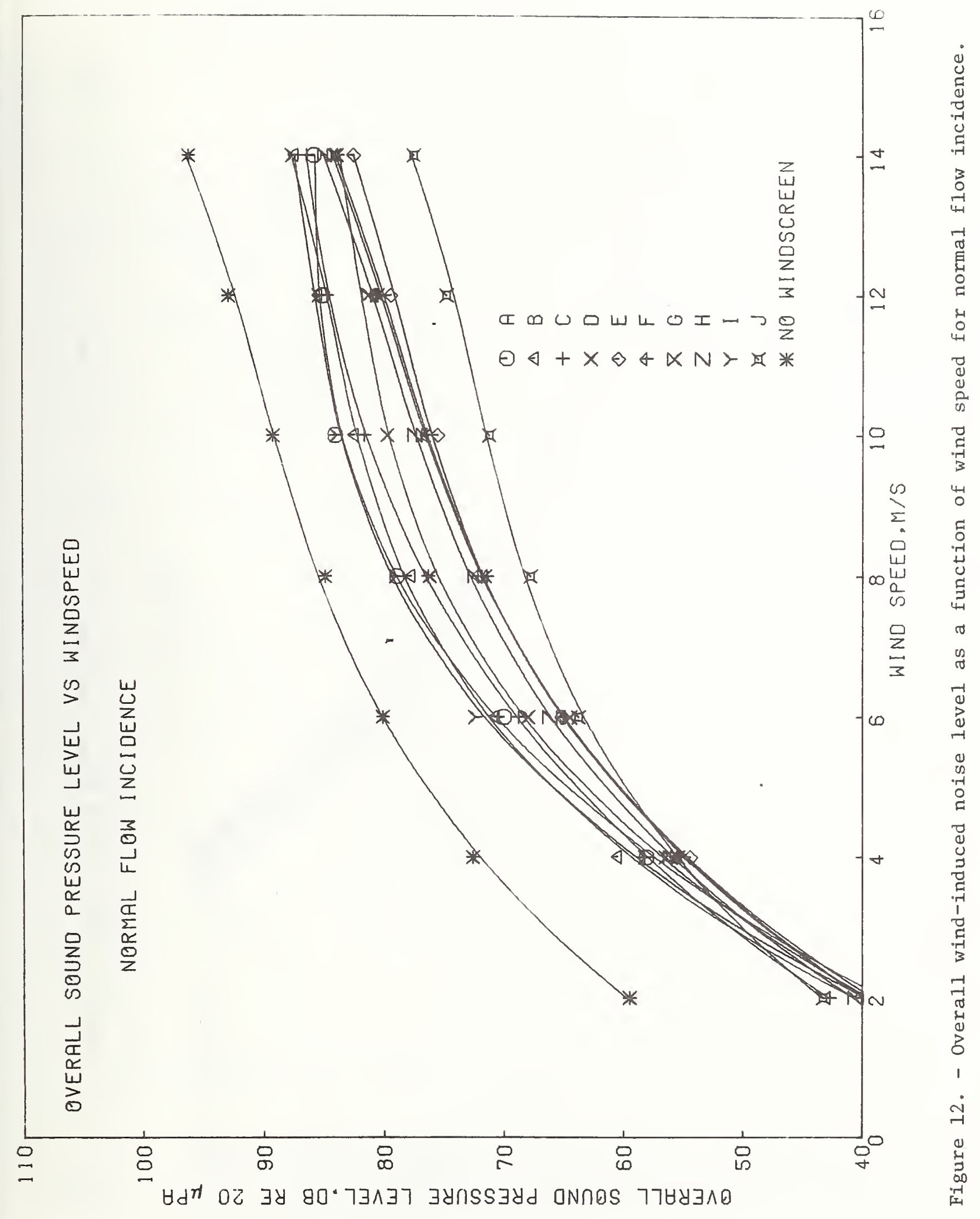




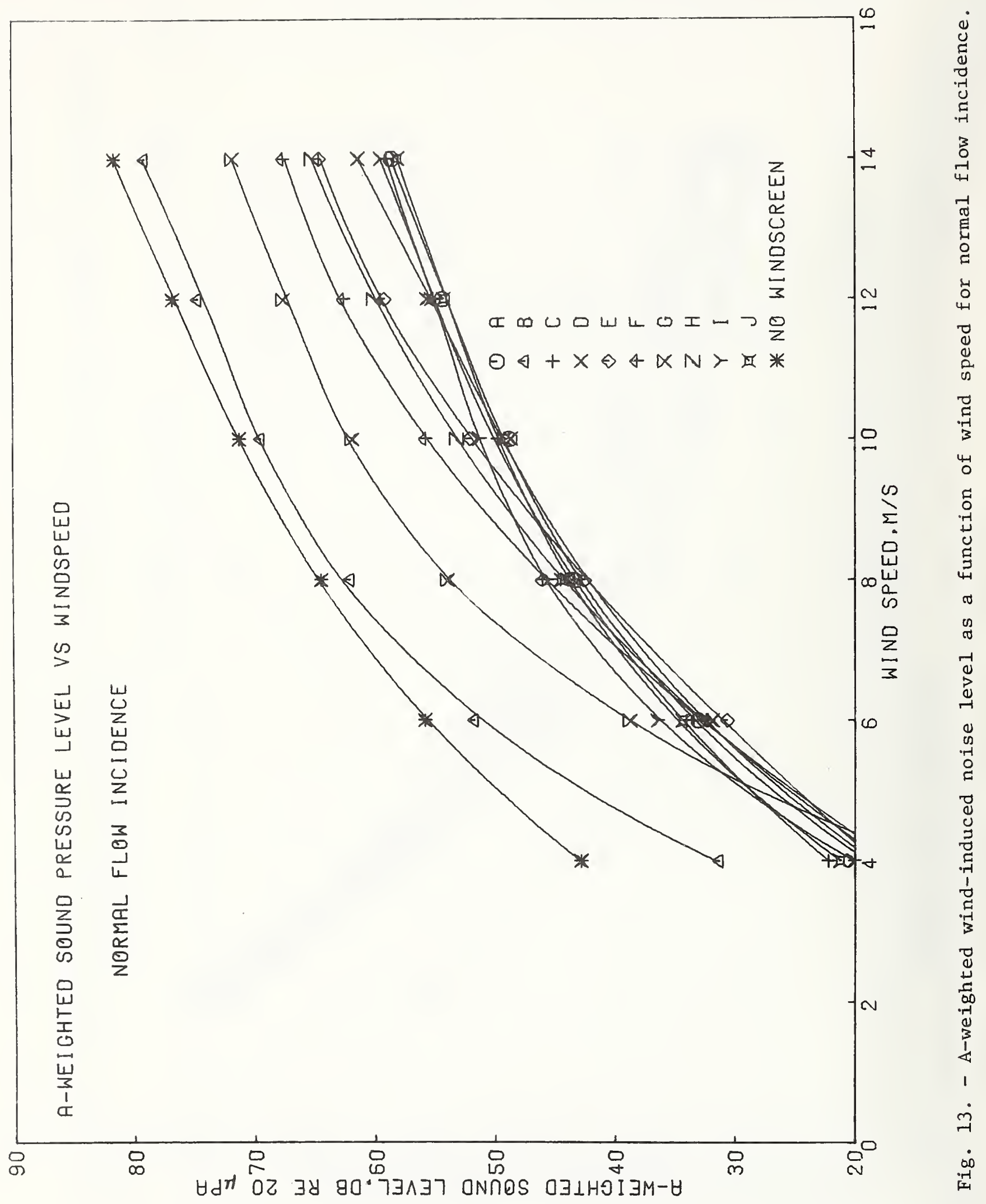




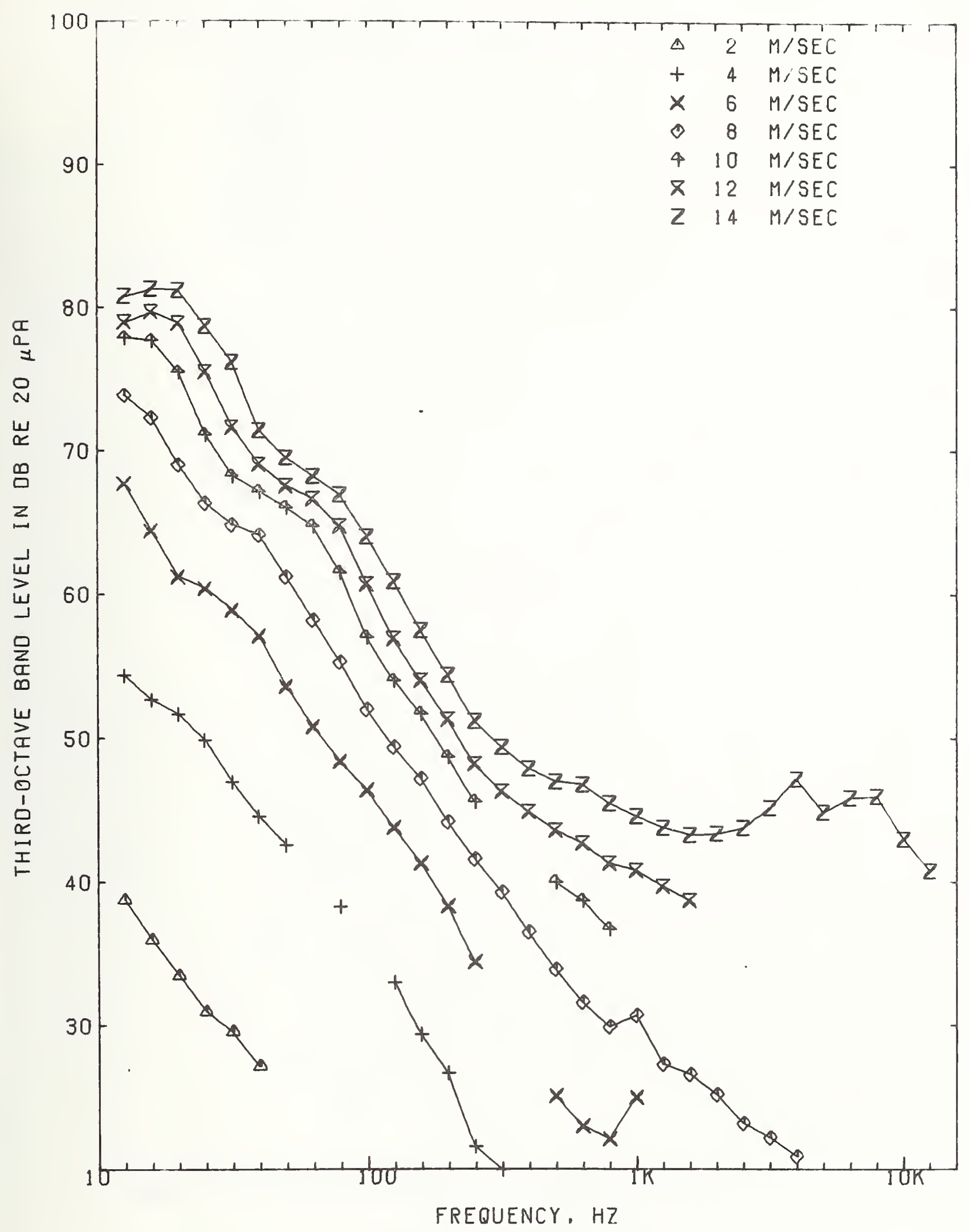

(a) Windscreen A - grazing flow

Figure 14. - One-third octave band wind-induced noise spectra as a function of wind speed for grazing flow incidence. 


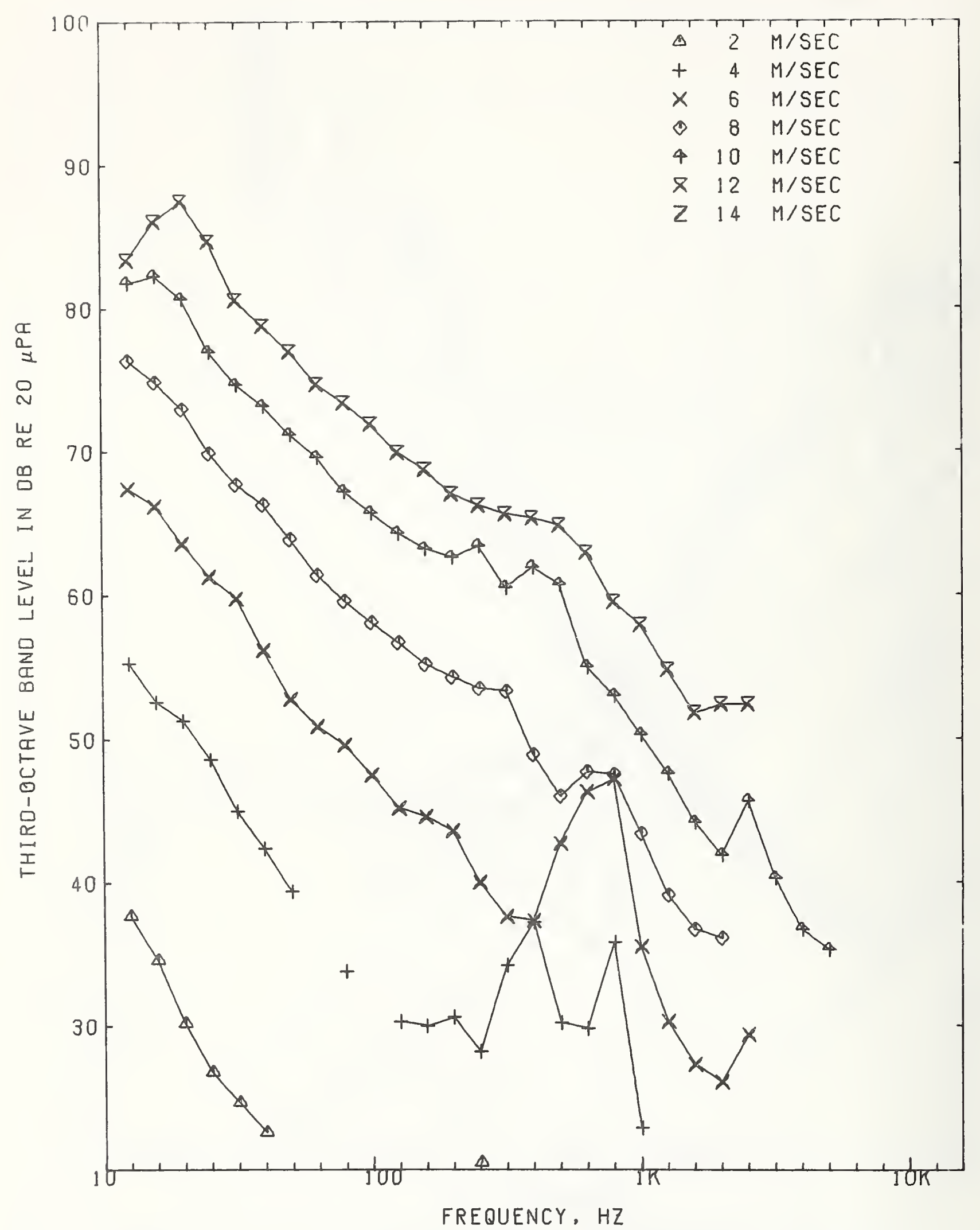

(b) Windscreen B - grazing flow

Figure 14. - Continued. 


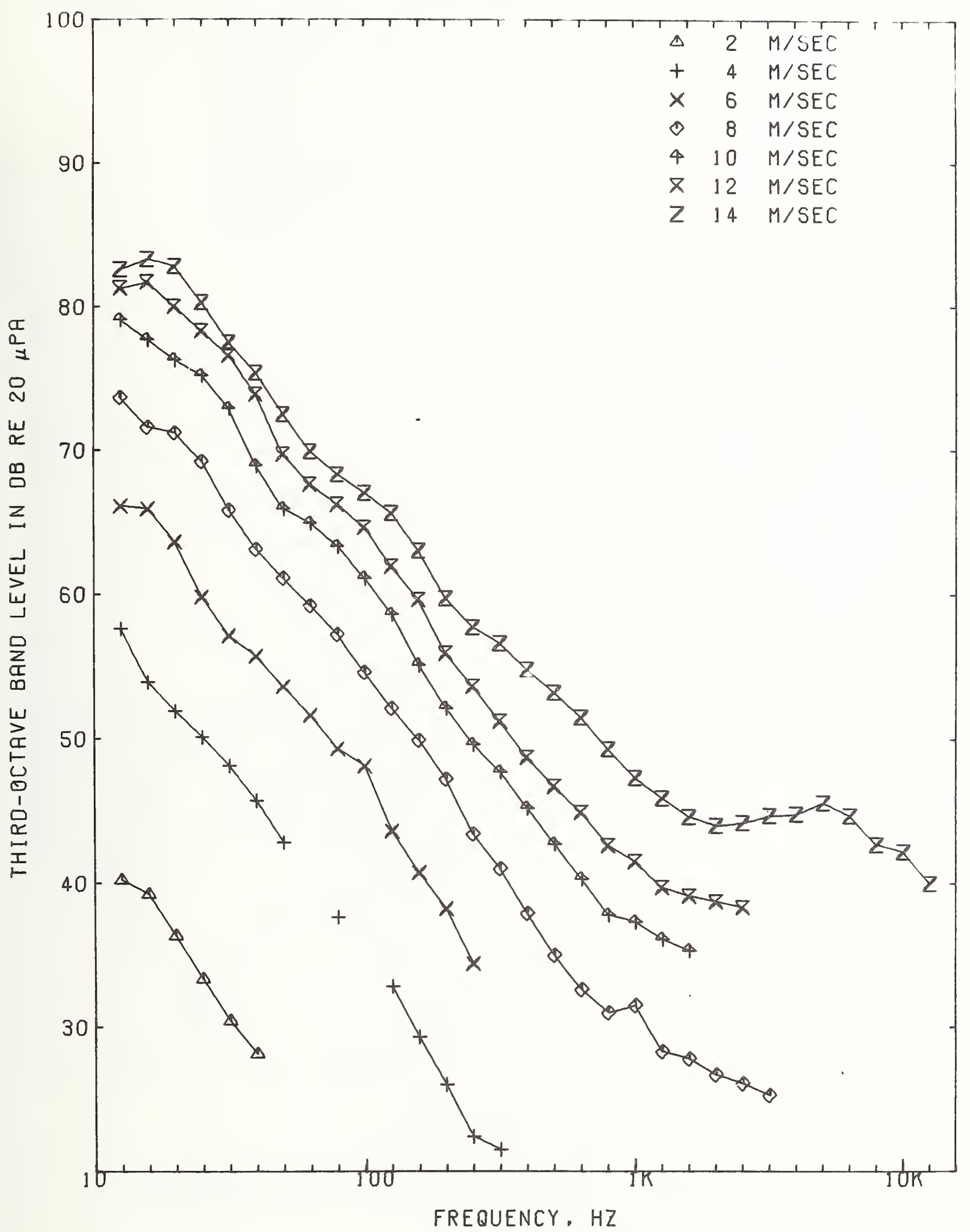

(c) Windscreen C - grazing flow

Figure 14. - Continued. 


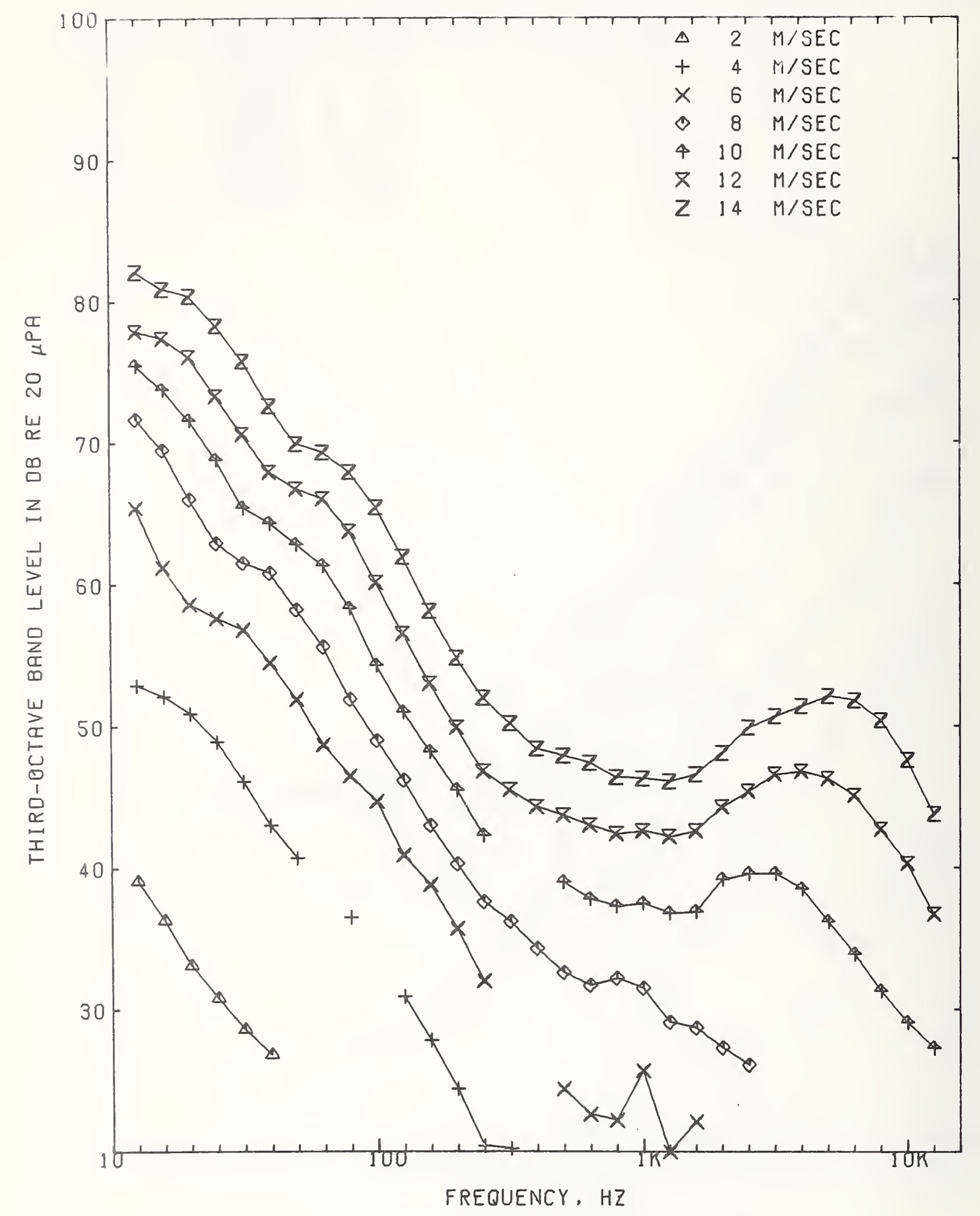

(d) Windscreen $D$ - grazing flow 


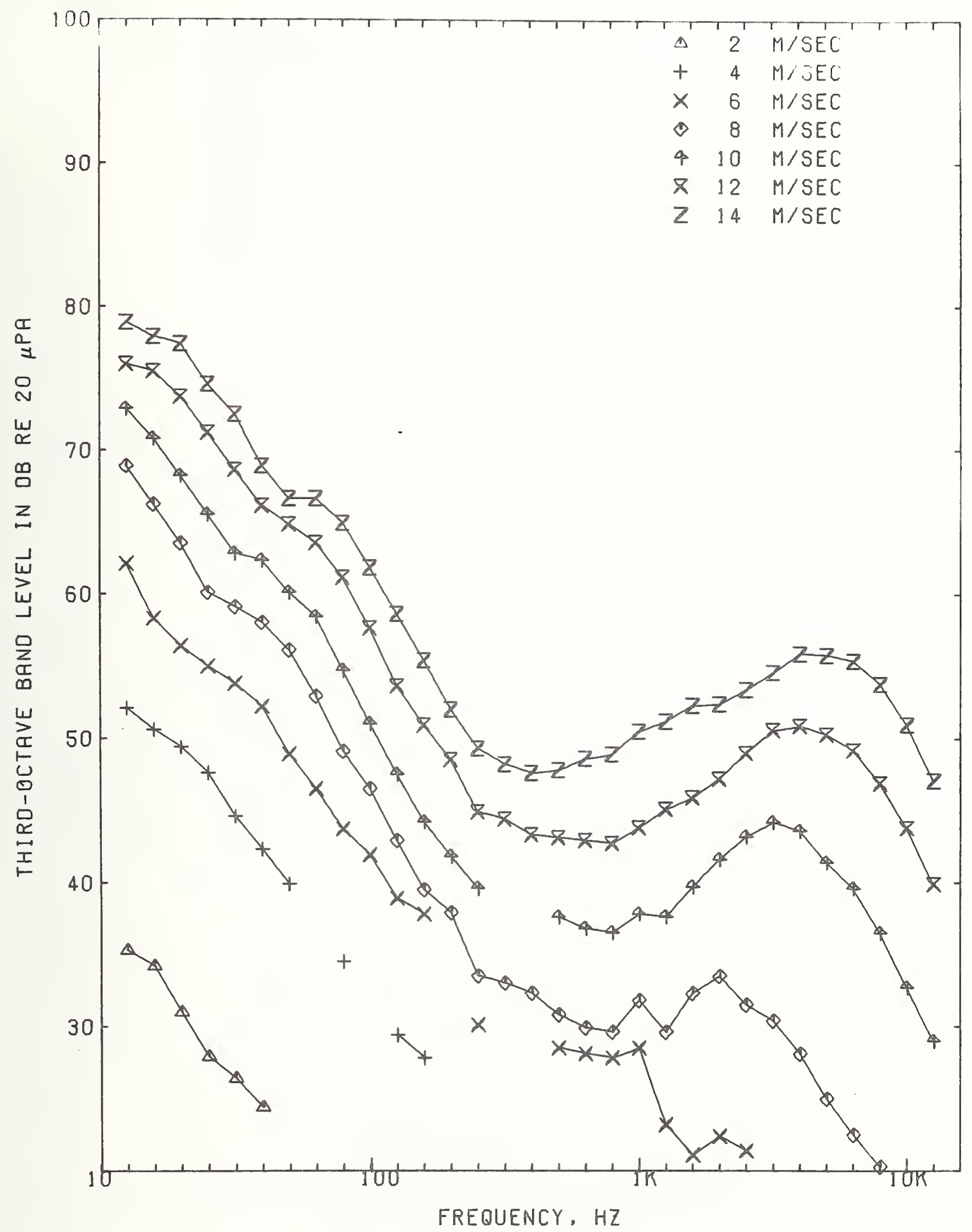

(e) Windscreen E - grazing flow

Figure 14. - Continued, 


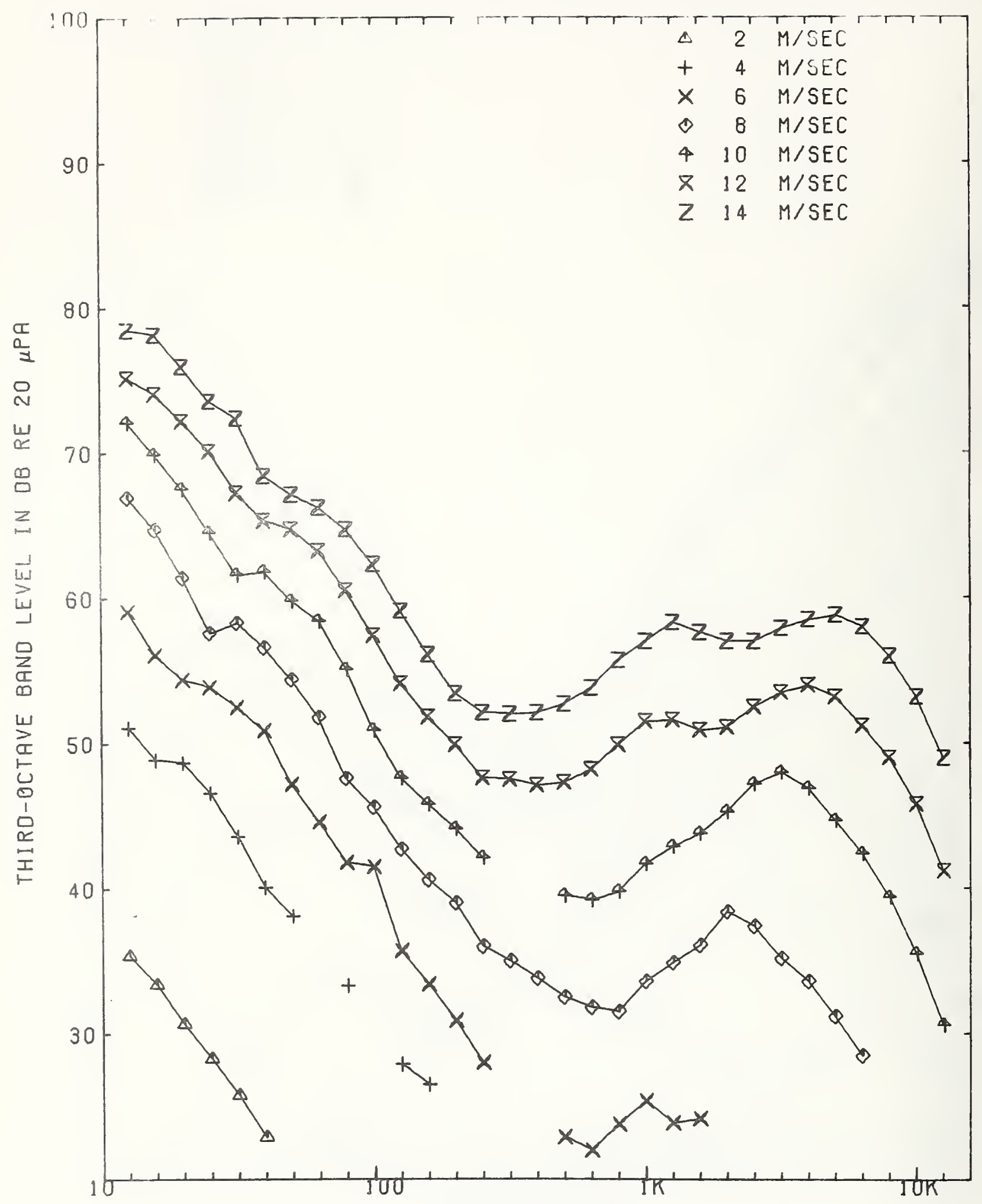

FREQUENCY, HZ

(f) Windscreen $F=$ grazing flow

Figure 14. - Continued. 


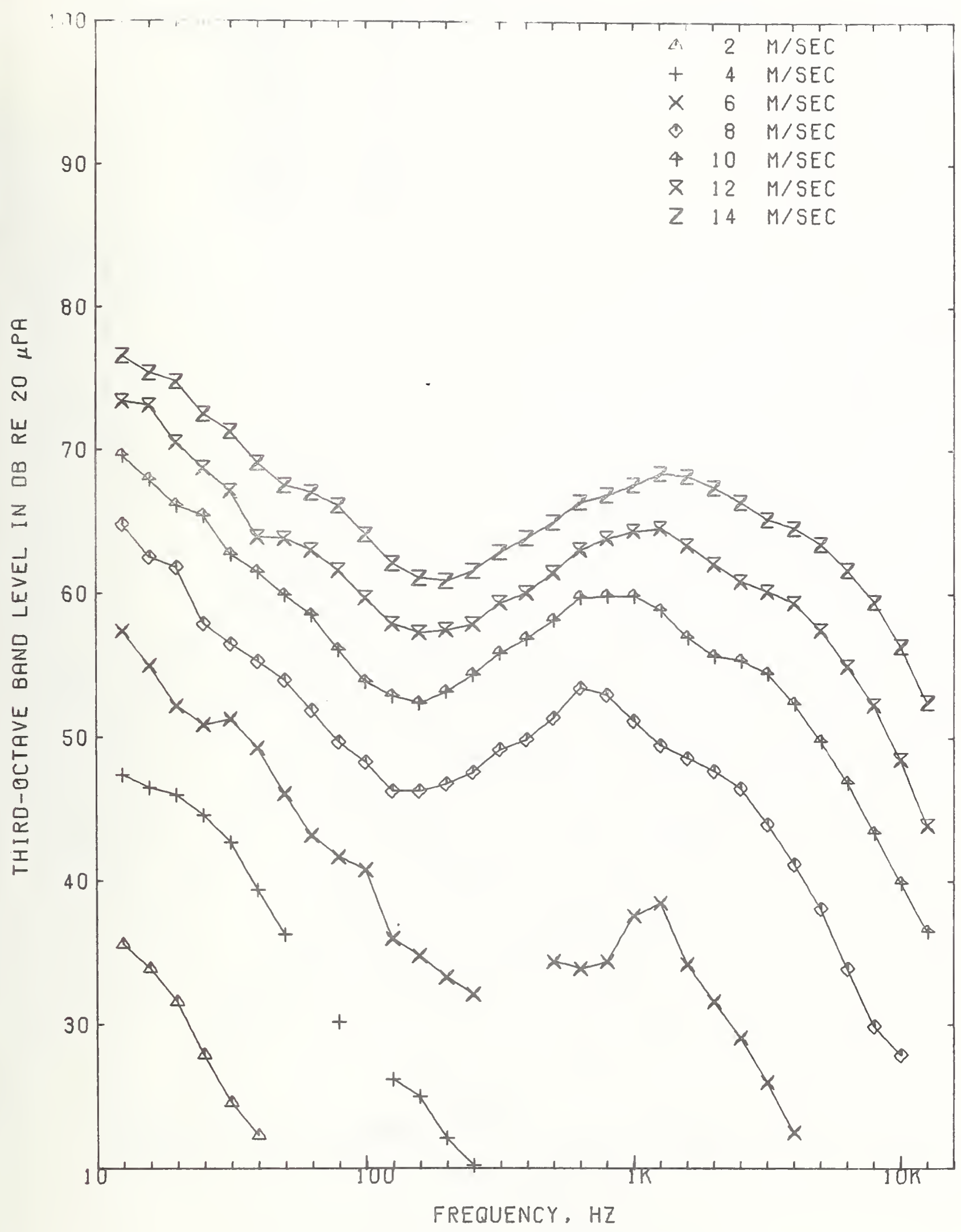

(g) Windscreen G - grazing flow

Figure 14. - Continued. 


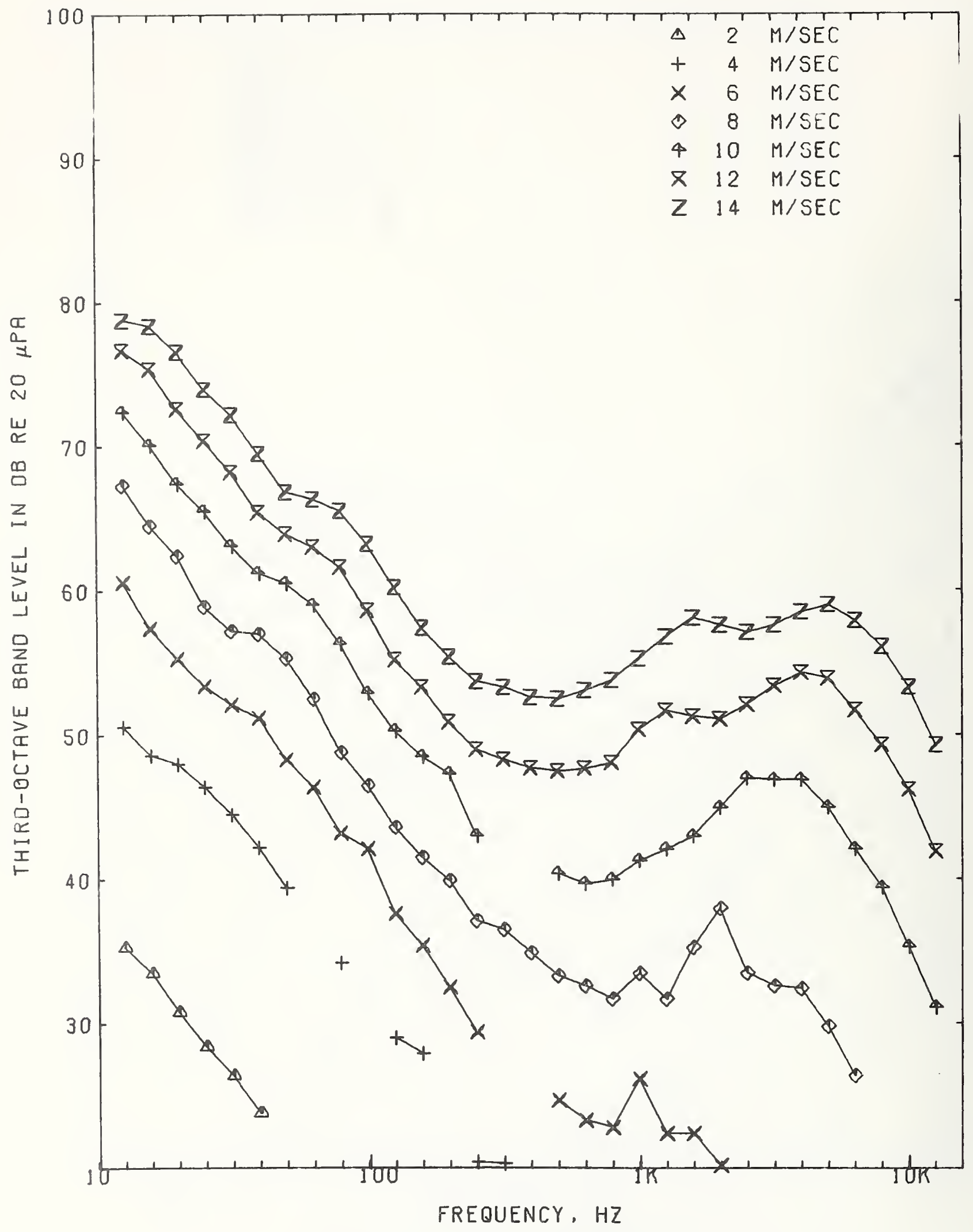

(h) Windscreen H - grazing flow

Figure 14. - Continued. 


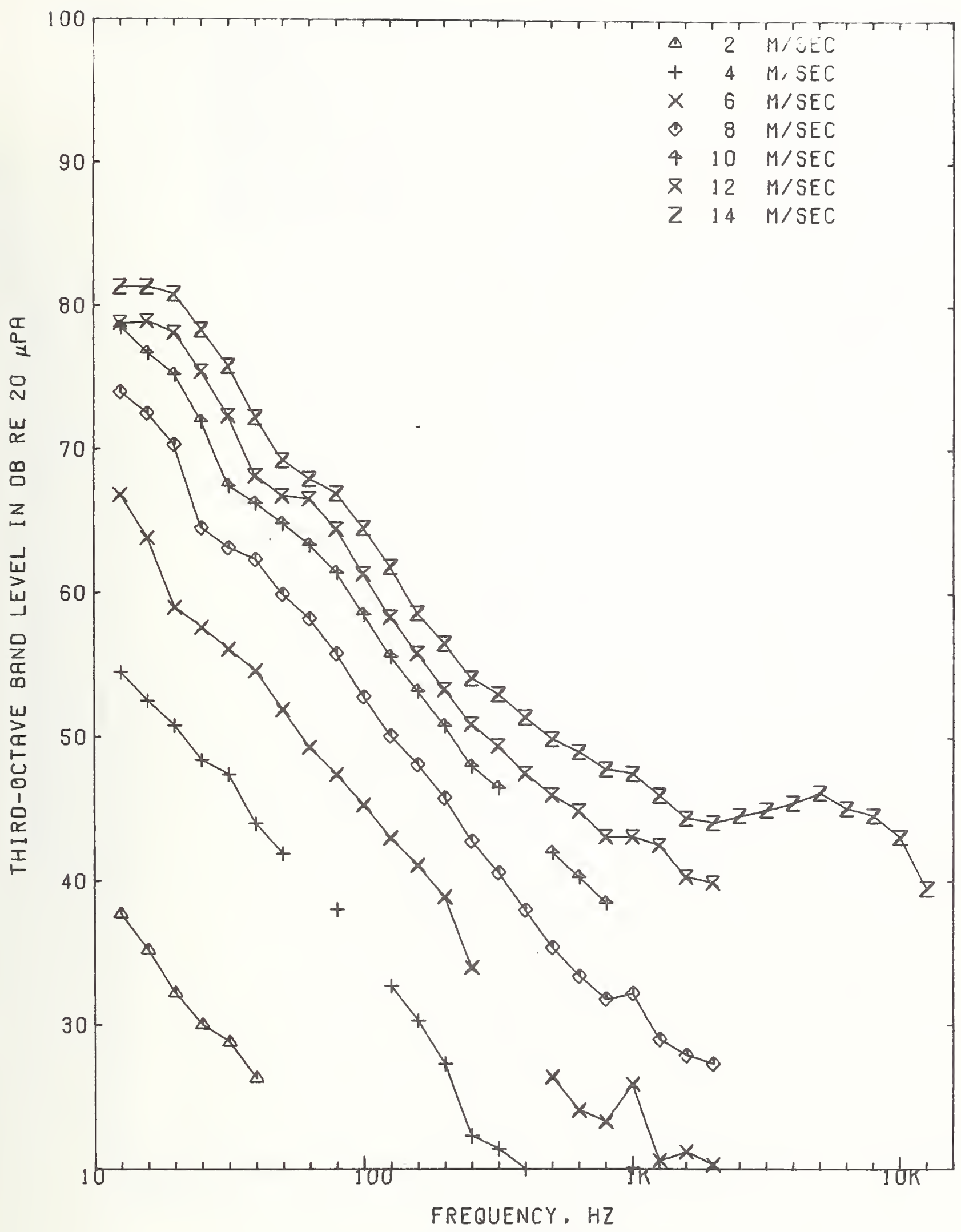

(i) Windscreen I - grazing flow 


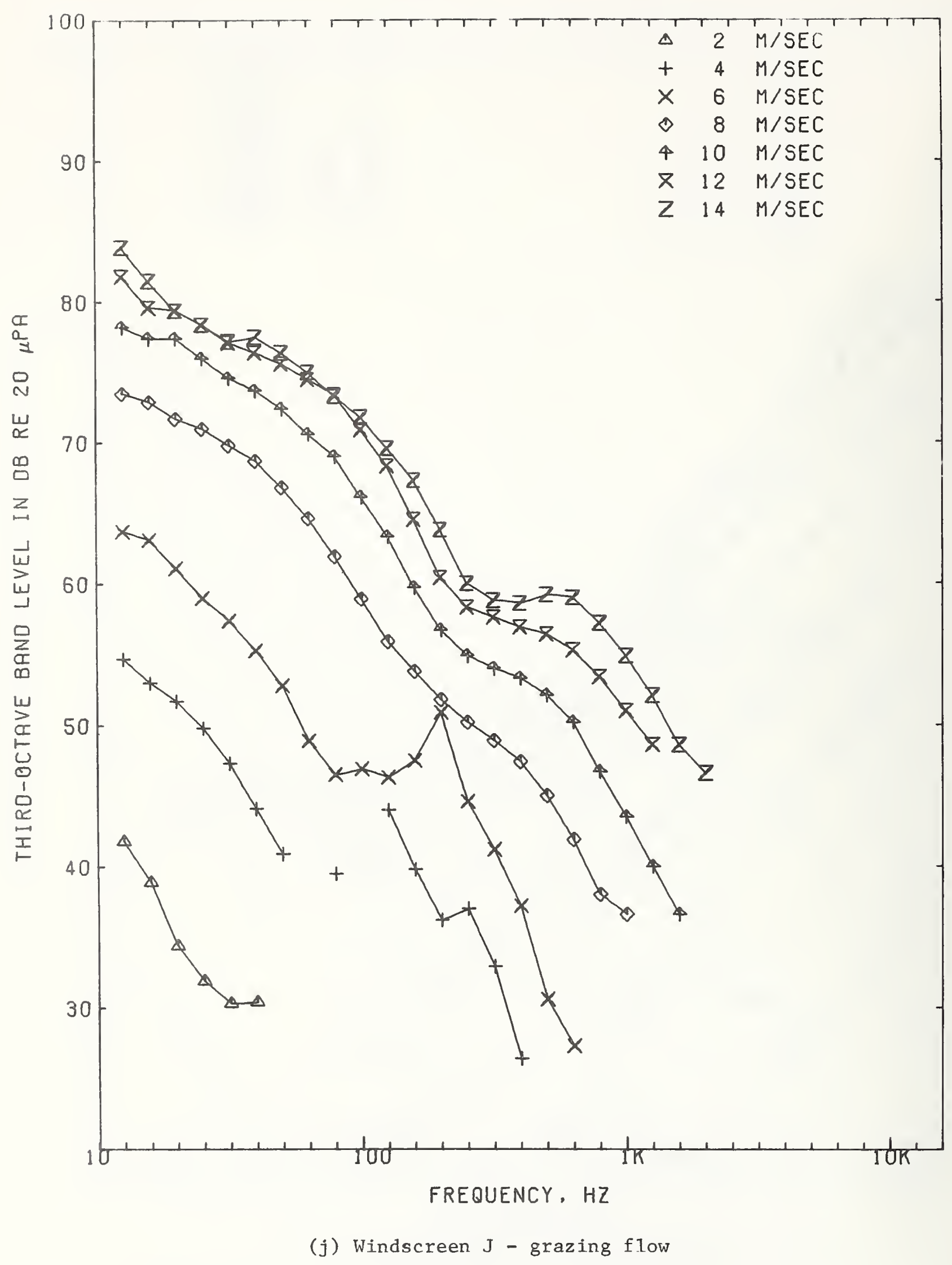

Figure 14. - Continued. 


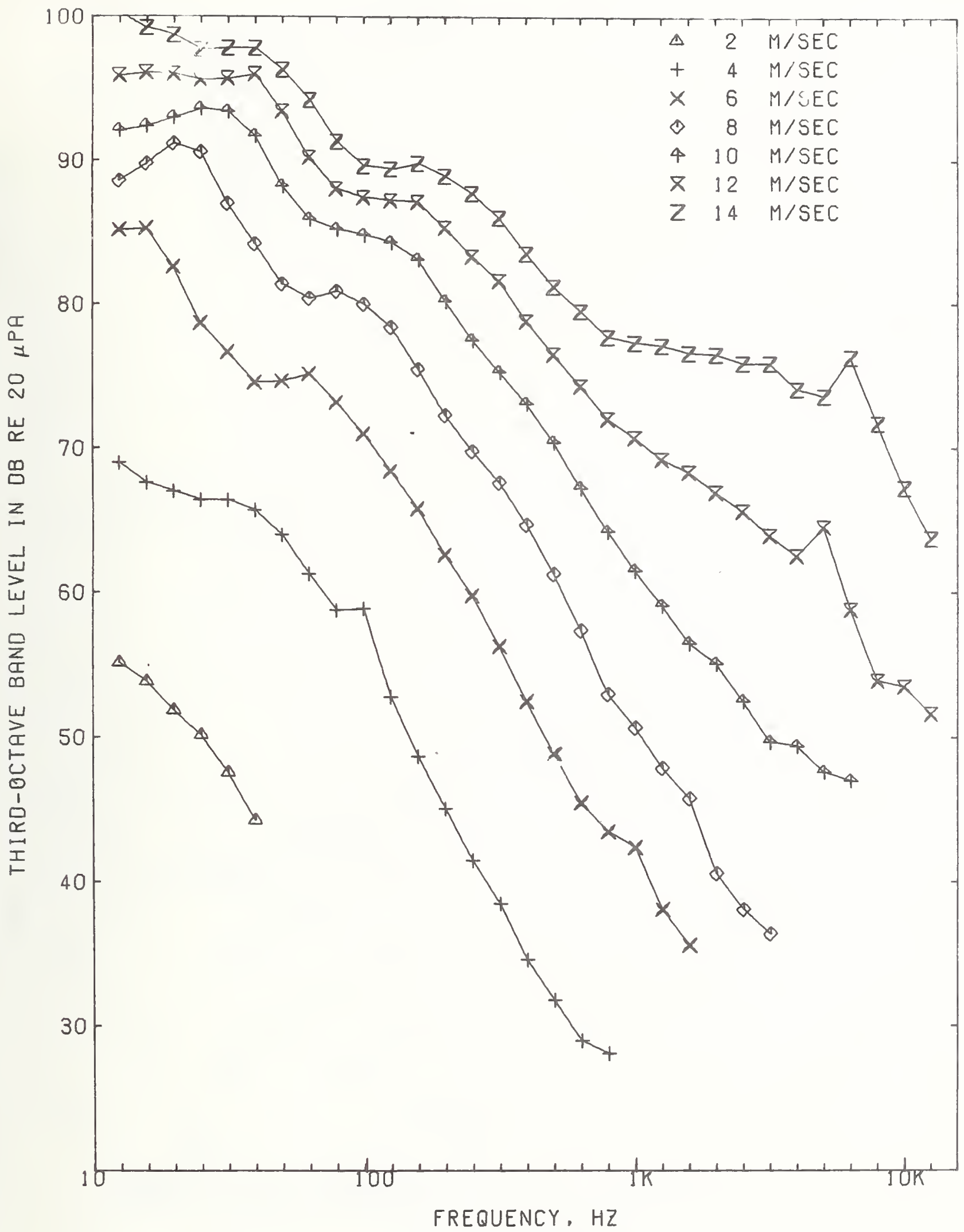

(k) No Windscreen - grazing flow

Figure 14. - Concluded. 


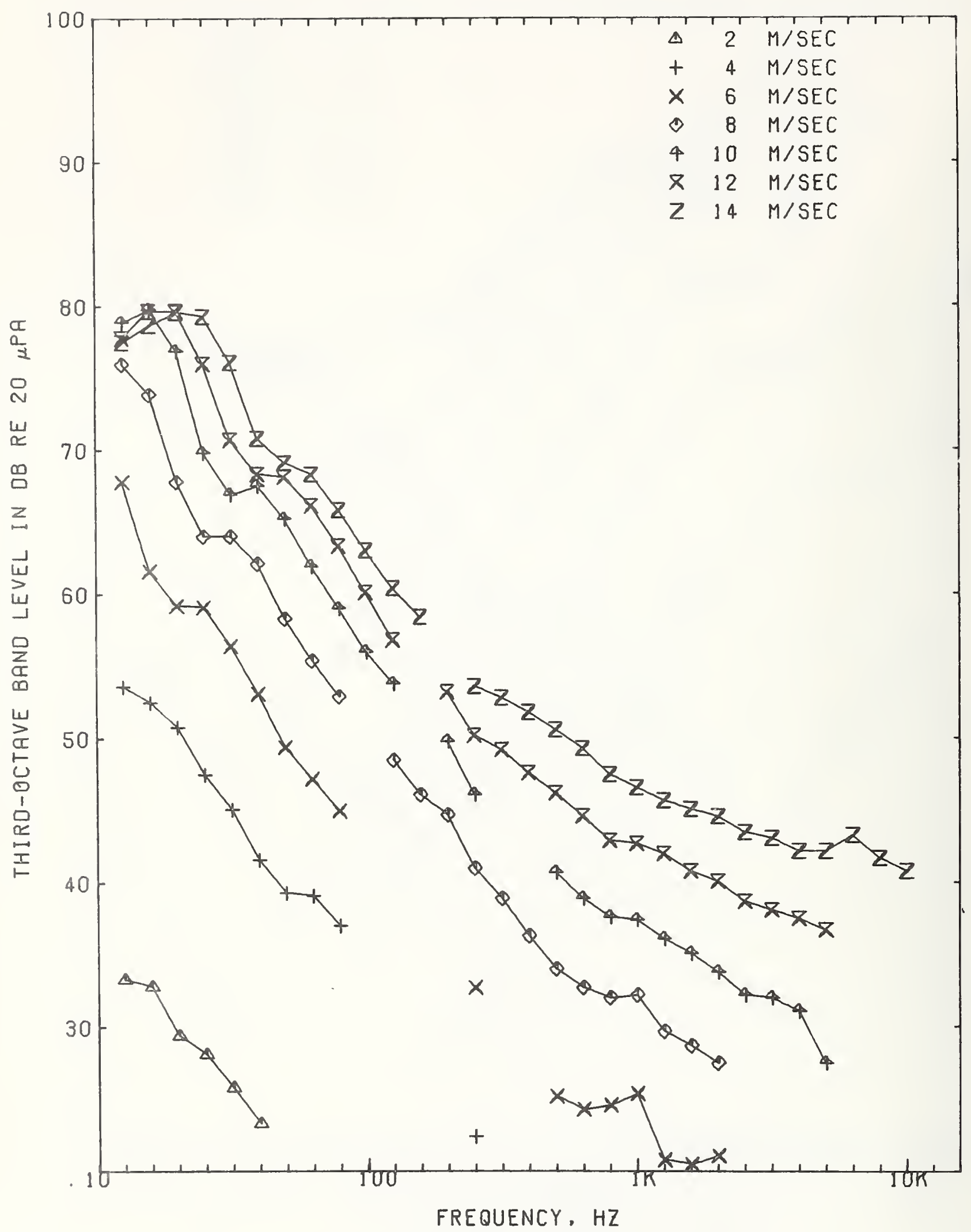

(a) Windscreen A - normal flow

Figure 15. - One-third octave band wind-induced noise spectra obtained as a function of wind speed for normal flow incidence. 


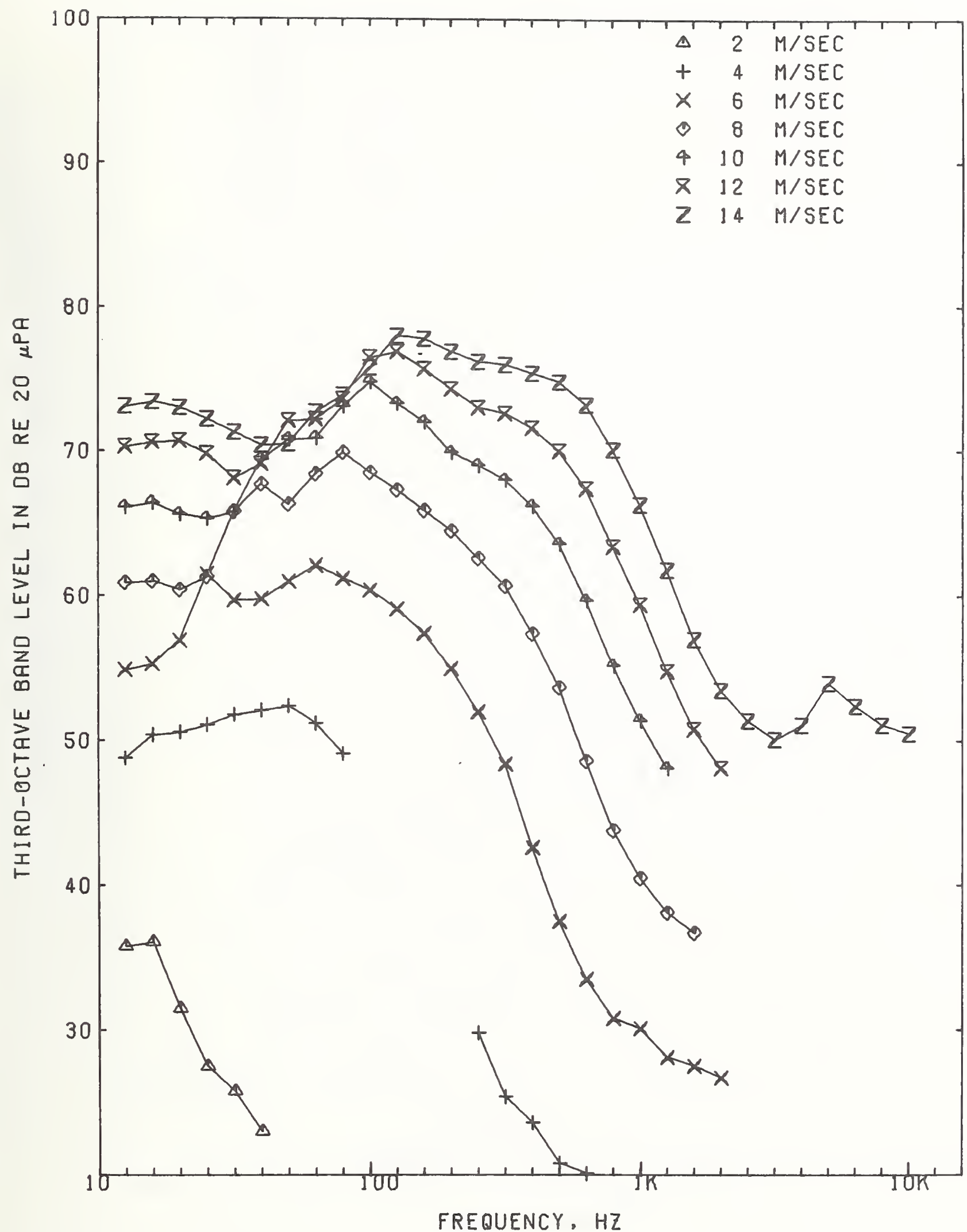

(b) Windscreen B - normal flow

Figure 15. - Continued. 


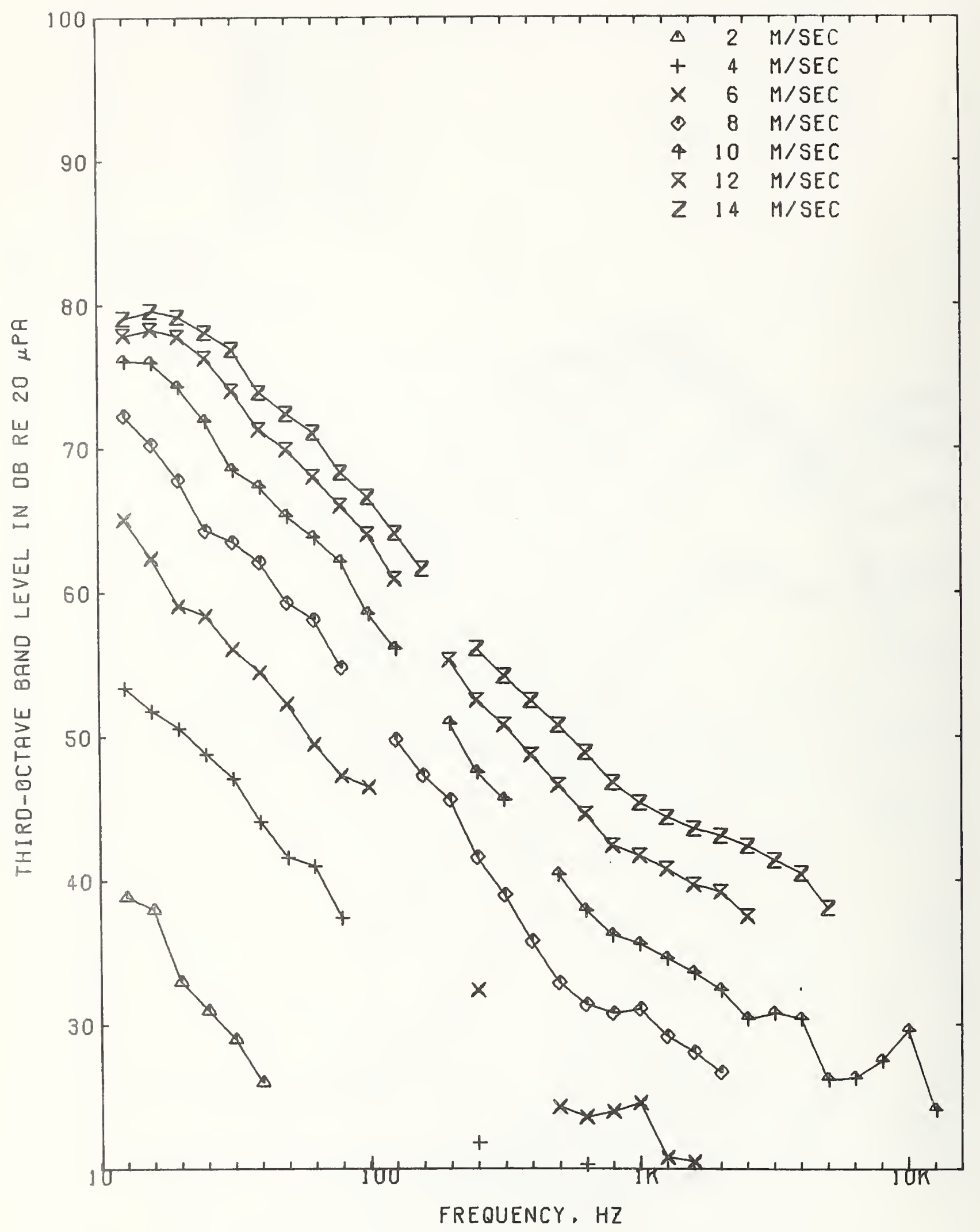

(c) Windscreen C - normal flow 


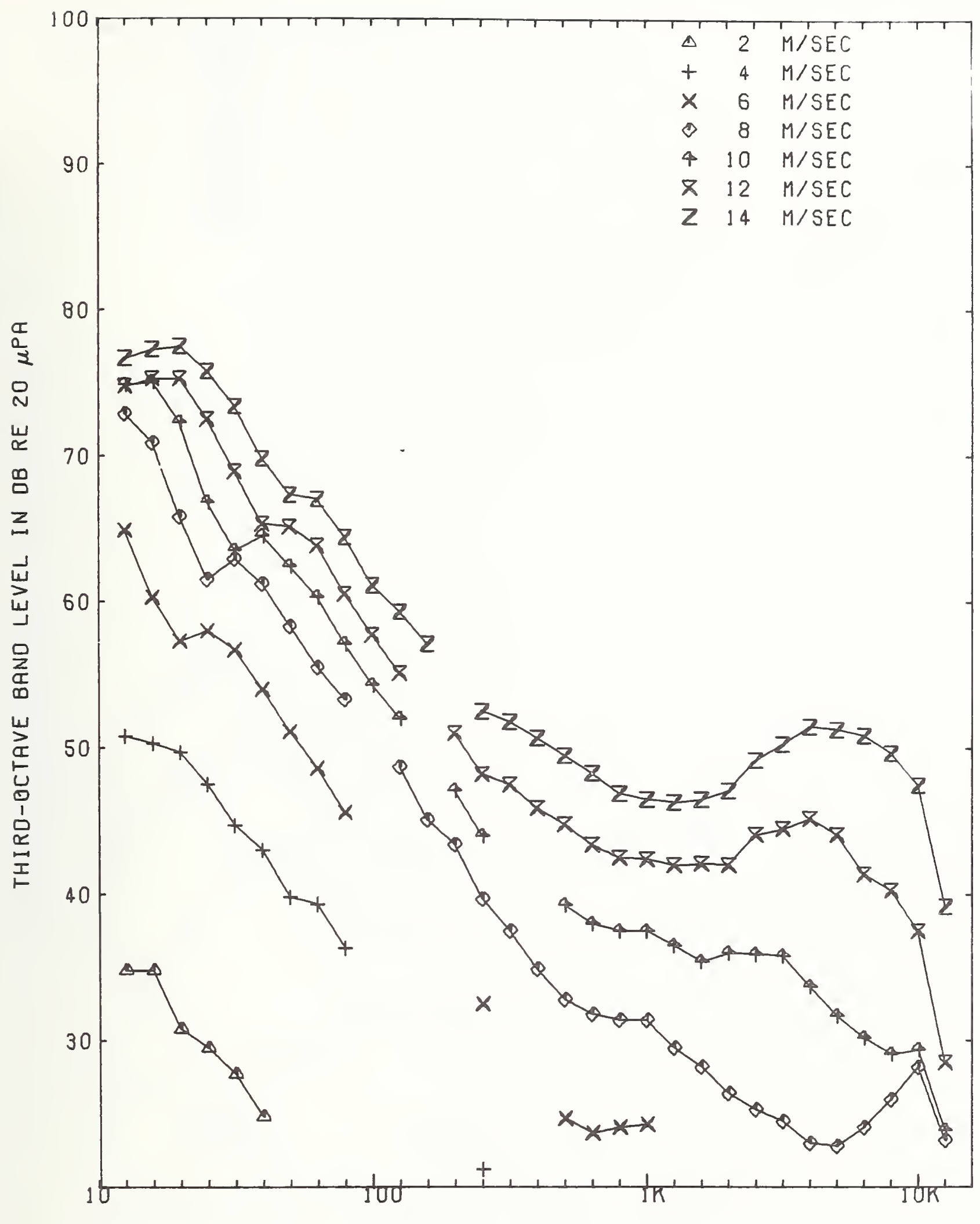

FREQUENCY, HZ

(d) Windscreen D - normal flow

Figure 15. - Continued. 


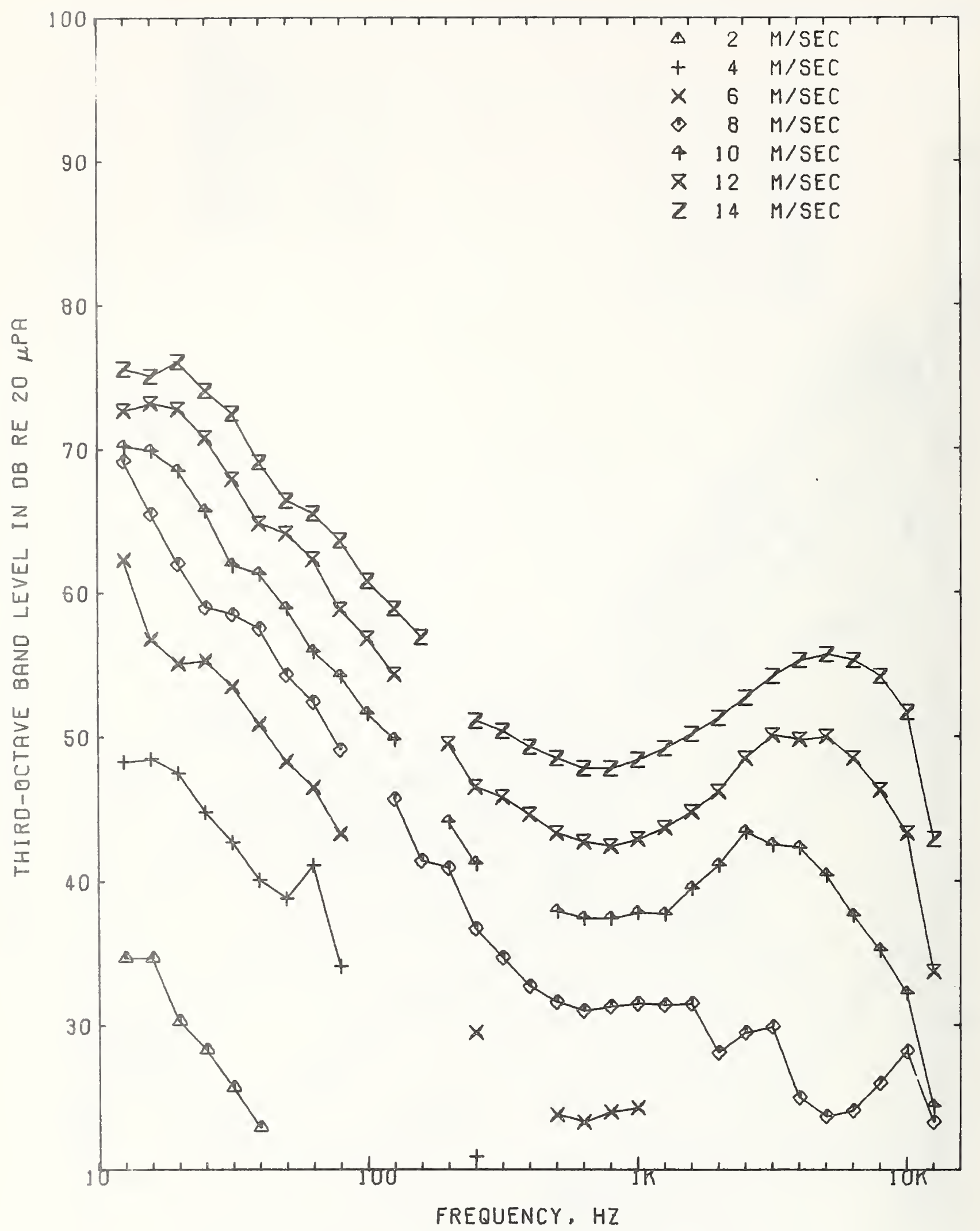

(e) Windscreen E - normal flow

Figure 15. - Continued. 


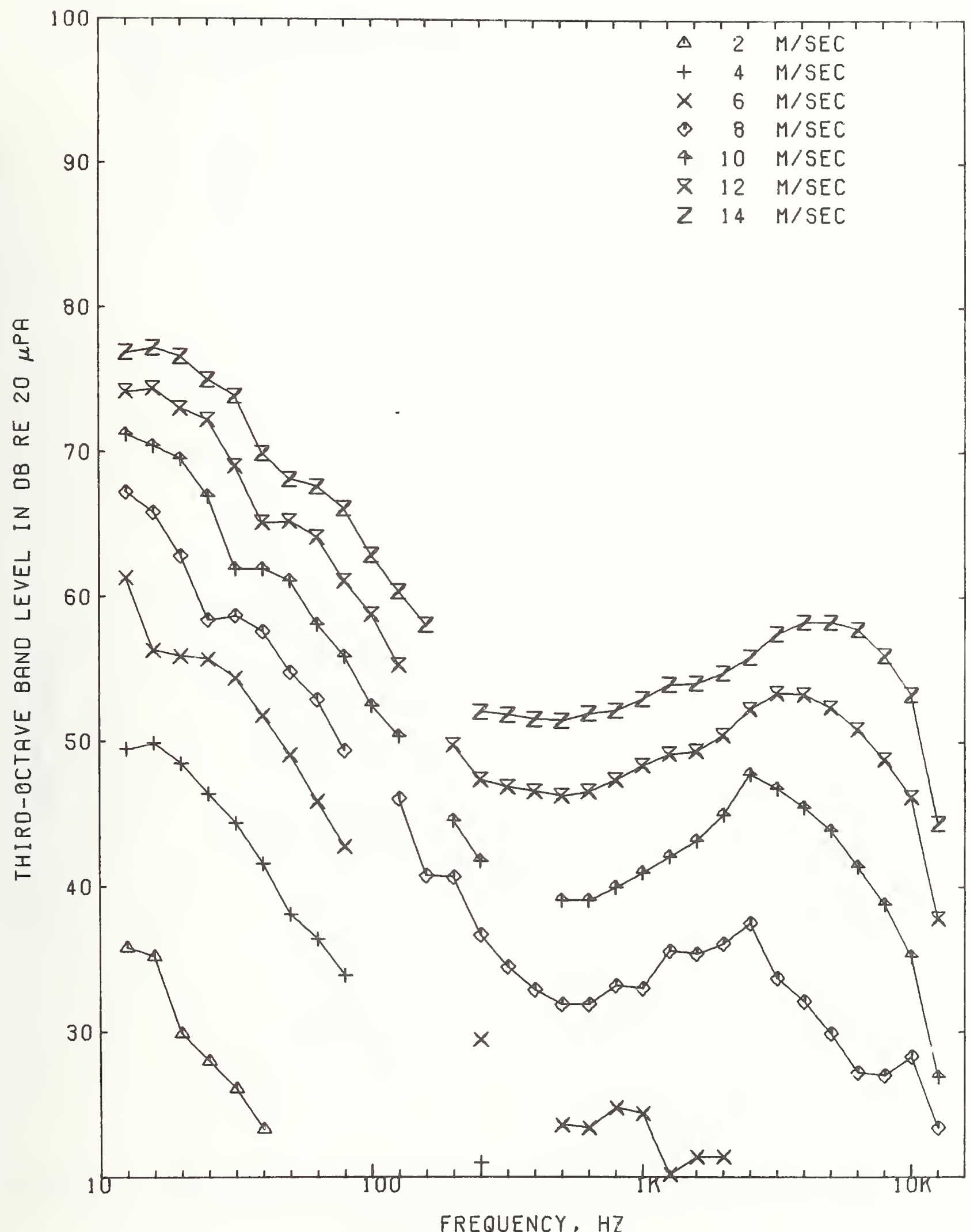

(f) Windscreen F - normal flow

Figure 15. - Continued. 


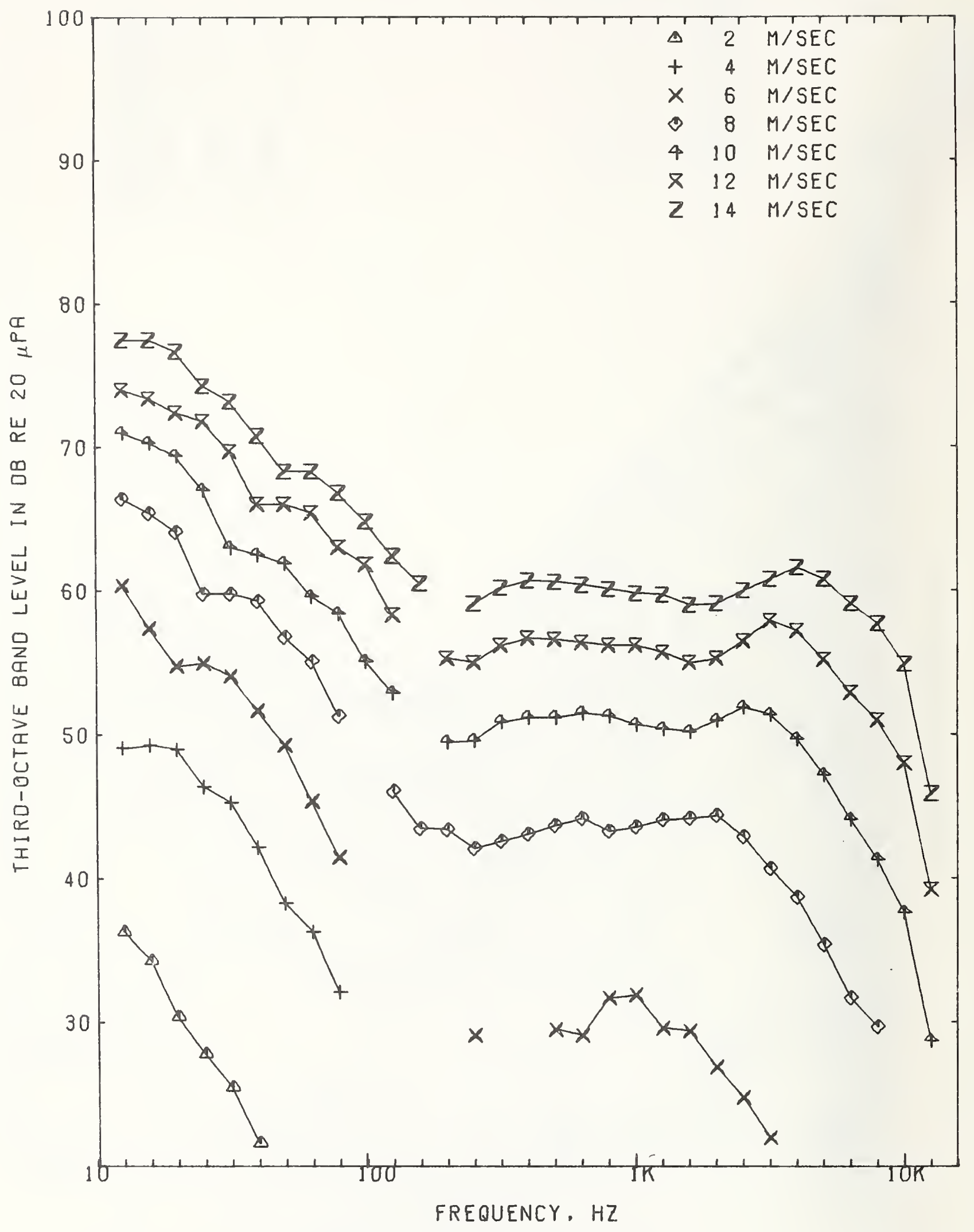

(g) Windscreen G - norma1 flow 


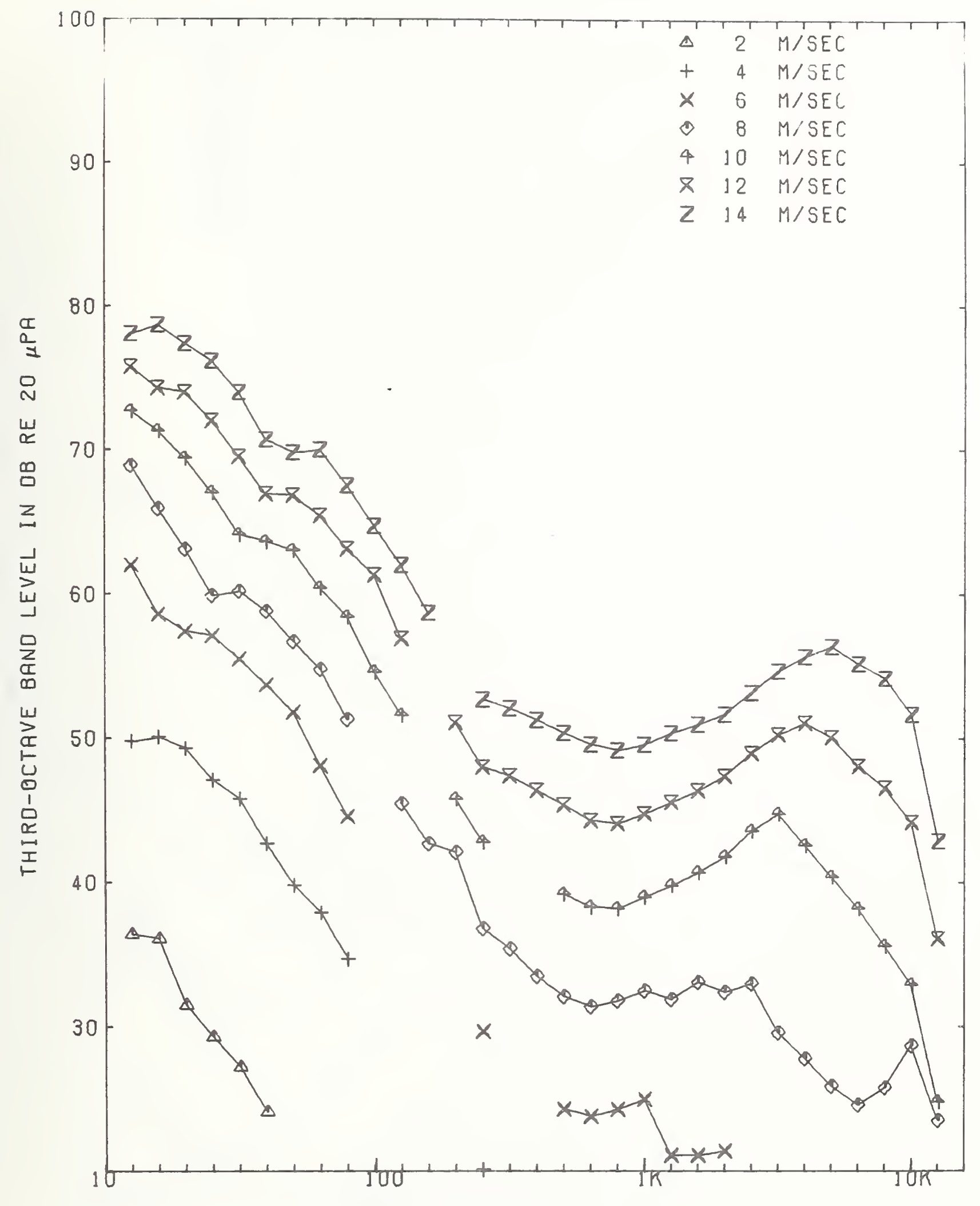

FREQUENCY, HZ

(h) Windscreen $\mathrm{H}$ - normal flow

Figure 15. - Continued. 


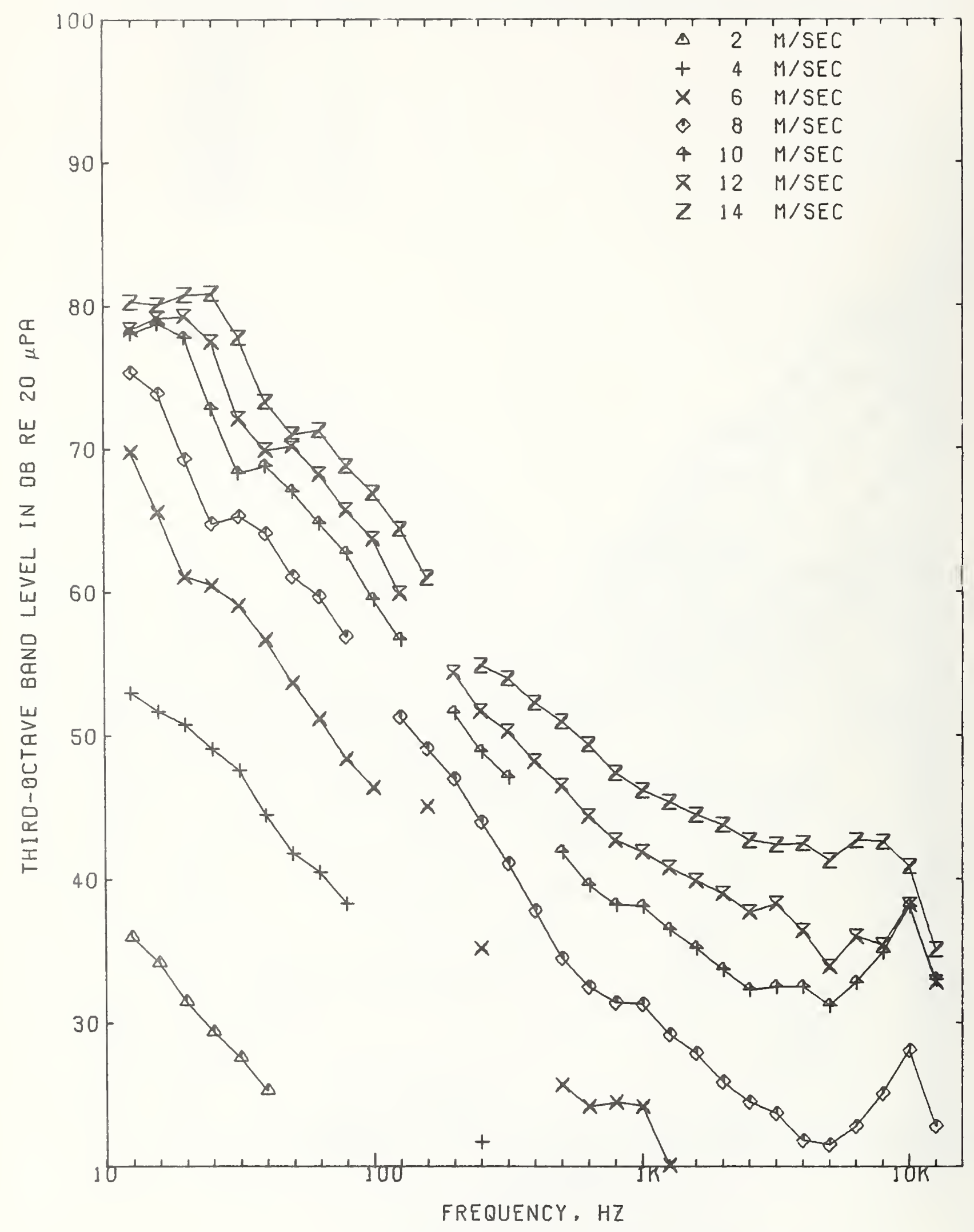

(i) Windscreen I - normal flow 


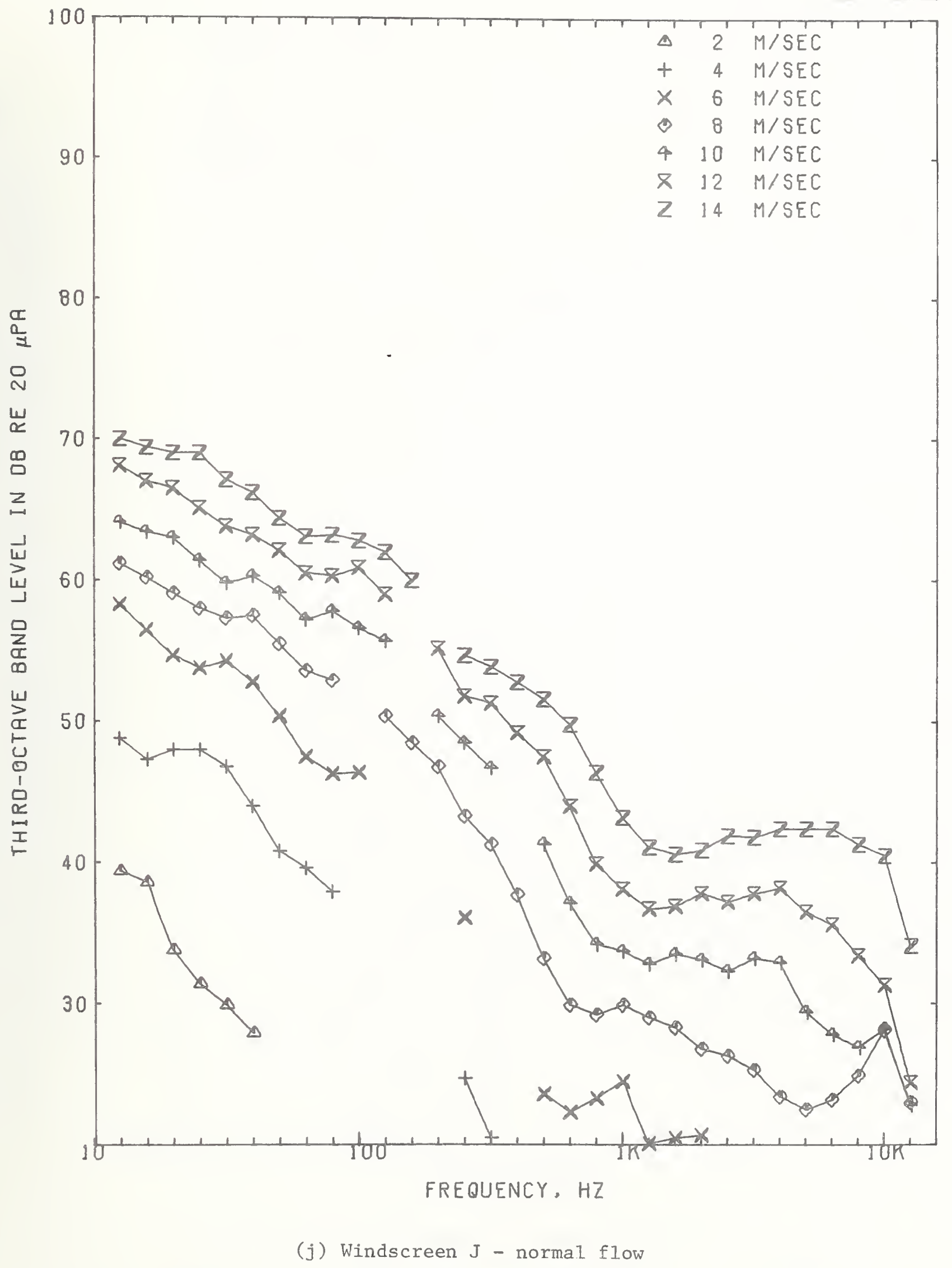

Figure 15. - Continued. 


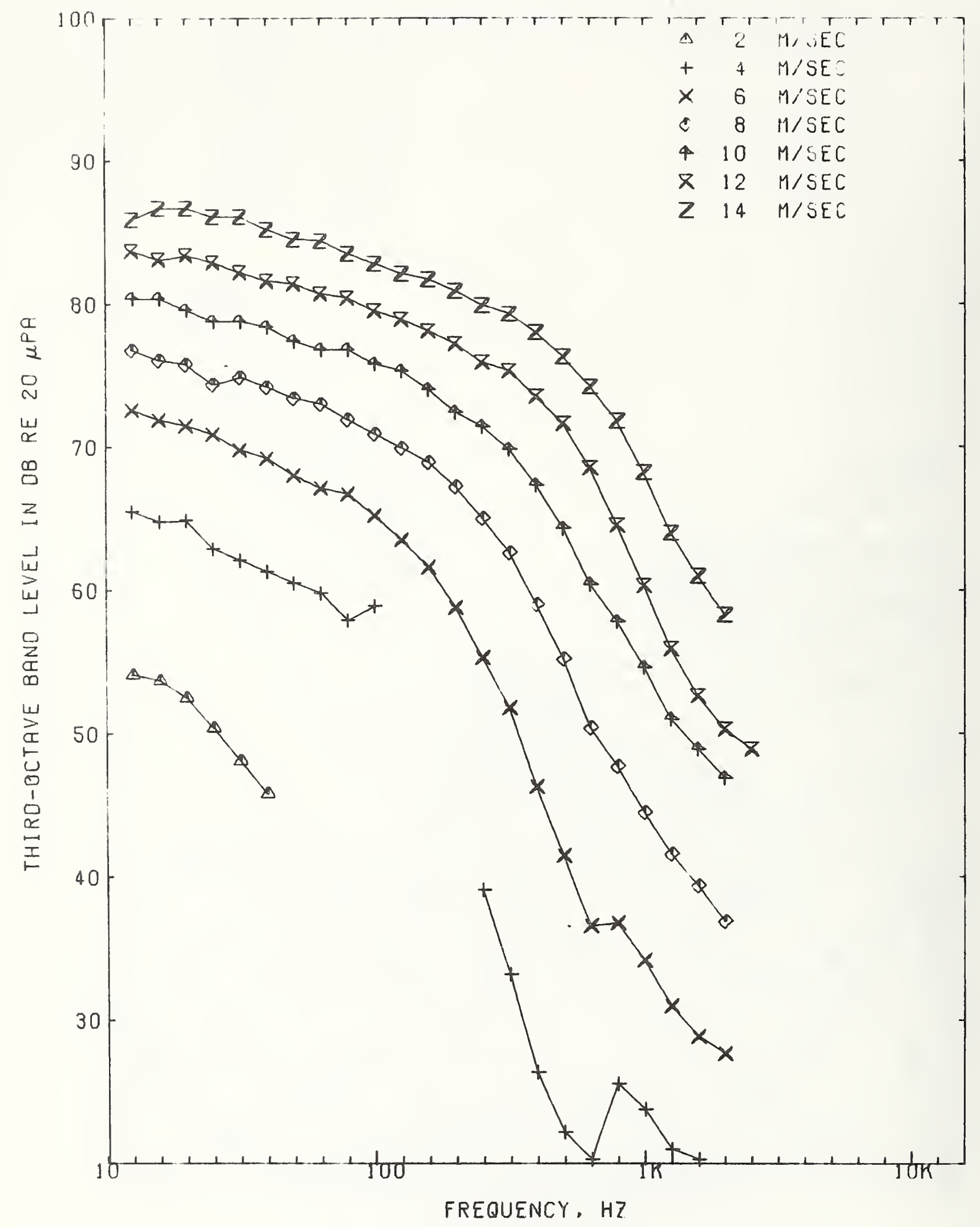

(k) No Windscreen - normal flow

Figure 15. - Concluded. 


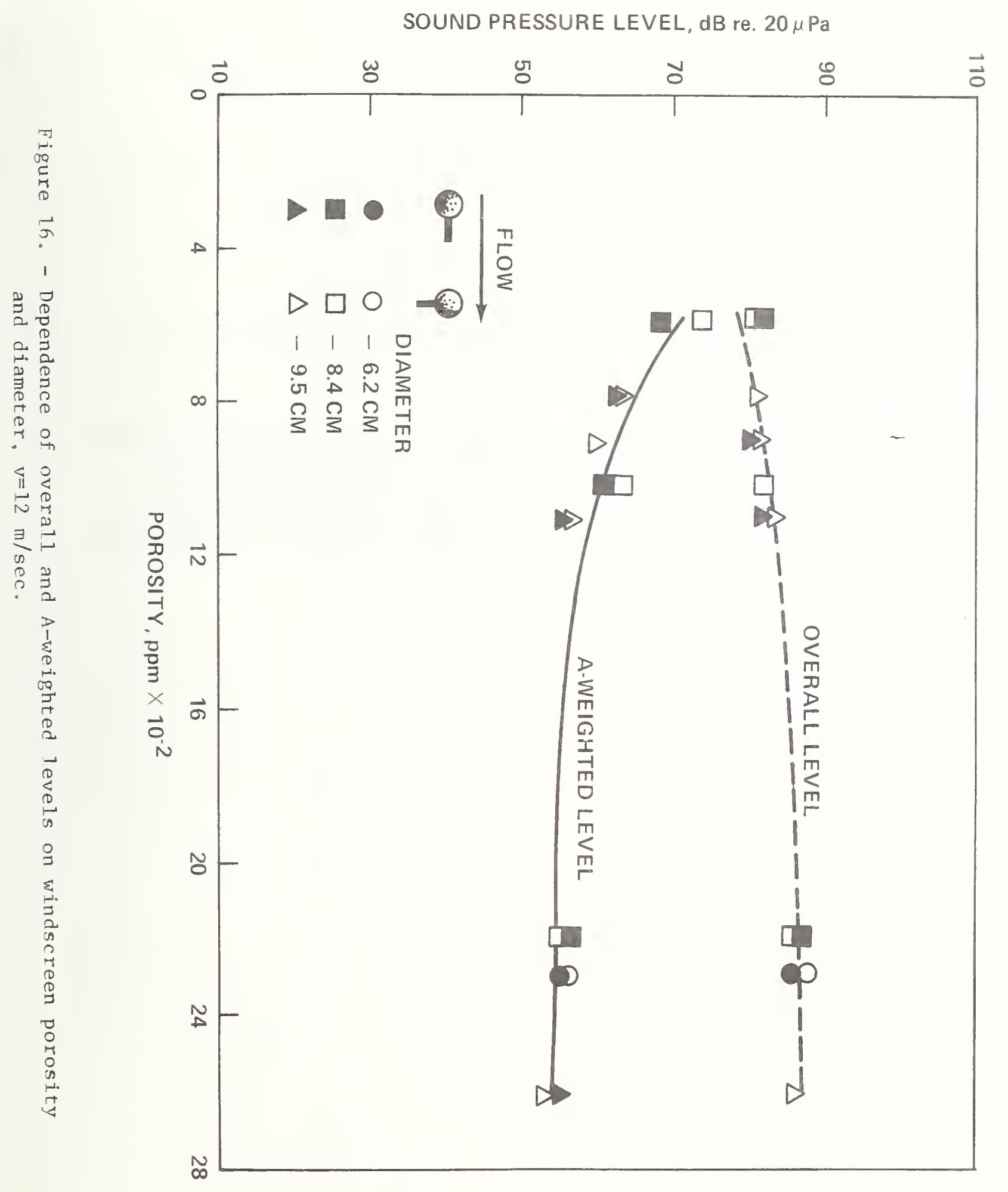


APPENDIX A: Tabulation of Wind-Induced Noise Levels for Grazing Flow Incidence

This appendix contains a tabulation of the one-third octave band A-weighted, and overall wind-induced noise levels ( $\mathrm{dB}$ re $20 \mu \mathrm{Pa}$ ) measured at grazing flow incidence over the wind speed range $0 \mathrm{~m} / \mathrm{sec}<\mathrm{v}<14 \mathrm{~m} / \mathrm{sec}$ for each windscreen shown in Figure 2 as well as for the microphone with no windscreen. Zeros have been inserted in the tables when the signal-to-noise ratio was insufficient to obtain meaningful data. 
Table A1. - One-Third Octave Band Wind-Induced Noise Levels ( $d B$ re $20 \mu \mathrm{Pa}$ ) for Windscreen $\mathrm{A}$

(Grazing Flow Incidence)

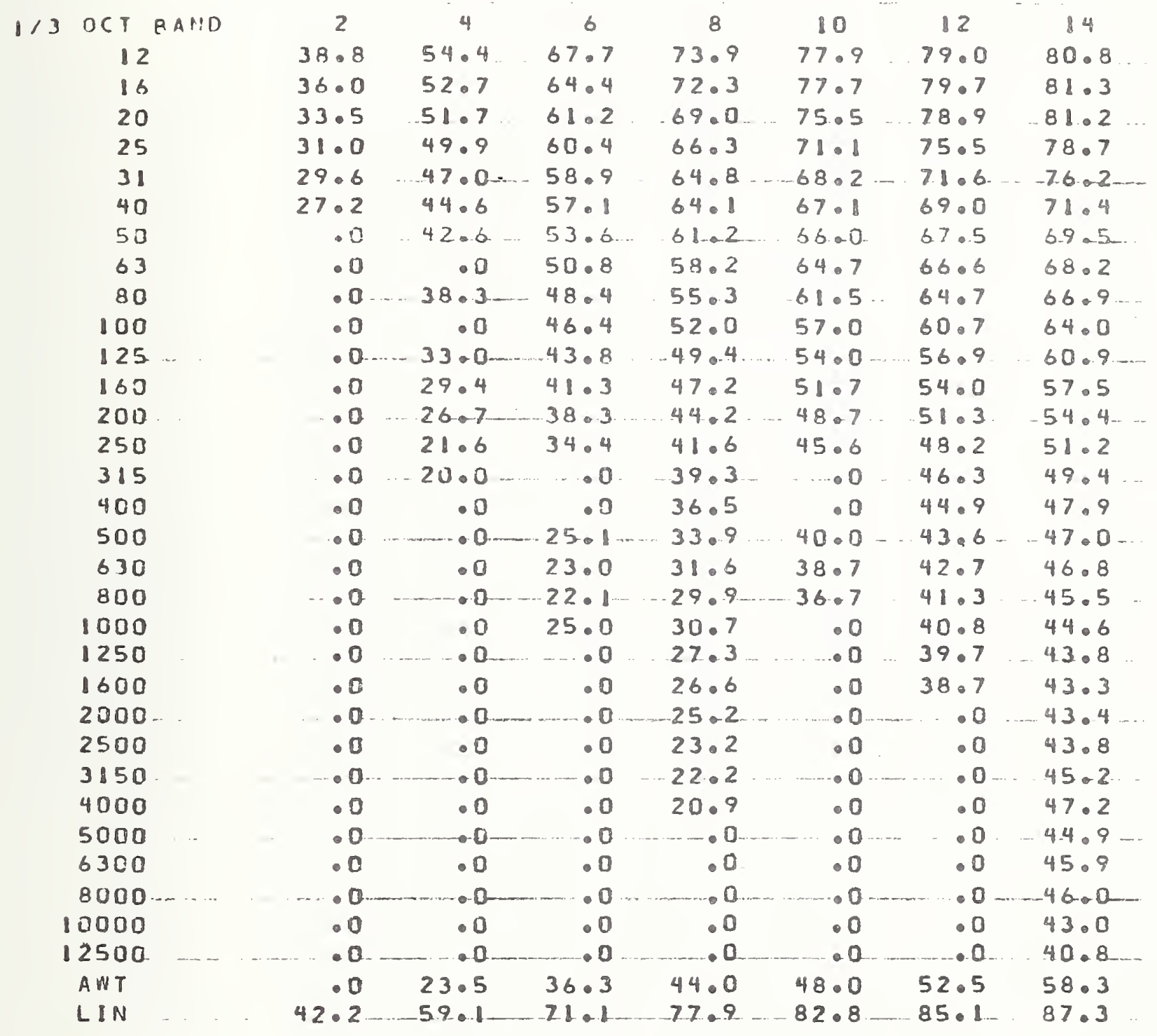


Table A2. - One-Third Octave Band Wind-Induced Noise Levels ( $d B$ re $20 \mu \mathrm{Pa}$ ) for Windscreen $B$

(Grazing Flow Incidence)

\begin{tabular}{|c|c|c|c|c|c|c|c|c|}
\hline 3 OCT $B$ & BAND & 2 & 4 & 6 & 8 & 10 & 12 & 14 \\
\hline 12 & & 37.7 & $55 \cdot 3$ & 67.4 & 76.4 & $81 \cdot 8$ & 83.4 & .0 \\
\hline 16 & & 34.6 & 52.6 & $66 \cdot 2$ & 74.9 & 82.3 & 86.1 & .0 \\
\hline 20 & & $30 \cdot 2$ & $51 \cdot 3$ & 63.6 & 7.3 .0 & 80.7 & 87.5 & .0 \\
\hline 25 & & $26 \cdot 8$ & $48 \cdot 6$ & $61 \cdot 3$ & 69.9 & 77.0 & 84.7 & .0 \\
\hline 31 & & 24.7 & 45.0 & 59.8 & 67.7 & 74.7 & $80 \cdot 6$ & .0 \\
\hline 40 & & $22 \cdot 6$ & $42 \cdot 4$ & $56 \cdot 2$ & 66.3 & 73.2 & 78.8 & .0 \\
\hline 50 & & .0 & 39.4 & 52.9 & 63.9 & $71 \cdot 2$ & 77.0 & .0 \\
\hline 63 & & .0 & .0 & 50.9 & $6 ! \cdot 4$ & 69.6 & 74.7 & .0 \\
\hline 80 & & 00 & 33.8 & 49.6 & 59.6 & $67 \cdot 2$ & $73 \cdot 4$ & .0 \\
\hline 100 & & .0 & .0 & 47.5 & 58.1 & $65 \cdot 7$ & 71.9 & .0 \\
\hline 125 & & $\cdot 0$ & $30 \cdot-3$ & $45 \cdot 2$ & -56.7 & 64.3 & 69.9 & $.0 \ldots$ \\
\hline $\begin{array}{l}160 \\
200\end{array}$ & & $\begin{array}{l}.0 \\
.0\end{array}$ & $\begin{array}{l}30.0 \\
30.6\end{array}$ & $\begin{array}{l}44.6 \\
43.6\end{array}$ & $\begin{array}{r}55.2 \\
54.3\end{array}$ & $\begin{array}{l}63.2 \\
62.6\end{array}$ & $\begin{array}{l}68.7 \\
67.0\end{array}$ & $\begin{array}{r}.0 \\
.0\end{array}$ \\
\hline 250 & & $20 \cdot 5$ & $28 \cdot 2$ & 40.0 & 53.5 & 63.4 & 66.2 & .0 \\
\hline 315 & & .0 & $-34 \cdot 2$ & $37 \cdot 6$ & -53.3 & $-60 \cdot 5$ & $65 \cdot 6$ & $\ldots .0$ \\
\hline 400 & & .0 & 37.2 & $37 \cdot 3$ & 48.9 & $61 \cdot 9$ & $65 \cdot 3$ & .0 \\
\hline 500 & & 0 & 30.2 & 42.7 & $\ldots 46.0$ & 60.7 & 64.8 & .0 \\
\hline 630 & & .0 & 29.8 & 46.3 & 47.7 & 55.0 & 62.9 & .0 \\
\hline 800 & & 0 & 35.8 & 47.2 & $-47 \cdot 5$ & $53 \cdot 0$ & 59.5 & .0 \\
\hline 1000 & & .0 & 22.9 & $35 \cdot 5$ & 43.4 & $50 \cdot 3$ & $57 \cdot 9$ & .0 \\
\hline 1250 & & .0 & .0 & $30 \cdot 3$ & $-39 \cdot 1$ & $47 \cdot 6$ & 54.8 & 0 \\
\hline 1600 & & .0 & 0 & 27.3 & 36.7 & 44.2 & 51.8 & .0 \\
\hline 2000 & & 0 & .0 & -26.1 & 36.1 & 41.9. & 52.4 & 0 \\
\hline 2500 & & .0 & .0 & 29.4 & .0 & 45.7 & 52.4 & .0 \\
\hline 3150 & $\cdots$ & .0 & 0 & .0 & .0 & $40 \cdot 3$ & $\circ 0$ & .0 \\
\hline 4000 & & .0 & .0 & .0 & .0 & 36.7 & .0 & .0 \\
\hline 5000 & & 0 & 0 & $\ldots 0$ & 0 & $-35 \cdot 3$ & $\ldots, 0$ &. \\
\hline 6300 & & .0 & .0 & .0 & .0 & .0 & .0 & .0 \\
\hline 8000 & & 0 & 0 & 0 & $\rightarrow 0$ & $\ldots$ & $\cdot 0$ & .0 \\
\hline 10000 & & .0 & .0 & .0 & .0 & .0 & .0 & .0 \\
\hline 12500 & & -0 & $\rightarrow 0$ & .0 & $\ldots$ & .0 & $\cdot 0$ & .0 \\
\hline AWT & & 11.9 & $38 \cdot 5$ & 49.9 & 55.0 & $64 \cdot 3$ & 69.5 & .0 \\
\hline LIN & & 40.4. & 59.1 & 71.9 & 80.8 & 87.7 & $.92 \cdot 6$ & .0 \\
\hline
\end{tabular}


Table A3. - One-Third Octave Band Wind-Induced Noise Levels ( $d B$ re $20 \mu \mathrm{Pa}$ ) for Windscreen $C$

(Grazing Flow Incidence)

\begin{tabular}{|c|c|c|c|c|c|c|c|c|c|}
\hline & & & & & SPE & $D C M / S E C$ & & & \\
\hline $1 / 3$ & OCT B & 3 AND & 2 & 4 & 6 & 8 & 10 & 12 & 14 \\
\hline & 12 & & 40.2 & 57.6 & 66.1. & 23.7 & 79.1 & $81 \cdot 3$ & 82.6 \\
\hline & 16 & & $39 \cdot 2$ & 53.9 & 65.9 & 71.6 & 77.7 & $81 \cdot 7$ & 83.3 \\
\hline & 20 & & $36 \cdot 3$ & 51.9 & 63.6 & 71.2 & 76.3 & 80.0 & 82.8 \\
\hline & 25 & & $33 \cdot 3$ & $50 \cdot 1$ & 59.8 & 69.2 & $75 \cdot 2$ & 78.3 & 80.3 \\
\hline & 31 & $\ldots$ & $30 \cdot 4 \ldots$ & $48 \cdot 1 \ldots$ & 57.1 & 65.8 & 72.9 & $76.6 \ldots$ & $77 \cdot 5$ \\
\hline & 40 & & $28 \cdot 1$ & 45.7 & 55.7 & 63.1 & 68.9 & 73.9 & 75.4 \\
\hline & 50 & & 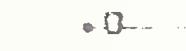 & $42 \cdot 3$ & 53.6 & 61.01 & 65.9 & 69.7 & 72.5 \\
\hline & 63 & & .0 &.$u$ & 51.6 & 59.2 & 64.9 & 07.6 & 69.7 \\
\hline & 80 & .. & .0 & $37 \cdot 6$ & 49.3 & 57.2 & 63.3. & 66.2 & $68.3 \ldots$ \\
\hline & 100 & & .0 & .0 & 48.1 & 54.6 & $61 \cdot 1$ & 64.6 & 67.0 \\
\hline & 125 & $\ldots$ & $\ldots .0$ & $32 \cdot 8$ & 43.6. & $\ldots .52 \cdot 1$ & $58 \cdot 6$ & 61.9. & 65.6 \\
\hline & 160 & & .0 & $29 \cdot 3$ & 40.7 & 49.9 & 55.1 & 59.6 & 63.0 \\
\hline & 200 & -. & .0. & $26 \cdot 0$ & $38 \cdot 2$ & 47.2 & $52 \cdot 1 \cdots$ & 55.9 & $59.7 \ldots$ \\
\hline & 250 & & .0 & 22.4 & 34.4 & 43.4 & 49.6 & 53.6 & 57.7 \\
\hline & 315 & & . 0 & $21 \cdot .5$ & .0 & -41.0 & 47.7 & $51 \cdot 2-$ & 56.6 \\
\hline & 400 & & .0 & .0 & .0 & 37.9 & $45 \cdot 2$ & 48.7 & 54.8 \\
\hline & 500 & $\ldots$ & - $\mathbf{2}$ & $\cdot \mathbf{0}$ & .0 & --35.0 & $-\ldots-42 \cdot-7$ & 46.0 .7 & .53 .2 \\
\hline & 630 & & .0 & .0 & .0 & 32.6 & $40 \cdot 3$ & 44.9 & 51.5 \\
\hline & 800 & & . 0 & .0 & .0 & 31.0 & $-37 \cdot 8$ & $42.6 \ldots$ & 49.3 \\
\hline & 1000 & & .0 & .0 & .0 & $31 \cdot 5$ & $37 \cdot 3$ & 41.5 & $47 \cdot 3$ \\
\hline & 1250 & & .0 & 0 & .0 & 28.3 & $36 \cdot 1$ & $39.7 \ldots$ & 45.9. \\
\hline & 1600 & & .0 & .0 & .0 & 27.8 & 35.3 & 39.1 & 44.6 \\
\hline & 2000 & & .0 & .0 & .0 & 26.7 & .0 & $38 \cdot 7 \ldots$ & $44.0 \ldots$ \\
\hline & 2500 & & .0 & .0 & .0 & 26.1 & .0 & 38.3 & 44.2 \\
\hline & 3150 & & $\cdot 0$ & $\ldots$ & .0 & $-25 \cdot 3$ & $\ldots 0$ & .0 & 44.7 \\
\hline & 4000 & & .0 & .0 & .0 & .0 & .0 & .0 & 44.8 \\
\hline & 5000 & & $\ldots .0$ & $a$ & .0 & $-\ldots$ & .0 & $\ldots 0 \ldots$ & 45.6 \\
\hline & 6300 & & .0 & .0 & .0 & .0 & .0 & .0 & 44.7 \\
\hline & 8000 & $\cdots$ & $-a$ & $0 \ldots$ & .0 & $\ldots$ & $\ldots$ & 0 & 42.7 \\
\hline & 10000 & & .0 & .0 & .0 & .0 & .0 & .0 & 42.2 \\
\hline & 12500 & & 0 & 0 & .0 & 0 & .0 & $\ldots \mathbf{0}$ & 40.0 \\
\hline & AWT & & .0 & 23.5 & 35.9 & 45.9 & 51.9 & 55.9 & 61.2 \\
\hline & LIN & & 44.3 & 60.8 & $71 \cdot 0$ & $78 \cdot 4$ & 84.1. & 87.4 & 89.2 \\
\hline
\end{tabular}


Table A4. - One-Third Octave Band Wind-Induced Noise Levels $(\mathrm{dB}$ re $20 \mu \mathrm{Pa}$ ) for Windscreen $\mathrm{D}$

(Grazing Flow Incidence)

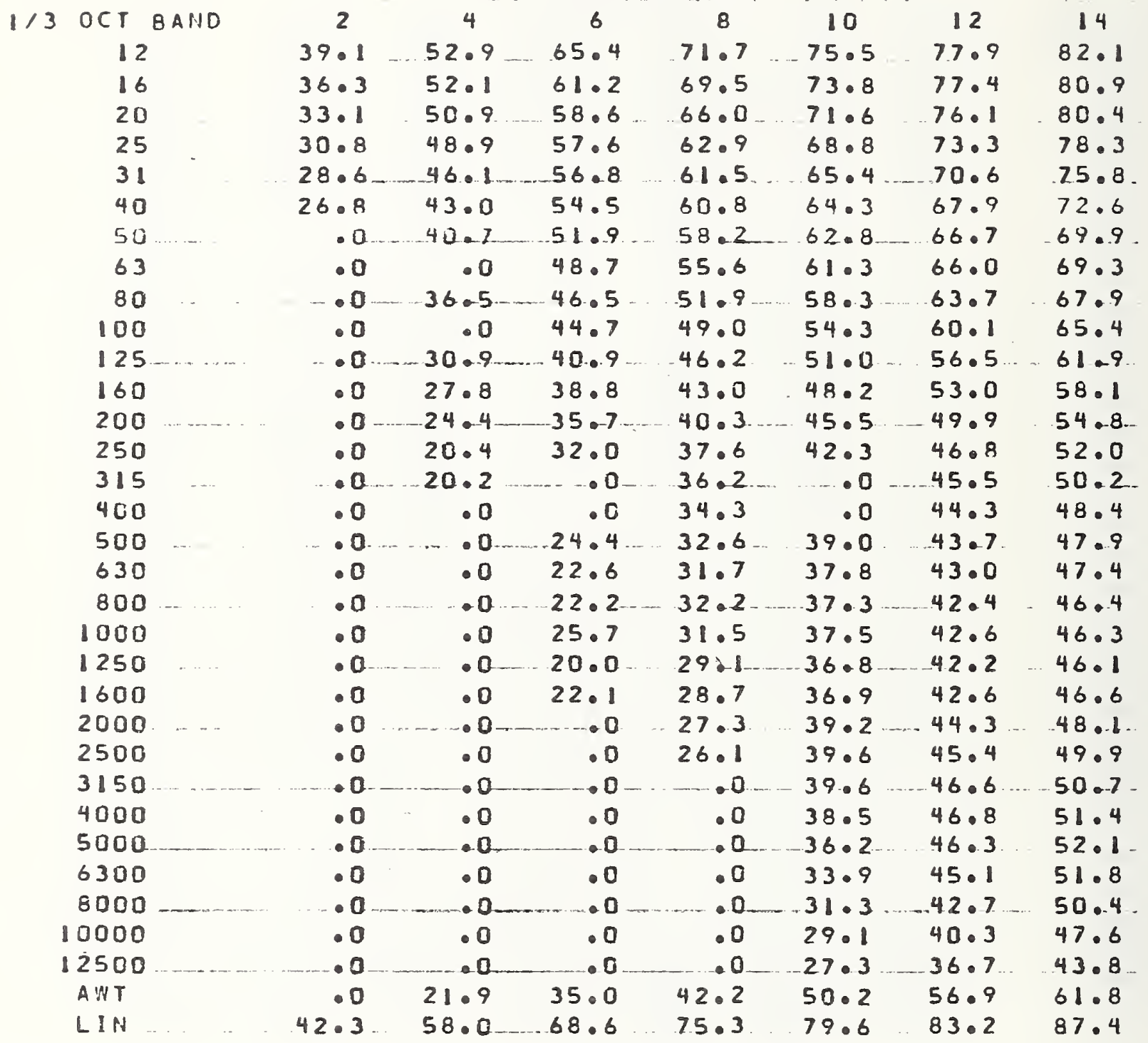


Table A5. - One-Third Octave Band Wind-Induced Noise Levels ( $d B$ re $20 \mu \mathrm{Pa}$ ) for Windscreen $\mathrm{E}$

(Grazing Flow Incidence)

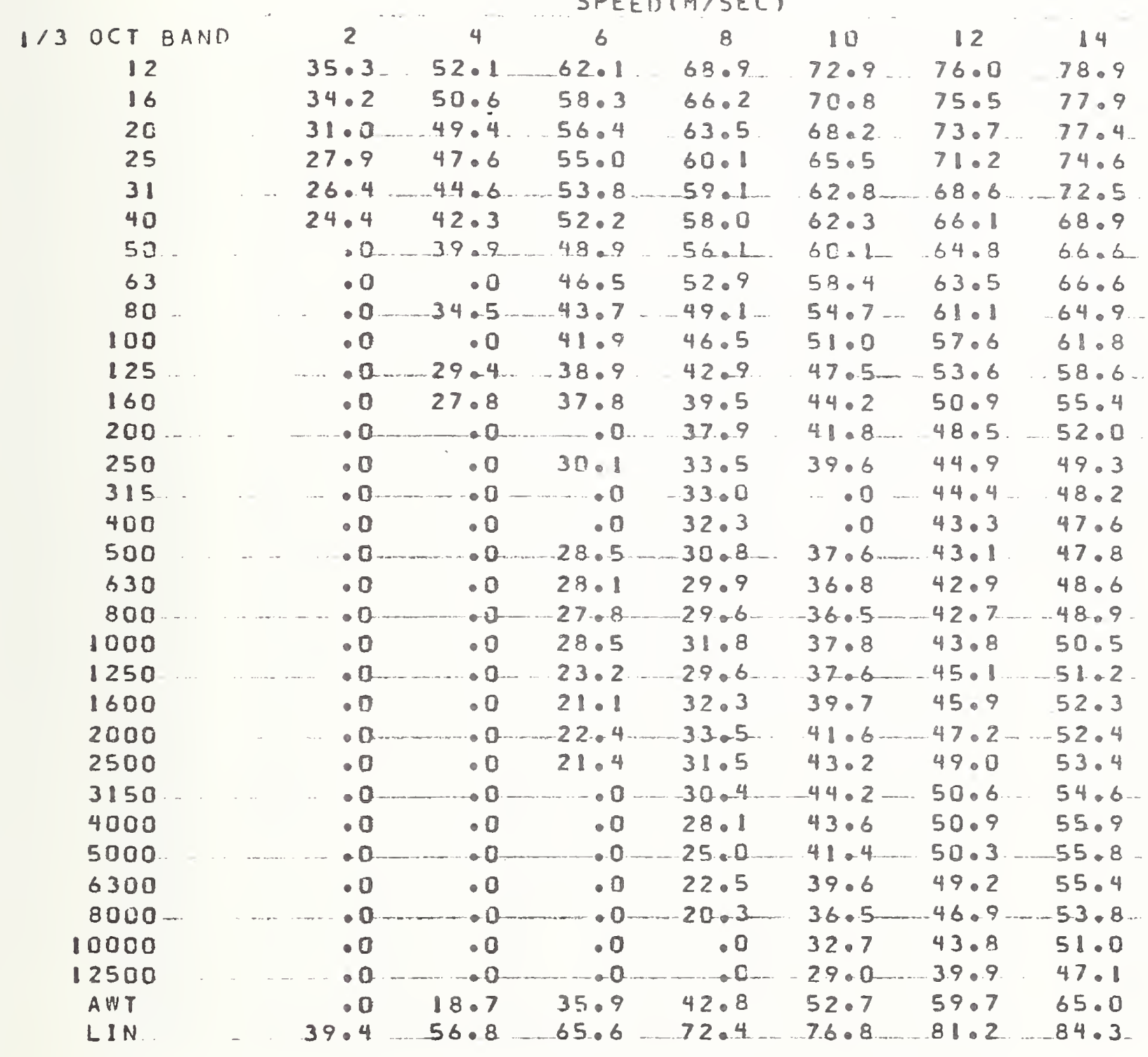


Table A6. - One-Third Octave Band Wind-Induced Noise Levels $(\mathrm{dB}$ re $20 \mu \mathrm{Pa}$ ) for Windscreen $\mathrm{F}$

(Grazing Flow Incidence)

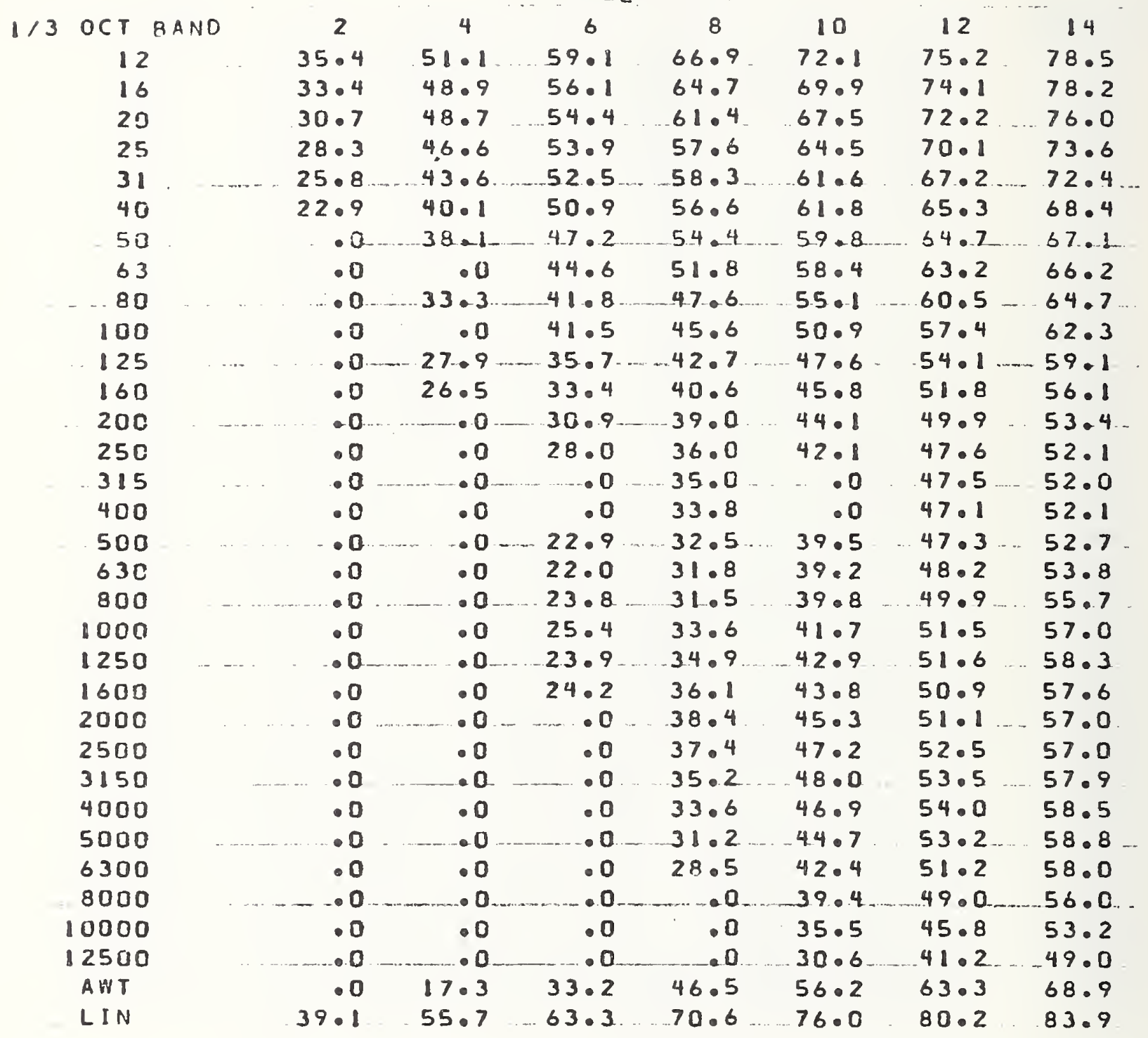


Table A7. - One-Third Octave Band Wind-Induced Noise Levels ( $d B$ re $20 \mu \mathrm{Pa}$ ) for Windscreen $\mathrm{G}$

(Grazing Flow Incidence) 
Table A8. - One-Third Octave Band Wind-Induced Noise Levels (dB re $20 \mu \mathrm{Pa}$ ) for Windscreen $\mathrm{H}$

(Grazing Flow Incidence)

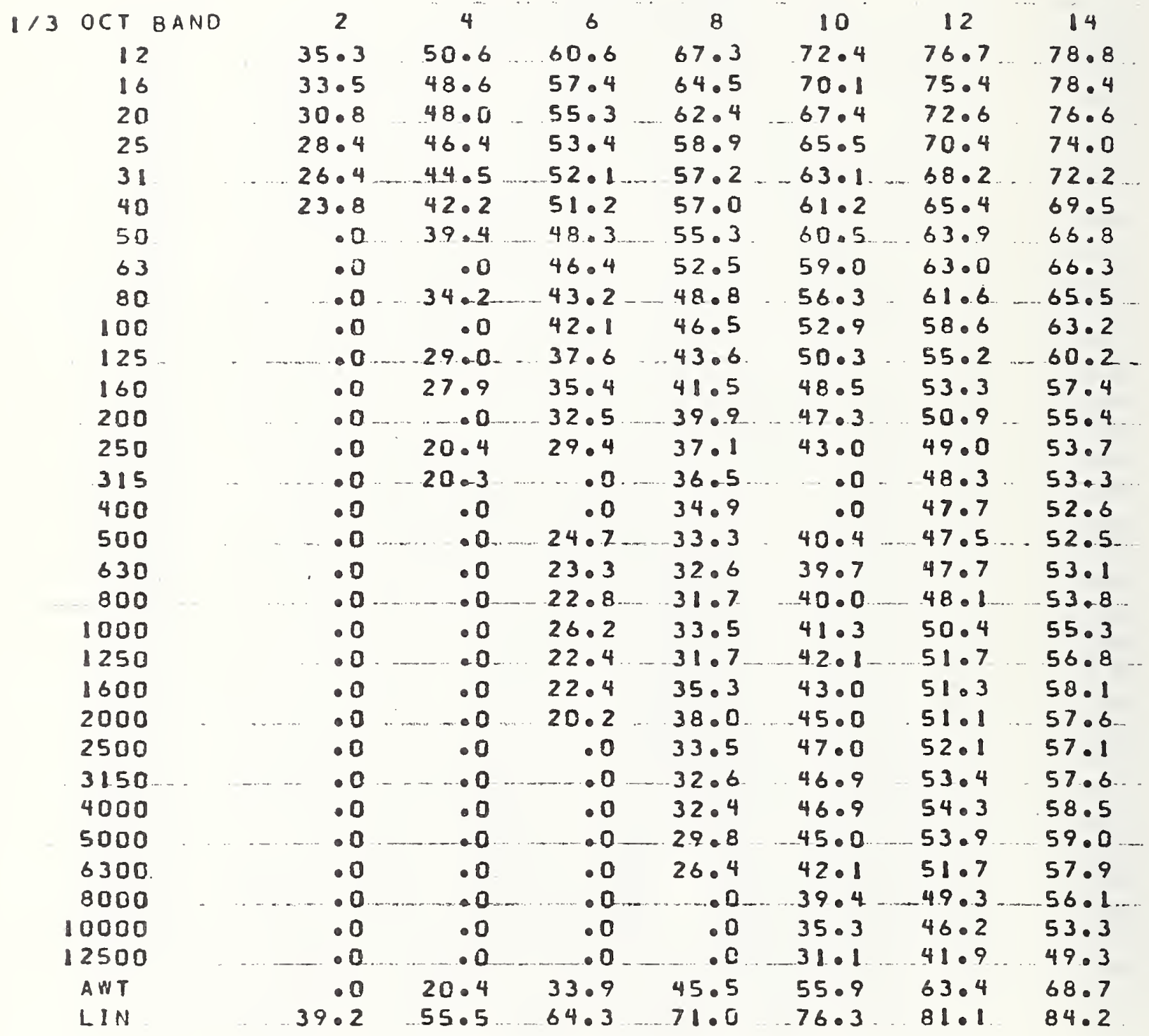


Table A9. - One-Third Octave Band Wind-Induced Noise Levels ( $d B$ re $20 \mu \mathrm{Pa}$ ) for Windscreen I

(Grazing Flow Incidence)

\begin{tabular}{|c|c|c|c|c|c|c|c|}
\hline 3 OCT BAMD & 2 & 4 & 6 & 8 & 10 & 12 & 84 \\
\hline 12 & 37.7 & 54.5 & $66.8 \ldots$ & 74.0 & 78.5 & 78.8 & 81.3 \\
\hline 16 & $35 \cdot 2$ & 52.5 & 63.8 & 72.5 & 76.7 & 78.9 & $81 \cdot 3$ \\
\hline 20 & 32.2 & 50.8 & 59.0 & 20.3 & $75 \cdot 2$ & 78.1 & 80.8 \\
\hline 25 & 30.0 & $48 \cdot 4$ & 57.6 & 64.5 & 71.9 & 75.4 & 78.3 \\
\hline 31 & $28 \cdot 8 \ldots$ & .47 .4 & $56 \cdot 1 \ldots$ & $-63 \cdot 1$ & 67.4 & 72.3 & -75.8 \\
\hline 40 & $26 \cdot 3$ & 44.0 & 54.6 & 62.3 & 66.2 & 68.1 & 72.2 \\
\hline 50 & 0 & $-41-9$ & 51.9 & 59.9 & 64.8 & 66.7 & $6.9 \cdot 2$. \\
\hline 63 & .0 & .0 & $47 \cdot 3$ & 58.2 & 63.3 & 66.5 & 67.9 \\
\hline 80 & 0 & $38 \cdot 0$ & $4.7 \cdot 4$ & 55.8 & $61 \cdot 4$ & 64.4 & 66.9 \\
\hline 100 & .0 & .0 & $45 \cdot 3$ & 52.8 & 58.5 & $61 \cdot 3$ & 64.5 \\
\hline 125 & .0 & $-32 \cdot .7$ & $43.0 \ldots$ & $-50 \cdot 1$ & $55 \cdot 6$. & 58.3 & 68.8 \\
\hline 160 & .0 & $30 \cdot 3$ & 41.1 & 48.1 & 53.2 & 55.8 & 58.6 \\
\hline 200 & 0 & 27.3 & 38.9 & -45.8 & 50.8 & 53.3 & 56.5 \\
\hline 250 & .0 & $22 \cdot 3$ & 34.0 & 42.8 & 48.0 & 50.9 & 54.1 \\
\hline 315 & .0 & $21 .-4$ & -0 & $-40 \cdot 6$ & 46.5 & 49.4 & 53.0 \\
\hline 400 & .0 & 20.0 & .0 & 38.0 & .0 & 47.5 & 51.4 \\
\hline 500 & .0 & $\cdots \cdot 0$ & $26 \cdot 4$ & 35.4 & 42.0 & $46.0 \ldots$ & 49.9 \\
\hline 630 & .0 & .0 & 24.1 & 33.4 & $40 \cdot 3$ & 44.9 & 49.0 \\
\hline 800 & .0 & 0. & $23 \cdot 3$ & 31.8 & $38 \cdot 5$ & 43.1 & 47.8 \\
\hline 1000 & .0 & $20 \cdot 1$ & 25.9 & $32 \cdot 2$ & .0 & 43.1 & 47.5 \\
\hline 1250 & .0 &.- .0 & 20.6 & 29.0 & .0 & 42.5 & 46.0 \\
\hline 1600 & - 5 & .0 & 21.2 & 27.9 & .0 & 40.3 & 44.4 \\
\hline 2000 & .0 & .0 & 20.3 & 27.3 & .0 & 39.9 & 44.1 \\
\hline 2500 & .0 & .0 & .0 & .0 & .0 & .0 & 44.6 \\
\hline 3150 & 0 & 0 & .0 & $\ldots 0$ & $\cdots \cdot 0$ & .0 & .45 .0 \\
\hline 4000 & .0 & .0 & .0 & .0 & .0 & .0 & $45 \cdot 5$ \\
\hline 5000 & 0 & 0 & .0 & $\cdots-0$ & .0 & $\cdots .0$ & 46.2 \\
\hline 6300 & .0 & .0 & .0 & .0 & .0 & .0 & 45.1 \\
\hline 8000 & 0 & 0 & .0 & $\ldots, a$ & .0 & . 0 & 44.6 \\
\hline 10000 & .0 & .0 & .0 & .0 & .0 & .0 & 43.1 \\
\hline 12500 & - 0 & .0 & 0 & .0 & .0 & $.0 \ldots$ & 39.5 \\
\hline AWT & .0 & 25.8 & 36.5 & 44.9 & 49.6 & 54.4 & 59.4 \\
\hline$L I N$ & $41 \cdot 2$ & $58.8 \ldots$ & 69.8 & $-78.0 \ldots$ & $\ldots 82.6$ & $84.6 \ldots$ & $87 \cdot 3$ \\
\hline
\end{tabular}


Table A10. - One-Third Octave Band Wind-Induced Noise Levels $(\mathrm{dB}$ re $20 \mu \mathrm{Pa}$ ) for Windscreen $\mathrm{J}$

(Grazing Flow Incidence)

\begin{tabular}{|c|c|c|c|c|c|c|c|c|}
\hline 3 OCT B & GAND & 2 & 4 & 6 & 8 & 10 & 12 & 14 \\
\hline 12 & & $41 \cdot 8$ & 54.7 & 63.7 & $-73 \cdot 5$ & $78 \cdot 2$ & 81.8 & 83.9 \\
\hline 16 & & 38.9 & 53.0 & 63.1 & 72.9 & $77 \cdot 4$ & 79.6 & 81.5 \\
\hline 20 & & 34.4 & 51.7. & 61.1 & 71.7 & 77.4 & 79.4 & 79.4 \\
\hline 25 & & 31.9 & 49.8 & 59.0 & 71.0 & 76.0 & 78.4 & 78.4 \\
\hline 31 & & $30 \cdot 3$ & $47 \cdot 3$ & 57.4 & 69.8 & 74.6 & 77.1 & 77.2 \\
\hline 40 & & $30 \cdot 4$ & 44.1 & $55 \cdot 3$ & 68.7 & 73.7 & 76.4 & 77.5 \\
\hline 50 & & .0 & 40.9 & $52 \cdot 8$ & -66.8 & 72.4 & $75 \cdot 6$ & 76.4 \\
\hline 63 & & .0 & .0 & 48.9 & 64.6 & 70.6 & 74.5 & 75.3 \\
\hline 80 & & .0 & $39 \cdot .5$ & .46 .5 & $-6.8 .9 \ldots$ & $-69 \cdot 0$. & 7.3 .4 & $73.3 \ldots$ \\
\hline 100 & & .0 & .0 & 46.9 & 58.9 & 6601 & 70.9 & 71.8 \\
\hline .125 & & .0 & $44.0 \ldots$ & $46 \cdot 3$ & .55 .8 & $63 \cdot 3$ & $68 \cdot 3$ & $69.6 \ldots$ \\
\hline 160 & & .0 & 39.8 & 47.5 & 53.8 & 59.7 & 64.5 & 67.3 \\
\hline 200 & & .0 & $-36 \cdot 2$ & 50.9 & $-51 \cdot 8$ & 56.7 & 60.4. & $63.8 \ldots$ \\
\hline 250 & & .0 & 37.0 & 44.6 & 50.2 & 54.9 & $58 \cdot 3$ & 60.0 \\
\hline 315 & & - 0 & $32 \cdot 9$ & $41 \cdot 2$ & $-48 \cdot 9 \ldots$ & $.54 \cdot 0$ & $57.6 \ldots$ & 58.8 \\
\hline 400 & & .0 & $26 \cdot 4$ & 37.2 & 47.4 & 53.3 & 56.9 & 58.6 \\
\hline 500 & & .0 & -0 & 30.6 & -45.0 & $52 \cdot 1$ & $56 \cdot 4 \ldots$ & 59.2. \\
\hline 630 & & .0 & .0 & $27 \cdot 3$ & 41.9 & 50.2 & 55.3 & 59.0 \\
\hline 800 & & .0 & $-\ldots$ & $\cdots \quad \cdot 0$ & $-38 \cdot 0$ & 46.7 & 53.4 & $5.7 \cdot 2$ \\
\hline 1000 & & .0 & .0 & .0 & 36.6 & 43.5 & 51.0 & 54.9 \\
\hline 1250 & & .0 & 0 & .0 & .0 & 40.0 & $48 \cdot 6$ & 52.1 \\
\hline 1600 & & .0 & .0 & . 0 & .0 & 36.6 & .0 & 48.6 \\
\hline 2000 & & -0 & .0 & $\cdots .0$ & $=0$. & $\ldots .0$ & .0 & 46.6 \\
\hline 2500 & & .0 & .0 & .0 & .0 & .0 & .0 & .0 \\
\hline 3150 & .. & .0 & $\ldots$ & 00 & $\cdots, 0$ & .0 & .0 & .0 \\
\hline 4000 & & .0 & .0 & .0 & .0 & .0 & .0 & .0 \\
\hline 5000 & & - 0 & .0 & .0 & 0 & 0 & 0 & .0 \\
\hline 6300 & & $\cdot 0$ & .0 & .0 & .0 & $\cdot 0$ & .0 & .0 \\
\hline 8000. & & 0 & 0 & .0 & $\ldots .0$ & -0 & .0. & .0 \\
\hline 10000 & & .0 & .0 & .0 & .0 & .0 & .0 & .0 \\
\hline 12500 & & 00 & 0 & -0 & $\ldots$ & 0 & -0. & .0 \\
\hline$A W T$ & & .0 & $34 \cdot 3$ & 43.9 & 51.7 & $58 \cdot 2$ & 62.9 & 65.6 \\
\hline LIN & & -44.7 & $59.5 \ldots$ & 69.0 & -29.9 & $8.5 \cdot 0$ & 87.8 & 89.0 \\
\hline
\end{tabular}


Table All. - One-Third Octave Band Wind-Induced Noise Levels $(\mathrm{dB}$ re $20 \mu \mathrm{Pa})$ for Microphone With No Windscreen (Grazing Flow Incidence)

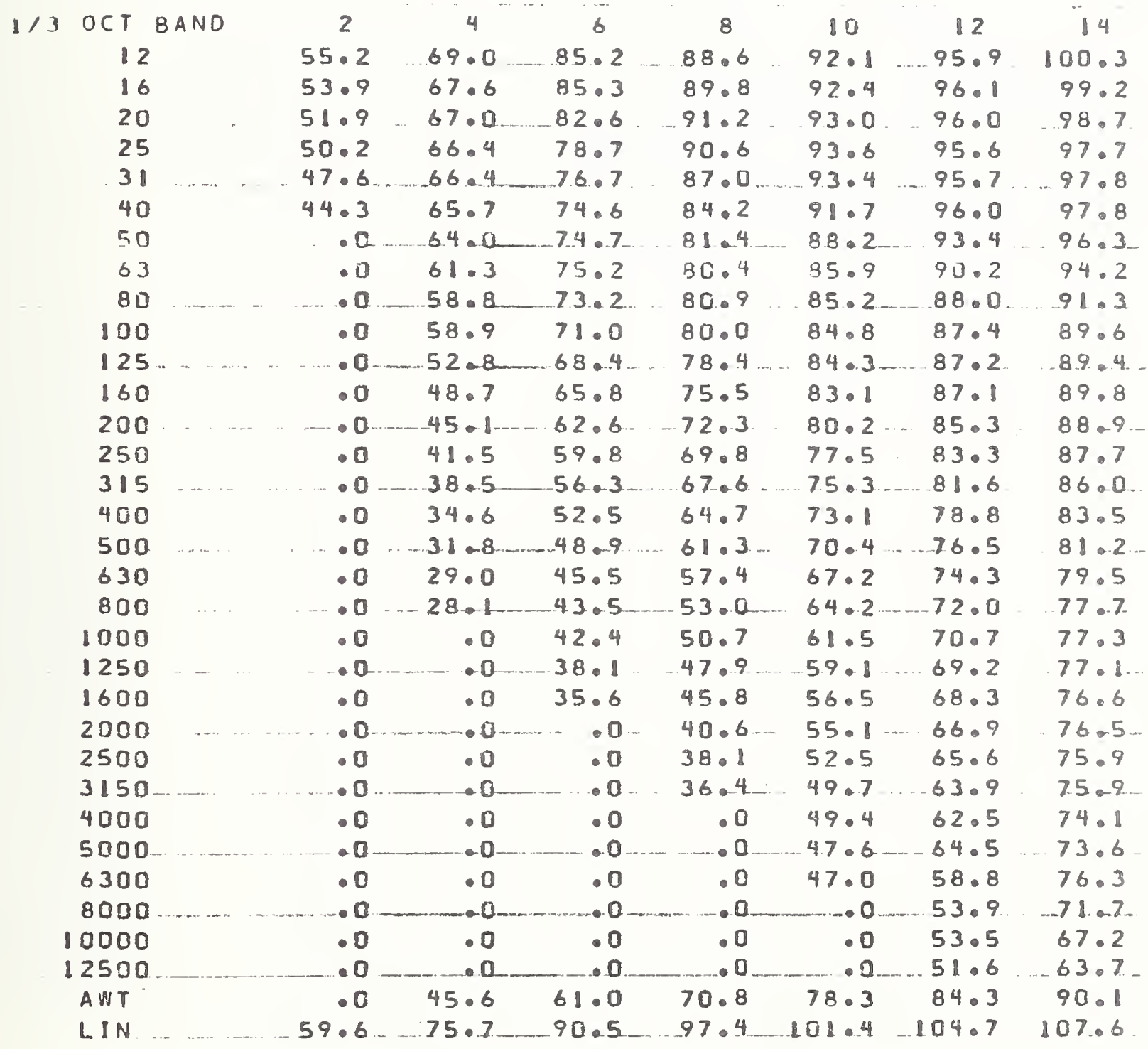


APPENDIX B: Tabulation of Wind-Induced Noise Levels for Normal Flow Incidence

This appendix contains a tabulation of the one-third octave band, A-weighted, and overall wind-induced noise levels ( $\mathrm{dB}$ re $20 \mu \mathrm{Pa}$ ) measured at normal flow incidence over the wind speed range $0 \mathrm{~m} / \mathrm{sec}<\mathrm{v}<14 \mathrm{~m} / \mathrm{sec}$ for each of the windscreens shown in Figure 2 as well as for the microphone with no windscreen. Zeros have been inserted in the tables when the signal-to-noise ratio was insufficient to obtain meaningful data. 
Table B1. - One-Third Octave Band Wind-Induced Noise Levels (dB re $20 \mu \mathrm{Pa}$ ) For Windscreen A

(Normal Flow Incidence)

\begin{tabular}{|c|c|c|c|c|c|c|c|c|}
\hline & & & & $S P$ & $M / S$ & & & \\
\hline $1 / 3$ OCT BAN & & 2 & 4 & $b$ & 8 & 10 & 12 & 14 \\
\hline 12 & & $33 \cdot 3$ & 53.6 & 67.8 & 76.0 & 78.9 & 77.8 & 77.5 \\
\hline 16 & & $32 \cdot 8$ & $52 \cdot 5$ & 61.6 & 73.9 & $79 \cdot 8$ & 79.7 & 78.7 \\
\hline 20 & & 29.4 & $50 \cdot 8$ & $5 ? \cdot 2$ & 67.8 & $76 \cdot 9$ & 79.7 & 79.6 \\
\hline $25^{\circ}$ & & $28 \cdot 1$ & 47.5 & $59: 1$ & 64.0 & 69.8 & 76.0 & 79.3 \\
\hline 31 & & $25 \cdot 8$ & $45 \cdot 1$ & 56.4 & 64.0 & 66.9 & 70.7 & 76.1 \\
\hline 40 & & $23 \cdot 3$ & $41 \cdot 6$ & 53.1 & 62.1 & 67.5 & $68 \cdot 3$ & 70.8 \\
\hline $5 ?$ & & .0 & 39.3 & $4 ? .4$ & $58 \cdot 3$ & $65 \cdot 2$ & 69.1 & 39.1 \\
\hline 63 & & .5 & 39.1 & $47 \cdot 2$ & $55 \cdot 4$ & 61.9 & $66 \cdot 1$ & 68.3 \\
\hline 80 & & .0 & 37.0 & $45 \cdot 0$ & 52.9 & 59.0 & $63 \cdot 3$ & 65.8 \\
\hline 100 & & .0 & .0 & .0 & .0 & $56 \cdot 0$ & $60 \cdot 1$ & 63.0 \\
\hline 125 & & $\bullet 0$ & .0 & .0 & $48 \cdot 5$ & 53.8 & $56 \cdot 8$ & 60.4 \\
\hline 160 & & .0 & .0 & .0 & 46.1 & .0 & .0 & 58.4 \\
\hline 200 & & .0 & .0 & .0 & 44.7 & 49.8 & 53.2 & .0 \\
\hline 250 & & .0 & 22.4 & 32.7 & 41.0 & $46 \cdot 1$ & $50 \cdot 2$ & 53.6 \\
\hline 315 & & .0 & .0 & $\cdot 0$ & 38.9 & .0 & 49.2 & 52.8 \\
\hline 400 & & .0 & .0 & .0 & 36.3 & .0 & 47.6 & 51.8 \\
\hline 500 & & .0 & .0 & $25 \cdot 2$ & 34.0 & 40.7 & $46 \cdot 2$ & 50.6 \\
\hline 630 & & .0 & .0 & $24 \cdot 3$ & 32.7 & 38.9 & 44.6 & 49.3 \\
\hline 800 & - & .0 & .0 & 24.6 & 32.0 & $37 \cdot 6$ & 42.9 & 47.5 \\
\hline $10 C 5$ & & .0 & $\because 0$ & $25 \cdot 4$ & 32.2 & 37.4 & 42.7 & 46.6 \\
\hline 1250. & & .0 & 0 & 20.8 & 29.7 & $36 \cdot 1$ & $42 \cdot C$ & 45.7 \\
\hline $1600^{\circ}$ & & .0 & 0 & $20 \cdot 5$ & 28.7 & $35 \cdot 1$ & 40.8 & 45.1 \\
\hline $\begin{array}{l}2000 \\
2500\end{array}$ & & $\begin{array}{l}-0 \\
\because 0\end{array}$ & $\begin{array}{l}.0 \\
0\end{array}$ & $\begin{array}{r}21 \cdot 1 \\
\cdot 0\end{array}$ & $\begin{array}{r}27.5 \\
. .0\end{array}$ & $\begin{array}{l}33 \cdot 8 \\
32 \cdot 2\end{array}$ & $\begin{array}{l}40.1 \\
38.7\end{array}$ & $\begin{array}{l}44.6 \\
43.5\end{array}$ \\
\hline 3150 & & .0 & .0 & .0 & .0 & 32.0 & 38.1 & 43.1 \\
\hline 4000 & & .0 & 0 & .0 & .0 & 31.1 & $37 \cdot 5$ & 42.2 \\
\hline 5000 & & .0 & .0 & .0 & .0 & $27 \cdot 5$ & 36.7 & 42.2 \\
\hline 6360 & & .0 & .0 & .0 & .0 & $\because 0$ & .0 & $43 \cdot 3$ \\
\hline 8000 & & .0 & $\cdot 5$ & .0 & .0 & .0 & .0 & 41.7 \\
\hline 10000 & & $.0^{\circ}$ & $.0^{-1}$ & .0 & .0 & .0 & .0 & 40.8 \\
\hline 12500 & & $\cdot 3$ & .2 & .0 & .0 & .0 & .0 & .0 \\
\hline$A W T$ & & $\cdot 0$ & 19.0 & 33.0 & $43 \cdot 3$ & $-48 \cdot 7$ & 54.3 & 58.5 \\
\hline$L I N$ & & 37.9 & $58 \cdot 1$ & $70 \cdot c$ & 78.9 & 84.0 & $85 \cdot 1$ & $85 \cdot 8$ \\
\hline
\end{tabular}


Table B2. - One-Third Octave Band Wind-Induced Noise Levels ( $d B$ re $20 \mu \mathrm{Pa}$ ) for Windscreen $\mathrm{B}$

(Normal Flow Incidence)

\begin{tabular}{|c|c|c|c|c|c|c|c|c|}
\hline \multirow{2}{*}{\multicolumn{2}{|c|}{ OCT BAND }} & \multicolumn{7}{|c|}{ SPEED $(M / S E C)$} \\
\hline & & 2 & 4 & 6 & 8 & 10 & 12 & 14 \\
\hline 12 & & $35 \cdot 8$ & 48.8 & 54.9 & 60.9 & $66 \cdot 1$ & $70 \cdot 3$ & 73.1 \\
\hline 16 & & $36 \cdot 1$ & $50 \cdot 4$ & $55 \cdot 3$ & $61 \cdot 0$ & 66.4 & $70 \cdot 6$ & 73.4 \\
\hline 23 & & $31 \cdot 5$ & $50 \cdot 6$ & 56.9 & 60.4 & 65.6 & 70.7 & 73.0 \\
\hline 25 & & $27 \cdot 5$ & $51 \cdot 1$ & 61.5 & $61 \cdot 3$ & $65 \cdot 3$ & 69.8 & 72.2 \\
\hline $\begin{array}{l}31 \\
40\end{array}$ & & $\begin{array}{l}25.8 \\
23.0\end{array}$ & $\begin{array}{l}51 \cdot 8 \\
52.1\end{array}$ & $\begin{array}{l}59.7 \\
59.8\end{array}$ & $\begin{array}{l}65.8 \\
67.7\end{array}$ & $\begin{array}{l}65.8 \\
69.4\end{array}$ & $\begin{array}{l}68.1 \\
69.1\end{array}$ & $\begin{array}{l}71 \cdot 3 \\
70.4\end{array}$ \\
\hline 50 & & .0 & 52.4 & 61.0 & $66 \cdot 3$ & 70.8 & $72 \cdot 1$ & 70.5 \\
\hline 63 & & .0 & $51 \cdot 2$ & $62 \cdot 1$ & 38.4 & 70.9 & $7 ? \cdot 2$ & 72.7 \\
\hline 80 & & .0 & 49.1 & $61 \cdot 2$ & 67.9 & $73 \cdot 1$ & $73 \cdot 6$ & 73.9 \\
\hline 100 & & .0 & .0 & $60 \cdot 4$ & 68.5 & 74.8 & $76 \cdot 5$ & 75.8 \\
\hline 125 & & .0 & $\cdot 0$ & $59 \cdot 1$ & $67 \cdot 3$ & $73 \cdot 3$ & $76 \cdot 9$ & 78.0 \\
\hline 160 & & $\cdot 0$ & .0 & 57.4 & 65.9 & $72 \cdot 6$ & $75 \cdot 7$ & 77.8 \\
\hline 200 & & .0 & .0 & 55.0 & $64 \cdot 5$ & 69.9 & $74 \cdot 3$ & 76.9 \\
\hline 250 & & $\cdot c$ & 29.8 & $52 \cdot 0$ & 62.6 & 69.0 & 73.0 & 76.2 \\
\hline 315 & & .0 & 25.4 & 48.4 & 60.7 & 68.0 & $72 \cdot 6$ & 76.0 \\
\hline 400 & & .0 & 23.6 & $42 \cdot 6$ & 57.4 & $66 \cdot 2$ & $71 \cdot 6$ & 75.4 \\
\hline 500 & $\ldots$ & .0 & $20 \cdot 8$ & 37.5 & 53.7 & 63.6 & 70.0 & 74.8 \\
\hline 630 & - & .9 & $20 \cdot 1$ & 33.5 & 48.6 & 59.7 & 67.4 & 73.2 \\
\hline 800 & & $\cdot 3$ & $\cdot 6$ & 30.8 & 43.8 & $55 \cdot 2$ & 63.4 & 70.1 \\
\hline 1000 & & .0 & .0 & 30.1 & 40.5 & $51 \cdot 4$ & 59.4 & 66.3 \\
\hline 1250 & & .0 & .0 & $28 \cdot 1$ & $38 \cdot 1$ & $43 \cdot 1$ & 54.8 & 61.8 \\
\hline 1600 & & .0 & .0 & 27.5 & $36 \cdot 7$ & .0 & $50 \cdot 8$ & 57.0 \\
\hline 2000 & & 0 & .0 & 26.7 & .0 & .0 & 48.1 & 53.5 \\
\hline 2500 & & 0 & .0 & .0 & .0 & .0 & .0 & 51.4 \\
\hline 3150 & & . $\mathrm{C}$ & .0 & .0 & .0 & .0 & .0 & 50.1 \\
\hline 4000 & & .0 & .0 & .0 & .0 & .0 & .0 & 51.1 \\
\hline 5000 & & .0 & .0 & .0 & .0 & $\cdot 0$ & .0 & 54.0 \\
\hline 6300 & & .0 & 0 & .0 & .0 & .0 & .0 & 52.4 \\
\hline 8000 & & 0 & .0 & .0 & .0 & .0 & .0 & 51.1 \\
\hline 13000 & & 0 & .0 & .0 & .0 & .0 & .0 & 50.5 \\
\hline$\$ 2500$ & & .0 & .0 & .0 & .0 & .0 & .0 & .0 \\
\hline$A N T$ & & .0 & $31 \cdot 3$ & 51.7 & 62.0 & 69.4 & 74.6 & 79.0 \\
\hline$L I N$ & & $40 \cdot 2$ & 60.5 & 70.7 & 77.7 & 82.4 & $85 \cdot 4$ & 87.4 \\
\hline
\end{tabular}


Table B3. - One-Third Octave Band Wind-Induced Noise Levels (dB re $20 \mu \mathrm{Pa}$ ) for Windscreen $C$

(Normal Flow Incidence)

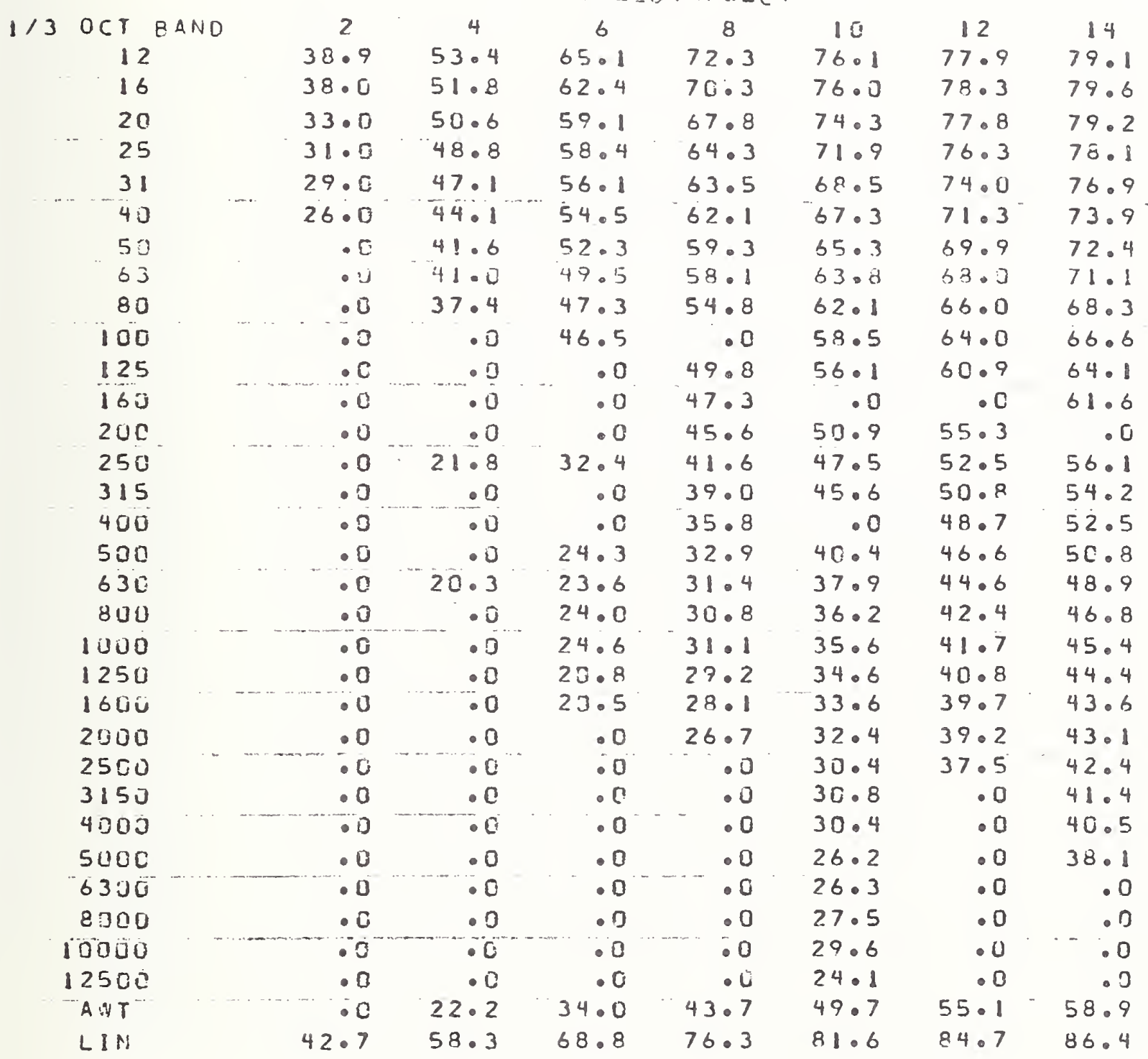


Table B4. - One-Third Octave Band Wind-Induced Noise Levels $(\mathrm{dB}$ re $20 \mu \mathrm{Pa}$ ) for Windscreen $\mathrm{D}$

(Normal Flow Incidence)

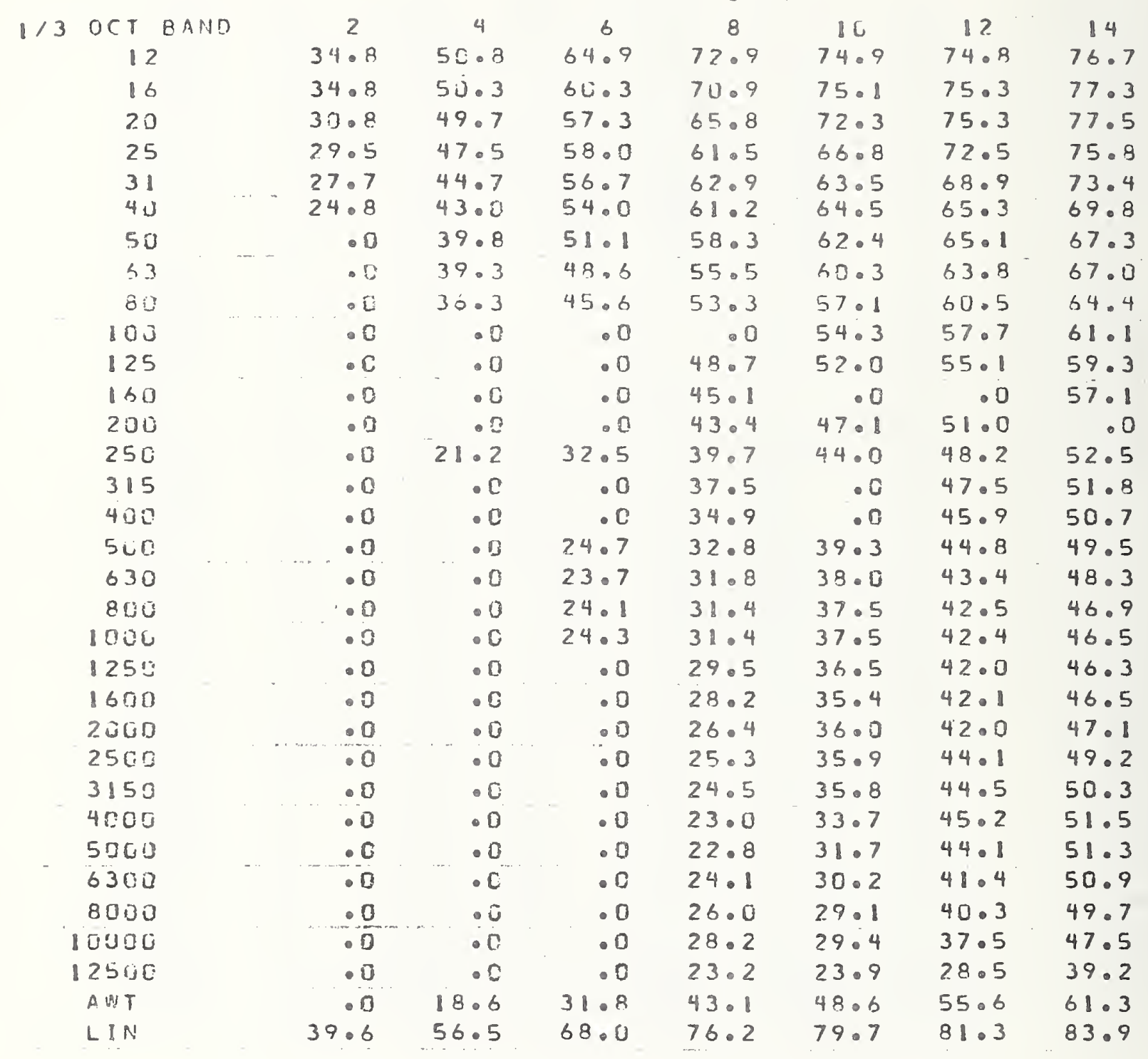


Table B5. - One-Third Octave Band Wind-Induced Noise Levels ( $d B$ re $20 \mu \mathrm{Pa}$ ) for Windscreen $\mathrm{E}$

(Normal Flow Incidence)

\begin{tabular}{|c|c|c|c|c|c|c|c|c|}
\hline \multicolumn{3}{|c|}{$s$} & \multicolumn{5}{|c|}{ SPEEN $(M / S E C)$} & \multirow[b]{2}{*}{14} \\
\hline $1 / 30 C T$ & BAND & 2 & 4 & 6 & 8 & 10 & 12 & \\
\hline 12 & & 34.7 & $48 \cdot 3$ & $62 \cdot 3$ & 69.2 & 70.2 & 72.7 & 75.6 \\
\hline 16 & & $34 \cdot 7$ & 48.5 & 56.8 & 65.5 & 67.9 & 73.2 & 75.1 \\
\hline 20 & & $30 \cdot 3$ & $47 \cdot 5$ & $55 \cdot 1$ & $62 \cdot 0$ & $68 \cdot 5$ & 72.8 & 76.1 \\
\hline 25 & & $29 \cdot 3$ & 44.8 & $55 \cdot 3$ & 59.0 & 65.7 & $70 \cdot 8$ & 74.1 \\
\hline 31 & & 25.7 & 42.7 & $53 \cdot 5$ & 58.5 & 61.9 & 67.9 & 72.5 \\
\hline 40 & & 22.9 & 40.1 & 50.9 & 57.5 & $61 \cdot 3$ & 64.8 & 69.1 \\
\hline 50 & & .0 & $38 \cdot 8$ & 48.3 & $54 \cdot 3$ & 58.9 & 64.1 & 66.4 \\
\hline 63 & & .3 & $41 \cdot 1$ & 45.5 & 52.4 & 55.9 & 32.3 & 65.5 \\
\hline 80 & & .0 & $34 \cdot 1$ & 43.3 & 49.1 & 54.2 & 58.8 & 63.6 \\
\hline 100 & & .0 & .0 & .0 & .0 & $51 \cdot 6$ & $56 \cdot 8$ & 60.8 \\
\hline 125 & & $\cdot c$ & .0 & .0 & $45 \cdot 7$ & $49 \cdot 8$ & 54.3 & 58.9 \\
\hline 160 & & .0 & $\cdot \mathrm{C}$ & .0 & $41 \cdot 4$ & .0 & .0 & 56.9 \\
\hline 200 & & .0 & .0 & .0 & 40.9 & 44.1 & 49.5 & .0 \\
\hline 250 & & .0 & 20.9 & 29.5 & 36.7 & $41 \cdot 2$ & 46.5 & $51 \cdot 1$ \\
\hline 315 & & .0 & .0 & .0 & 34.7 & .0 & $45 \cdot 8$ & 50.4 \\
\hline 400 & & .3 & .0 & .0 & 32.7 & .0 & 44.6 & 49.3 \\
\hline 500 & &.$c$ & .0 & 23.8 & $31 \cdot 6$ & 37.9 & 43.3 & 48.5 \\
\hline 630 & & .5 & .0 & $23 \cdot 3$ & 31.0 & 37.4 & 42.7 & 47.8 \\
\hline 800 & & .0 & 0 & $24 \cdot c$ & $31 \cdot 3$ & 37.4 & 42.4 & 47.9 \\
\hline 1000 & & 2 & .0 & 24.3 & 31.5 & $37 \cdot 8$ & 42.9 & 48.4 \\
\hline 1250 & & . 0 & .0 & .0 & 31.4 & 37.7 & 43.7 & 49.2 \\
\hline 1600 & & .0 & .0 & .0 & 31.5 & 39.5 & $44 \cdot 8$ & 50.2 \\
\hline 2000 & & .0 & .0 & .0 & 28.1 & 41.1 & 46.2 & 51.3 \\
\hline $2500^{\circ}$ & & .0 & .0 & .0 & 29.5 & 43.4 & 48.5 & 52.7 \\
\hline 3150 & & .0 & $\cdot c$ & .0 & 29.9 & 42.5 & $50 \cdot 1$ & 54.2 \\
\hline 4000 & & .0 & .0 & .0 & 25.0 & $42 \cdot 3$ & 49.8 & $55 \cdot 3$ \\
\hline 5000 & & $\cdot 0$ & .0 & .0 & 23.7 & $40 \cdot 4$ & 50.0 & 55.7 \\
\hline 6300 & & 0 & .0 & .0 & 24.1 & 37.6 & 48.5 & $55 \cdot 3$ \\
\hline 8000 & & .0 & .0 & $\cdot 0$ & $26 \cdot 0$ & $35 \cdot 2$ & $46 \cdot 3$ & 54.2 \\
\hline 10000 & & $\because 0^{\circ}$ & $.0^{-}$ & .0 & 28.2 & $32 \cdot 2$ & $43 \cdot 3$ & 51.7 \\
\hline 12500 & & .0 & .0 & .0 & 23.3 & $24 \cdot 4$ & 33.7 & 42.9 \\
\hline$A M T$ & & .0 & 18.4 & 30.6 & 42.5 & $52 \cdot 3$ & 59.1 & 64.5 \\
\hline LIN & & $39 \cdot 2$ & 54.4 & 65.2 & $72 \cdot 1$ & 75.5 & 79.4 & 82.5 \\
\hline
\end{tabular}




\begin{abstract}
Table B6. - One-Third Octave Band Wind-Induced Noise Levels $(\mathrm{dB}$ re $20 \mu \mathrm{Pa}$ ) for Windscreen $\mathrm{F}$
\end{abstract}

(Normal Flow Incidence)

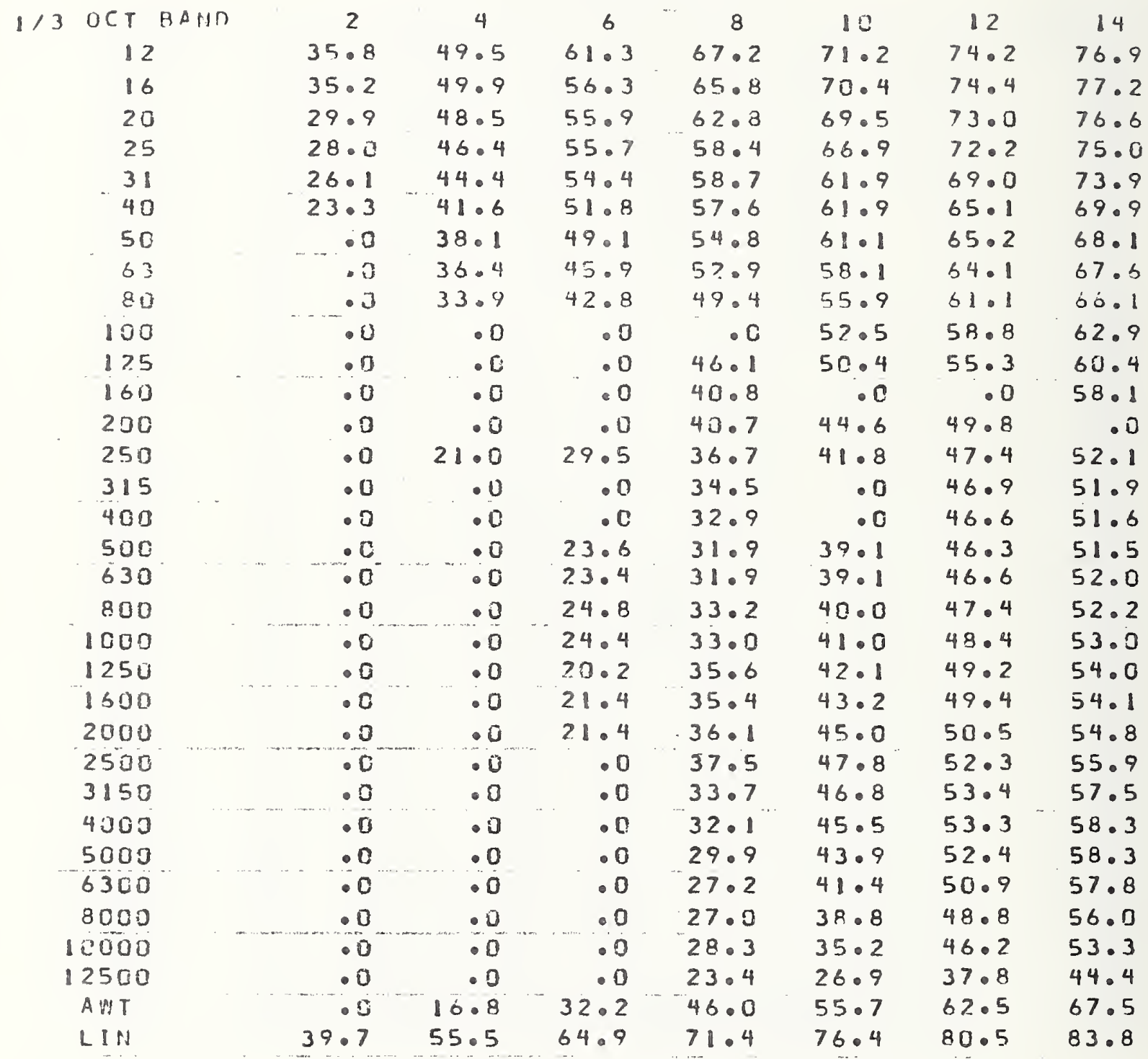


Table B7. - One-Third Octave Band Wind-Induced Noise Levels ( $d B$ re $20 \mu \mathrm{Pa}$ ) for Windscreen $\mathrm{G}$

(Normal Flow Incidence)

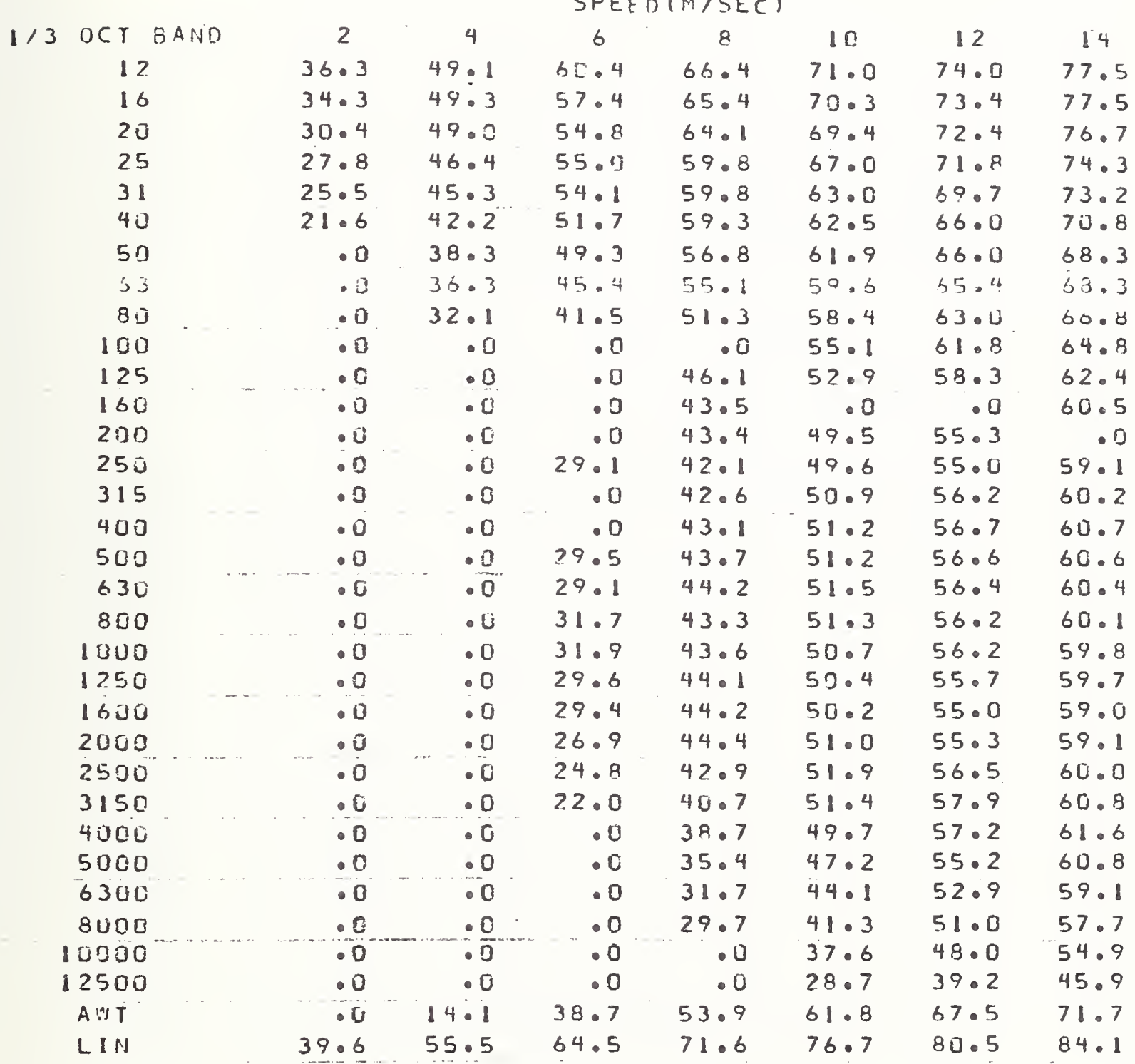


Table B8. - One-Third Octave Band Wind-Induced Noise Levels ( $d B$ re $20 \mu \mathrm{Pa}$ ) for Windscreen $\mathrm{H}$

(Norma1 Flow Incidence)

\section{SPEED $(M / S E C)$}

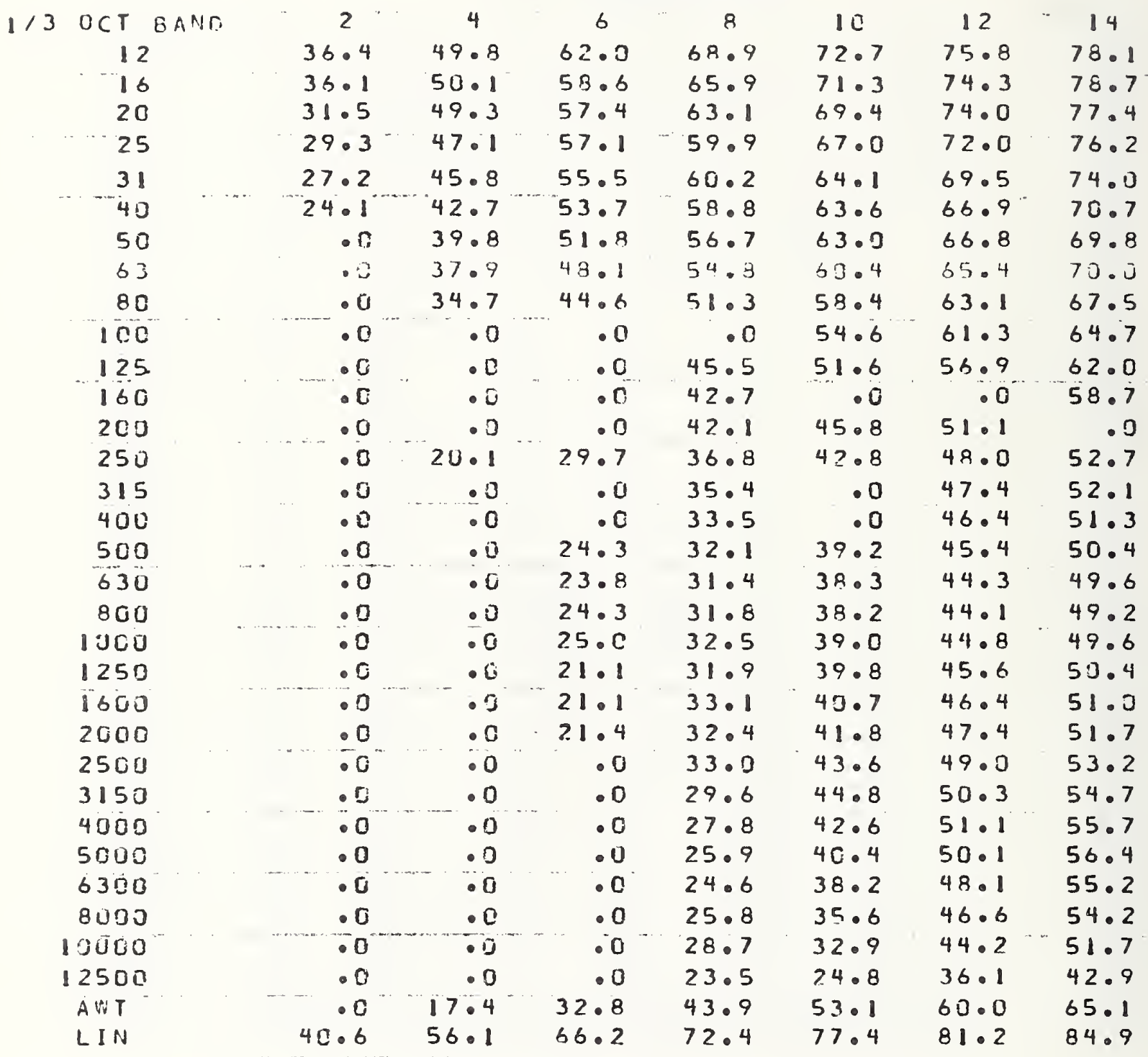


Table B9. - One-Third Octave Band Wind-Induced Noise Levels (dB re $20 \mu \mathrm{Pa}$ ) for Windscreen I

(Normal Flow Incidence)

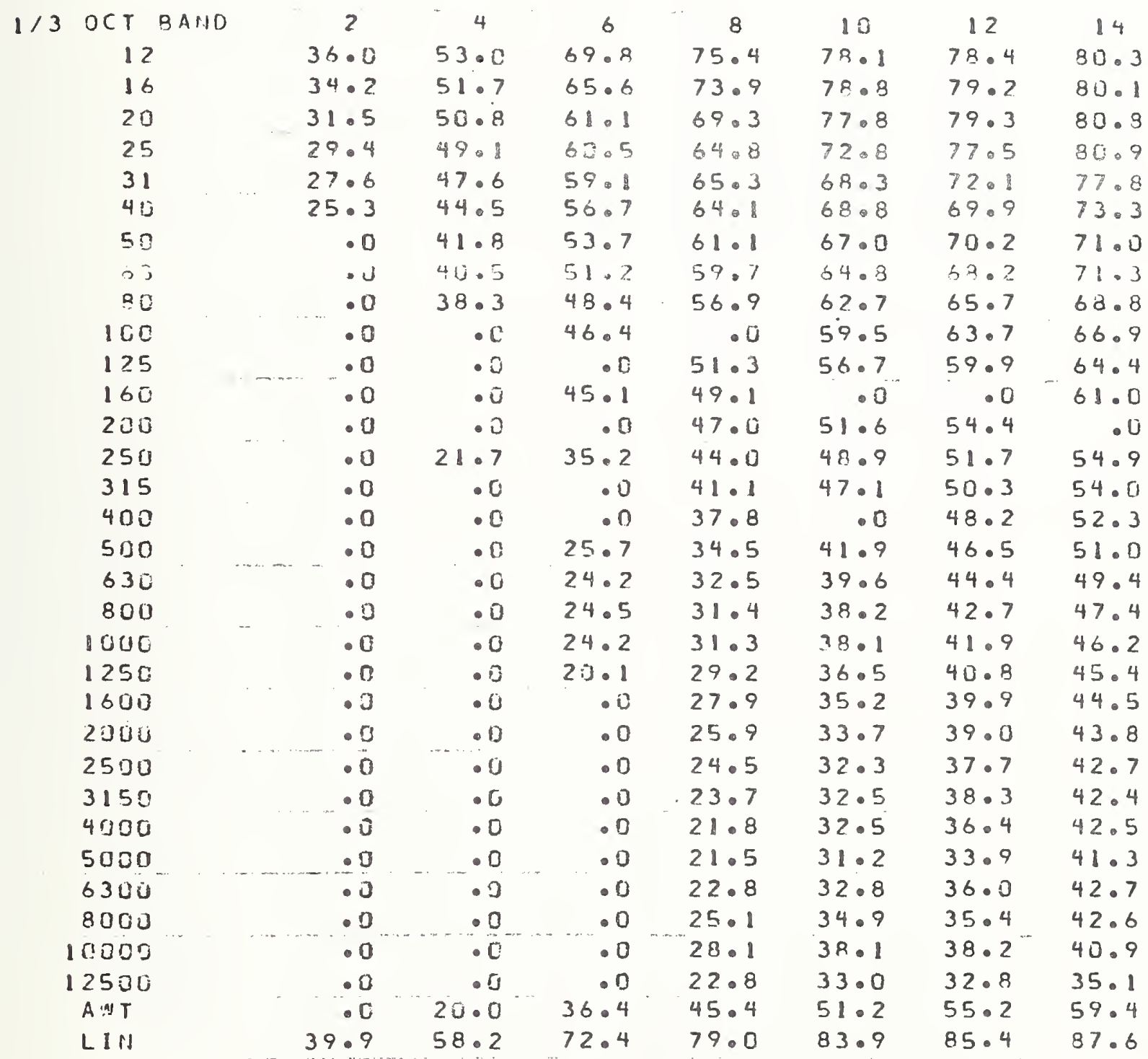


Table B10. - One-Third Octave Band Wind-Induced Noise Levels (dB re $20 \mu \mathrm{Pa}$ ) for Windscreen $J$

(Normal Flow Incidence)

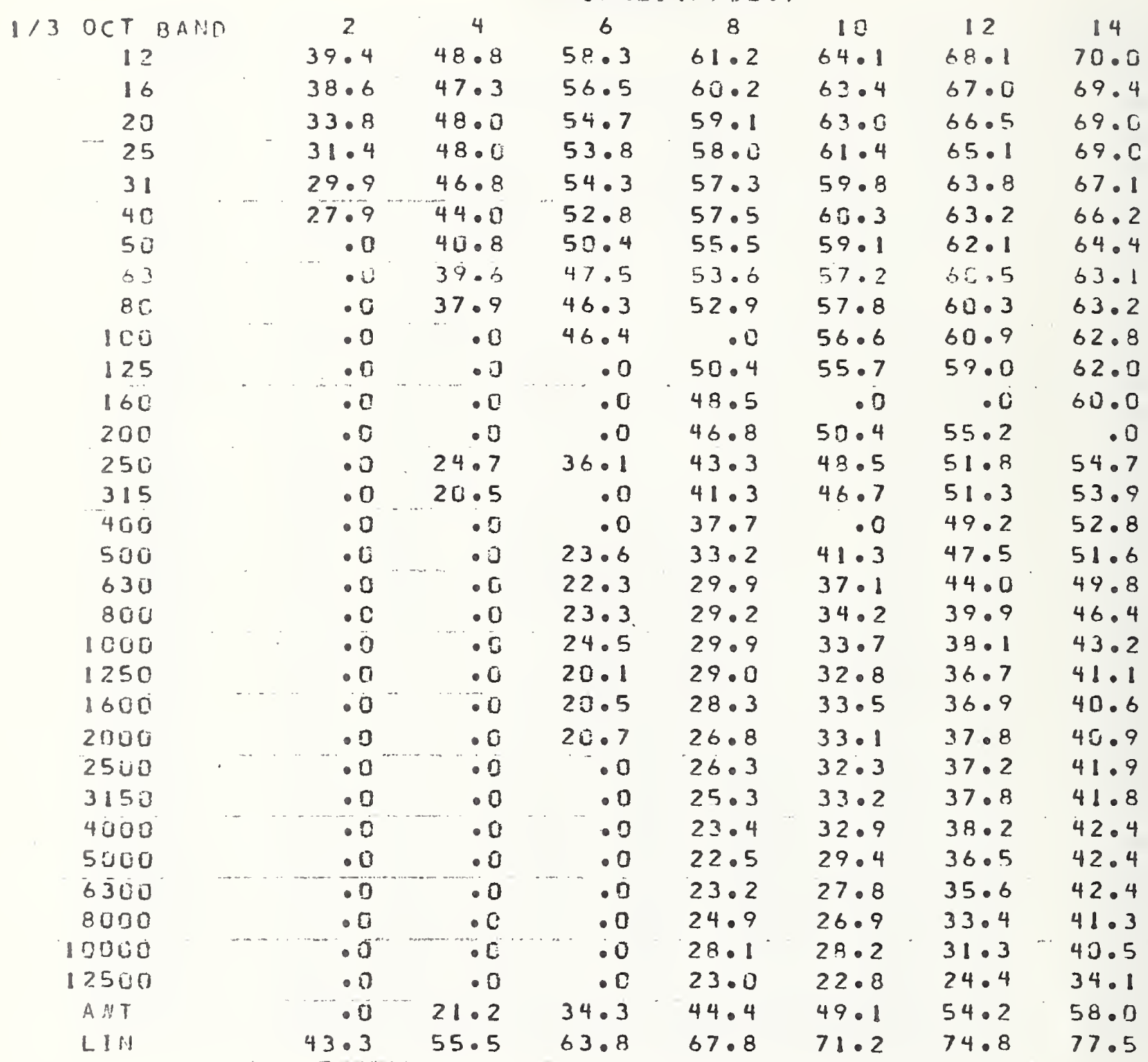


Table B11. - One-Third Octave Band Wind-Induced Noise Levels ( $\mathrm{dB}$ re $20 \mu \mathrm{Pa}$ ) for Microphone With No Windscreen (Normal Flow Incidence) 
APPENDIX C: Tabulation of Insertion Loss Measurements for Grazing F1ow and Normal Acoustic Incidence

This appendix contains a tabulation of the one-third octave band, A-weighted, and cverall insertion loss ( $d B$ re $20 \mu \mathrm{Pa}$ ) measured for grazing flow and normal acoustic incidence over the wind speed range $0 \mathrm{~m} / \mathrm{sec}$ $<\mathrm{v}<12 \mathrm{~m} / \mathrm{sec}$ for each of the windscreens shown in Figure 1 . The insertion loss was computed by subtracting the level measuref with the windscreen from the level measured without the windscreen on the microphone. It will be noted that the numbers generally are only a few tenths of a decibel. and that both positive and negative values were measured. Thus, at some frequencies insertion gain, rather than loss, was measured. 
Table Cl. - One-Third Octave Band Insertion Loss (dB) for Windscreen A

(Grazing Flow - Normal Acoustic Incidence)

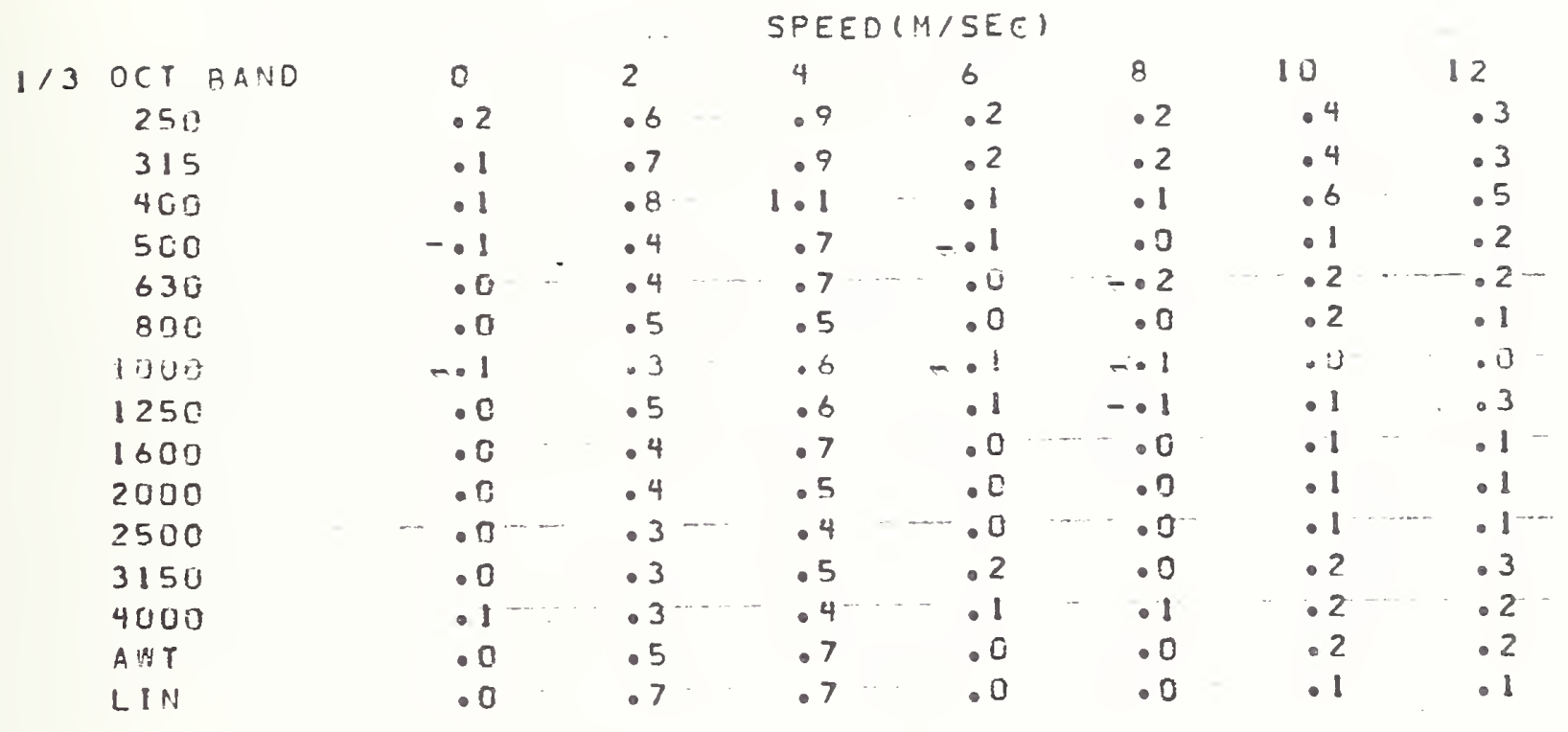

\footnotetext{
Table C2. - One-Third Octave Band Insertion Loss (dB) for Windscreen $B$

(Grazing Flow - Normal Acoustic Incidence)
}

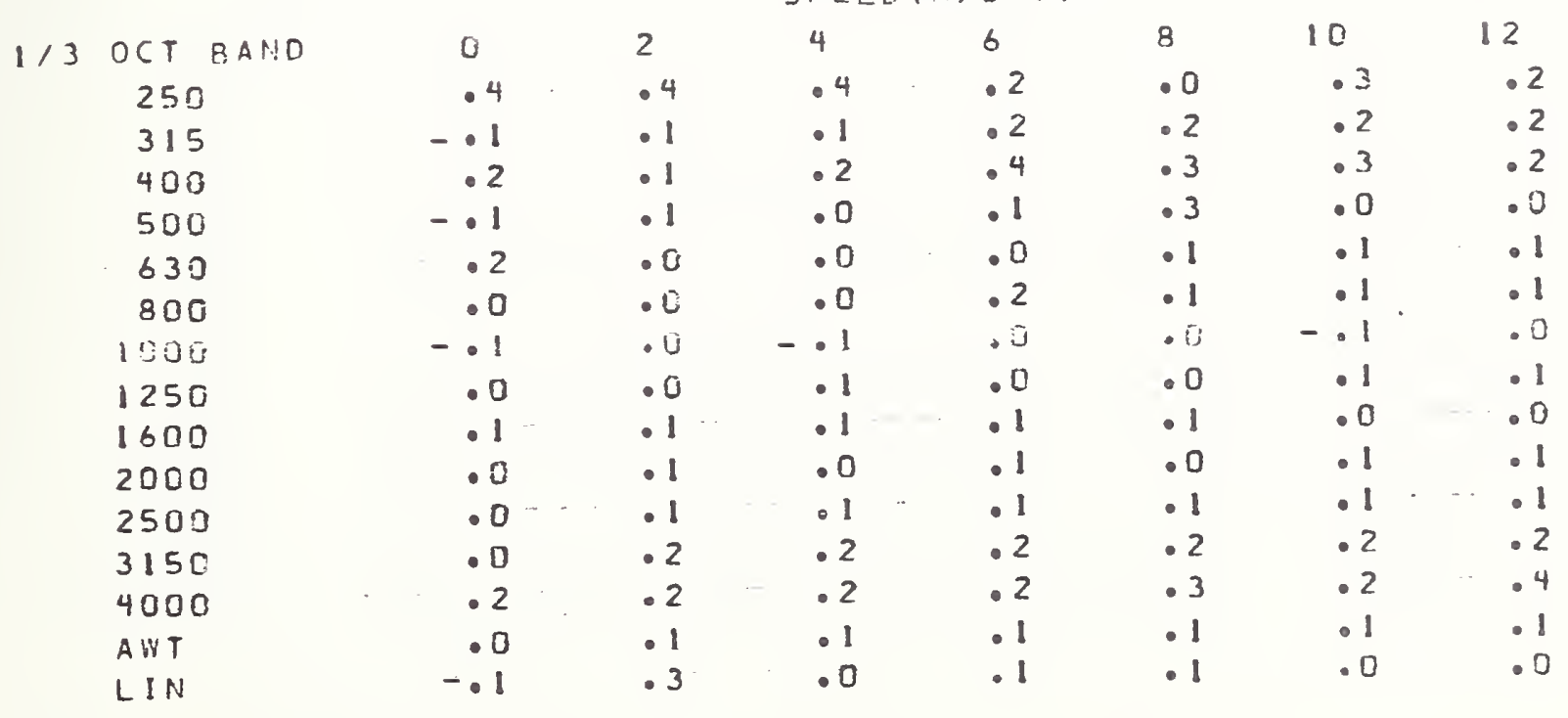


Table C3. - One-Third Octave Band Insertion Loss (dB) for Windscreen C

(Grazing Flow - Normal Acoustic Incidence)

\begin{tabular}{|c|c|c|c|c|c|c|c|}
\hline \multirow[b]{2}{*}{ OCT BAN!D } & \multicolumn{7}{|c|}{$S P E E D(M / S E C)$} \\
\hline & 0 & 2 & 4 & 6 & 8 & 10 & 12 \\
\hline 250 & .0 & .1 & .1 & .1 & .0 & .0 & .1 \\
\hline 315 & $\cdot 1$ & .0 & $\cdot 1$ & -.1 & -.1 & -.1 & - 1 \\
\hline 400 & -.1 & $\cdot 1$ & $\cdot 1$ & .1 & .1 & $\cdot 1$ & $\cdot 2$ \\
\hline 500 & .1 & .1 & $\cdot 3$ & .0 & $\cdot 1$ & .4 & $\cdot 1$ \\
\hline 630 & .0 & $\bullet 0$ & $\cdot 1$ & .0 & $\cdot 2$ & $\cdot 2$ & $\cdot 2$ \\
\hline 800 & $\cdot 0$ & .0 & $\cdot 1$ & .0 & $\cdot 2$ & $\cdot 2$ & $\cdot 2$ \\
\hline 1000 & -.1 & --.2 & -.2 & -.2 & .0 & -.1 & .0 \\
\hline 1250 & - 1 &.$\overline{0}$ & .0 & .0 & $\cdot 0$ & $\cdot 2$ & .2 \\
\hline 1605 & .1 & $\cdot 2$ & .2 & .2 & .2 & - $1 \ldots$ & $\cdot 2$ \\
\hline 2000 & -.1 & .0 & .0 & .0 & $\cdot 1$ & .0 & - 1 \\
\hline 2500 & .0 & .0 & .0 &.$- \varepsilon$ & -.0 & $.0 \ldots$ & .0 \\
\hline 3150 & .0 & .0 & .0 & .0 & .0 & .0 & .1 \\
\hline 4000 & .0 & $.0 \cdots$ & .0 & .0 & $\cdot 0$ & - 0 ......... & .0 \\
\hline$A W T$ & .0 & .1 & .1 & .0 & - 1 & .1 & .1 \\
\hline LIN & .1 & .4 & $\cdot 2$ & .1 & $\cdot 1$ & .1 & .1 \\
\hline
\end{tabular}

Table C4. - One-Third Octave Band Insertion Loss (dB) for Windscreen $D$

(Grazing Flow - Normal Acoustic Incidence)

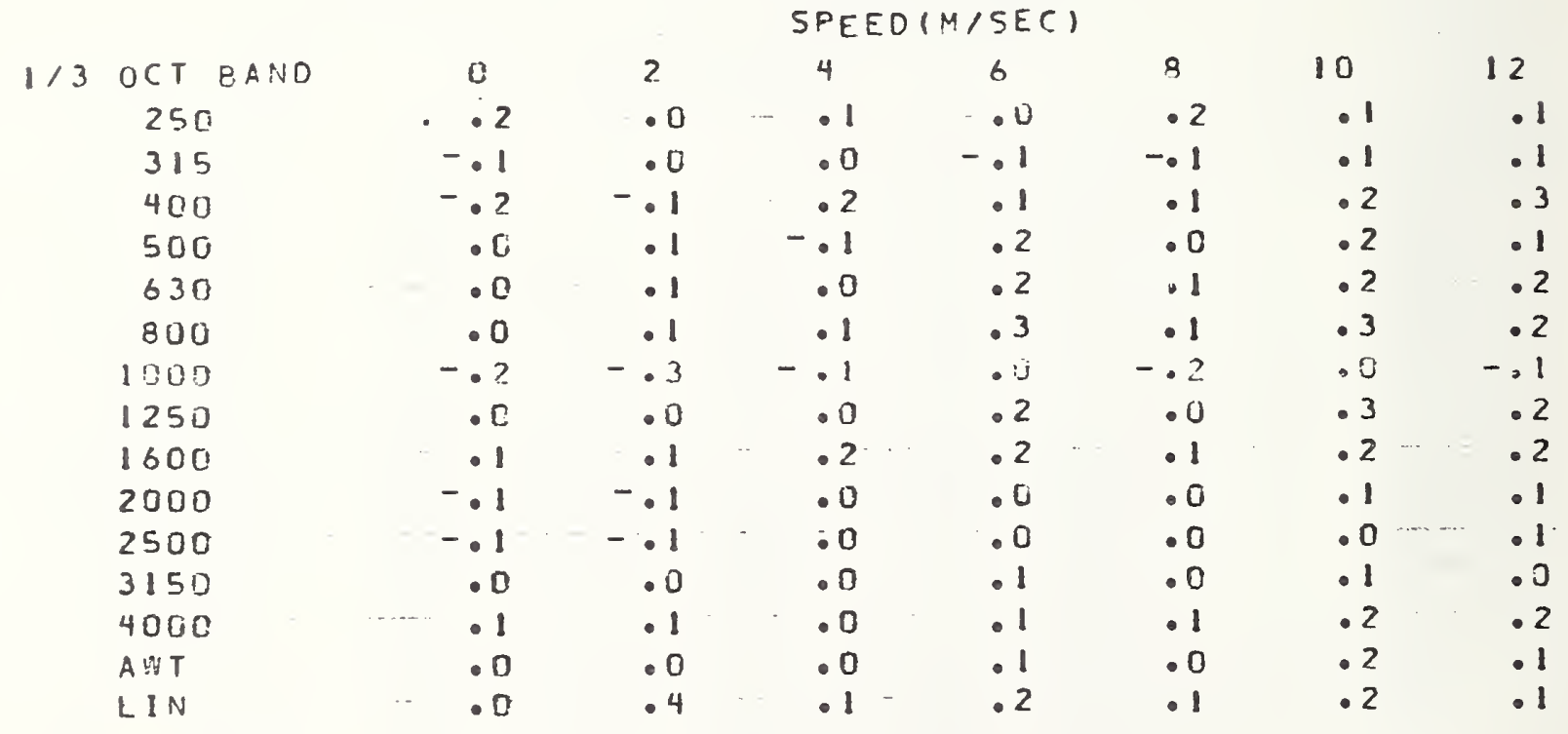




\section{Table C5. - One-Third Octave Band Insertion Loss (dB) for Windscreen $E$ \\ (Grazing Flow - Normal Acoustic Incidence)}

\begin{tabular}{|c|c|c|c|c|c|c|c|c|}
\hline \multirow[b]{2}{*}{$1 / 3$} & \multirow[b]{2}{*}{ OCT BAND } & \multicolumn{6}{|c|}{ SPEED $(1 / S E C)$} & \multirow[b]{2}{*}{12} \\
\hline & & v & 2 & 4 & 6 & 8 & 10 & \\
\hline & 250 & -.2 & $\cdot 1$ & .0 & $\cdot 1$ & $\cdot 1$ & $\cdot 3$ & .1 \\
\hline & 315 & -.1 & -.1 & -.2 & -.2 & -.1 & .3 & -.1 \\
\hline & 400 & -.1 & -.1 & -1 & .0 & .0 & $\cdot 3$ & .0 \\
\hline & 500 & -.1 & .0 & .1 & .1 & $\cdot 1$ & .3 & .1 \\
\hline & 630 & $\cdot 2$ & .2 & $\cdots$ & .3 & -.3 & .6 & .4 \\
\hline & 800 & $\cdot 2$ & .1 & .0 & .1 & $\cdot 1$ & .4 & $\cdot 2$ \\
\hline & 1000 & .3 & -.1 & $\cdots \cdot 0 \cdots$ & .1 & .1 & $.4 \ldots$ & .2 \\
\hline & 1250 & -.1 & .0 & .0 & .0 & $\cdot 2$ & .4 & $\cdot 2$ \\
\hline & 1600 & -.1 & $-.1 \cdots$ & $-1 \cdots$ & -.1 & .0 & $\cdot 2$ & .0 \\
\hline & 2000 & -.1 & -.1 & -.2 & -.1 & .0 & $\cdot 3$ & .1 \\
\hline & 2500 & -.1 & $-.1 \cdots$ & .0 & $\cdots .0$ & .0 & $.3-$ & .11 \\
\hline & 3150 & -.2 & .0 & .0 & .0 & .0 & .2 & .1 \\
\hline & 4000 & $\cdot 1$ & .0 & $.0^{-}$ & .1 & .0 & $\cdot 2^{\cdots}$ & .2 \\
\hline & $A W T$ & .0 & .0 & .0 & .0 & .1 & $\cdot 3$ & .1 \\
\hline & $L I N$ & .0 & $\cdot 3$ & $.0^{\cdots}$ & .1 & .1 & .4 & .1 \\
\hline
\end{tabular}

Table C6. - One-Third Octave Band Insertion Loss (dB) for Windscreen $F$.

(Grazing Flow - Normal Acoustic Incidence)

\begin{tabular}{|c|c|c|c|c|c|c|c|c|c|}
\hline \multirow[b]{2}{*}{$1 / 3$} & \multirow[b]{2}{*}{ OCT BAND } & \multicolumn{8}{|c|}{ SPEED (N/SEC) } \\
\hline & & 0 & 2 & 4 & 6 & 8 & 10 & & 12 \\
\hline & 250 & -.2 & $\cdot 1$ & -.2 & .1 & .0 & -.2 & & .0 \\
\hline & 315 & -.3 & -.2 & -.3 & -.1 & $-\cdot 1$ & -.2 & & -.2 \\
\hline & 400 & $-\cdot 3$ & -.3 & -.3 & -.1 & -.2 & -.2 & & -.2 \\
\hline & 500 & -.2 & -.1 & .0 & .0 & .0 & $\bullet 0$ & & -.1 \\
\hline & 630 & .0 & $\cdot 2$ & .2 & $\cdot .2$ & $\cdot 2$ & $\cdot 3$ & & $\cdot 2$ \\
\hline & 800 & -.1 & .0 & .0 & $\cdot \mathrm{C}$ & .0 & .0 & & .0 \\
\hline & 1000 & -.1 & -.1 & -.1 & -.1 & -.1 & .0 & . & .0 \\
\hline & 1250 & -.1 & -.1 & -.1 & -.1 & -.1 & .0 & & .0 \\
\hline & 1600 & -.2 & -.2 & -.1 & -.1 & -.1 & -.1 & - & -.1 \\
\hline & 2000 & -.2 & -.2 & -.2 & -.2 & -.1 & -.1 & & -1 \\
\hline & 2500 & -.2 & -.2 & -.2 & -.1 & -.2 & -.1 & - & $\cdots 1$ \\
\hline & 3150 & -.2 & -.2 & -.2 & -.2 & .0 & .0 & & -.2 \\
\hline & 4000 & -.1 & -.1 & -.1 & -.1 & -.1 & -.1 & & -.1 \\
\hline & AWT & -.2 & -.1 & -.1 & -.1 & -.1 & .0 & & -.1 \\
\hline & $L I N$ & -.1 & $\cdot 2$ & -.1 & .0 & .0 & .0 & & .0 \\
\hline
\end{tabular}


Table C7. - One-Third Octave Band Insertion Loss (dB) for Windscreen $G$

(Grazing Flow - Normal Acoustic Incidence)

$1 / 3$ OCT BANO
250
315
400
500
630
800
1000
1250
1600
2000
2500
3150
4000
A $10 T$
L1N

\begin{tabular}{|c|c|c|c|}
\hline C & 2 & 4 & 6 \\
\hline - 1 & -.2 & -.2 & -.2 \\
\hline . 2 & .3 & .3 & .3 \\
\hline$\cdot 1$ & $\cdot 1$ & -.1 & -.1 \\
\hline-.1 & .2 & .1 & - 1 \\
\hline-.2 & -.2 & -.2 & .0 \\
\hline-1 & .0 & .0 & - 1 \\
\hline .0 & .0 & .1 & .0 \\
\hline .3 & -.1 & .0 & . I \\
\hline .0 & .0 & .0 & .0 \\
\hline .0 & .0 & .1 & - 1 \\
\hline .0 & .0 & .1 & .0 \\
\hline - $C$ & .0 & .0 & .0 \\
\hline .0 & -.1 & .0 & - $C$ \\
\hline .0 & .0 & .0 & .0 \\
\hline .0 & .4 & $\cdot 1$ & .1 \\
\hline
\end{tabular}

8
-.2
.4
.0
.1
.0
.1
.0
.1
.0
.1
.1
.0
-.1
.0
.1

$\begin{array}{lr}10 & 12 \\ -.2 & -.2 \\ .3 & .3 \\ -.2 & -.1 \\ .1 & .1 \\ .1 & .0 \\ .0 & .0 \\ .1 & .1 \\ .1 & .1 \\ .0 & .0 \\ .1 & .1 \\ .1 & .0 \\ .0 & .2 \\ .0 & .0 .0 \\ .1 & .0 \\ .1 & .1\end{array}$

Table C8. - One-Third Octave Band Insertion Loss (dB) for Windscreen $\mathrm{H}$

(Grazing Flow - Normal Acoustic Incidence)

$1 / 3$ OCT BAPIO
250
315
400
500
630
800
1000
1250
1600
2000
2500
3150
4000
$A W T$
LIN

$\begin{array}{rrrr}0 & 2 & 4 & 6 \\ -.0 & -.4 & -.02 & -.4 \\ -.3 & .3 & .5 & .3 \\ -.2 & -.2 & -.1 & -.2 \\ .0 & .0 & .0 & .0 \\ -.2 & .0 & -.2 & -.2 \\ .0 & .0 & -.1 & .0 \\ .0 & .0 & .0 & .0 \\ .0 & .0 & .0 & .0 \\ .0 & .0 & .0 & .0 \\ .0 & .1 & .0 & .1 \\ .0 & -.0 & .0 & .0 \\ .0 & .0 & .0 & .0 \\ .0 & .0 & .0 & -.1 \\ .0 & .0 & .0 & .0 \\ .0 & .0 & .0 & .0\end{array}$

8
-.2
.
-.1
.1
.1
.0
.1
.0
.0
.1
.1
.0
-.1
.0
.1

10

12

.5

1. 3

.9

1.1

.9

.8

1.0

1.0

- 8

.9

- 9

.9

.5

.9

- 9 

Table C9. - One-Third Octave Band Insertion Loss (dB) for Windscreen I
(Grazing Flow - Normal Acoustic Incidence)

$\begin{array}{ccccc}1 / 3 \text { OCT BAND } & 0 & 2 & 4 & 6 \\ 250 & -.1 & .0 & .7 & -.1 \\ 315 & .3 & .3 & 1.3 & .4 \\ 400 & .0 & -.1 & 1.0 & -.1 \\ 500 & .1 & .2 & 1.1 & .2 \\ 630 & .1 & -.2 & .9 & .1 \\ 800 & .0 & .0 & 1.0 & .1 \\ 1000 & .0 & .0 & 1.0 & .1 \\ 1250 & .0 & .1 & 1.0 & .1 \\ 1600 & .0 & .0 & .9 & .0 \\ 2000 & .1 & .1 & .9 & .1 \\ 2500 & .0 & .2 & .9 & .2 \\ 3150 & .0 & .0 & .7 & .2 \\ 4000 & .0 & .0 & .0 & .0 \\ \text { AWT } & .0 & .1 & 1.0 & .1 \\ \text { LIN } & .1 & .4 & 1.0 & .1\end{array}$
Table C10. - One-Third Octave Band Insertion Loss (dB) for Windscreen $\mathrm{J}$
(Grazing Flow - Normal Acoustic Incidence)

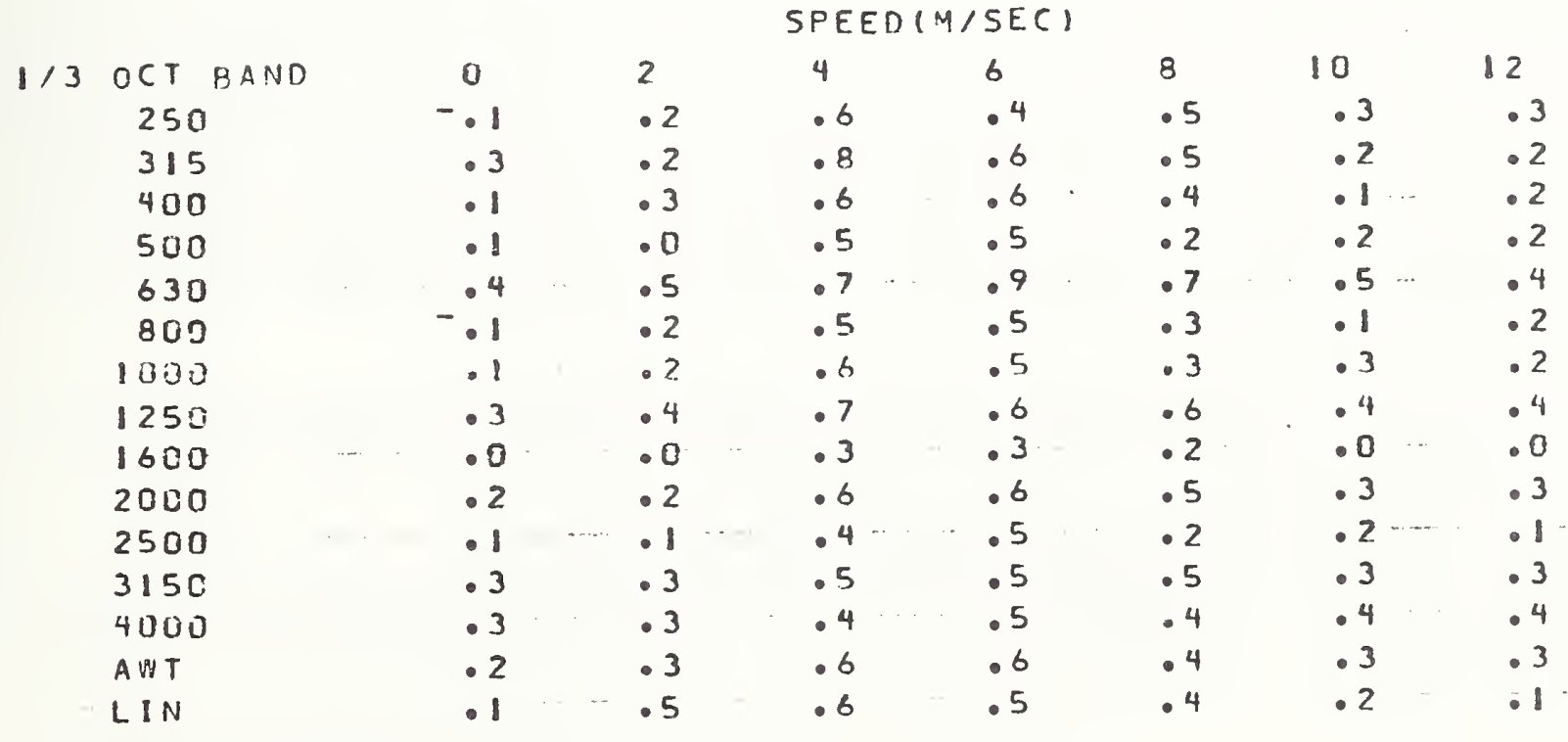


NBS-114A (REV. 7-73)

\begin{tabular}{|c|c|c|c|}
\hline $\begin{array}{l}\text { U.S. DEPT. OF COMM. } \\
\text { BIBLIOGRAPHIC DATA } \\
\text { SHEET }\end{array}$ & $\begin{array}{l}\text { 1. PUIBLICATION OR REPORT NO. } \\
\text { NBSIR 79-1599 }\end{array}$ & $\begin{array}{l}\text { 2. Gov't Accession } \\
\text { No. }\end{array}$ & 3. Recipient's Accession No. \\
\hline \multicolumn{3}{|l|}{ 4. TI'TLI: AND SURTITLE } & $\begin{array}{l}\text { 5. Publication Date } \\
\text { January } 1979\end{array}$ \\
\hline \multicolumn{3}{|c|}{ Microphone Windscreen Performance } & 6. Performing Organization Code \\
\hline \multicolumn{3}{|c|}{$\begin{array}{l}\text { 7. AlfliOR(S) } \\
\text { Robert N. Hosier and Paul R. Donavan }\end{array}$} & $\begin{array}{l}\text { 8. Performing Organ. Report No. } \\
\text { NBSIR } 99-1599\end{array}$ \\
\hline \multicolumn{3}{|c|}{ 9. I'IRF ORMINC } & $\begin{array}{l}\text { 10. Project/Task/Work Unit No. } \\
2004450\end{array}$ \\
\hline \multicolumn{3}{|c|}{$\begin{array}{l}\text { NATIONAL BUREAU OF STANDARDS } \\
\text { DEPARTMENT OF COMMERCE } \\
\text { WASHINGTON, D.C. } 20234\end{array}$} & $\begin{array}{l}\text { 11. Contract/Grant No. } \\
\text { EPA-IAG-D7-41087 }\end{array}$ \\
\hline \multirow{2}{*}{\multicolumn{3}{|c|}{$\begin{array}{l}\text { 12. Sponsoring Organization Name and Complete Address (Street, City, State, ZIP) } \\
\text { Office of Noise Abatement and Control } \\
\text { U. S. Envifumenta1 Protection Agency } \\
\text { Washington, or }>20460\end{array}$}} & $\begin{array}{l}\text { 13. Type of Report \& Period } \\
\text { Covered } \\
\text { Final }\end{array}$ \\
\hline & & & 14. Sponsoring Agency Code \\
\hline
\end{tabular}

15. SUPPLEMENTARY NOTES

16. ABSTRACT (A 200-word or less factual summary of most significant information. If document includes a significant bibliography or literature survey, mention it here.)

Measurements were made of the wind-induced noise and acoustic insertion loss of ten microphone windscreens. Eight of these were reticulated polyester spheres of varying porosity. The other two were the metal cage type typically used in long term outdoor noise monitoring. The measurements were made under laboratory conditions for normal and grazing flow incidence at wind speeds up to $14 \mathrm{~m} / \mathrm{sec}$. The data show that the windscreens are very different in the amount of wind-induced noise reduction they provide, with some achieving more than $25 \mathrm{~dB}$. In general the foam windscreens provided more wind-induced noise reduction than the cage windscreens; however, the cylindrical cage windscreen performed better than any of the foam windscreens for normal flow incidence. The insertion loss measurements proved difficult to make because of the small insertion losses encountered. However, data for grazing flow and normal acoustic incidence show no strong velocity dependence for any of the windscreens tested. Examination of the wind-induced noise spectra provided significant insight into the noise generating mechanisms associated with flow around a porous sphere. Effects of inflow turbulence, self-generated turbulence, mean flow, flow through the sphere, and flow incidence angle were identified. Test results are provided in the form of curves and tables for easy use in evaluating potential wind noise levels in outdoor measurements.

17. KEY WORDS (six to twelve entries; alphabetical order; capitalize only the first letter of the first key word unless a proper name; separated by semicolons)

Acoustics; flow; insertion loss; microphone; porous sphere; sphere; spheres; wind noise; windscreen; windscreens; windscreen performance

18. AVAILABILITY X Unlimited

lior Official Distribution. Do Not Release to NTIS

\begin{tabular}{|l|c|}
\hline $\begin{array}{l}\text { 19. SECURITY CLASS } \\
\text { (THIS REPURT) } \\
\text { UNCLASSIFIED }\end{array}$ & 21. NO. OF PAGES \\
\hline $\begin{array}{l}\text { 20. SECURITY CLASS } \\
\text { (TIIIS PAGE) } \\
\text { UNCLASSIFIED }\end{array}$ & 22. Price \\
\hline
\end{tabular}




.


